\title{
PSYCHIATRIC DISORDER IN WOMEN SERVING A PRISON SENTENCE
}

Thesis for the degree of Doctor of Medicine (M.D.) submitted to the University of London by:

Dr. Anthony Maden, MRCPsych,

Dept. of Forensic Psychiatry,

The Institute of Psychiatry. 
ProQuest Number: 10045769

All rights reserved

INFORMATION TO ALL USERS

The quality of this reproduction is dependent upon the quality of the copy submitted.

In the unlikely event that the author did not send a complete manuscript and there are missing pages, these will be noted. Also, if material had to be removed, a note will indicate the deletion.

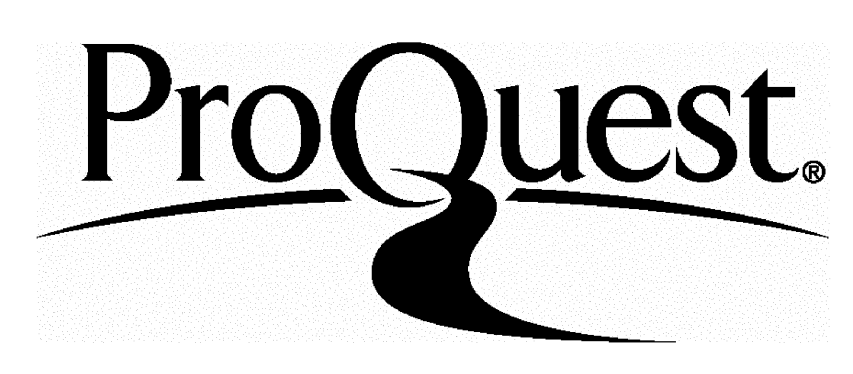

ProQuest 10045769

Published by ProQuest LLC(2016). Copyright of the Dissertation is held by the Author.

All rights reserved.

This work is protected against unauthorized copying under Title 17, United States Code. Microform Edition @ ProQuest LLC.

\author{
ProQuest LLC \\ 789 East Eisenhower Parkway \\ P.O. Box 1346 \\ Ann Arbor, MI 48106-1346
}




\section{PSYCHIATRIC DISORDER IN WOMEN SERVING A PRISON SENTENCE}

\section{M.D. thesis by Dr. Anthony Maden}

\section{Abstract}

Women commit less crime than men and this has contributed to a tendency to regard female prisoners as psychiatrically abnormal. This idea has helped to shape penal policy but the empirical evidence is inconclusive. A review of studies of psychiatric disorder in prisoners shows that no survey in this country has applied the same methods to comparable groups of women and men.

The thesis describes a case-note and interview study of a representative, crosssectional sample comprising $25 \%$ of all women serving a prison sentence in England and Wales. A five percent sample of the male sentenced prison population was used for comparison purposes. Diagnoses were assigned on clinical grounds and an assessment was made of the treatment needs of all "cases".

The prevalence of psychosis, around two percent, was similar in the two groups but women had higher rates of mental handicap (6 v. 2.3\%), personality disorder (18 v $10 \%)$, neurosis $(18 \times 10 \%)$ and substance abuse (26 $\mathrm{v} 12 \%)$. Within each diagnostic group, female and male prisoners share many clinical and criminological characteristics.

The higher prevalence rates can be explained in part by the low rate of "normal" offending in women, which means that a greater proportion of female offenders are likely to be psychiatrically "abnormal", even when the absolute number of mentally disordered male offenders is far higher. Neurotic disorders are more common in women and have no straightforward relationship to offending.

The implications of the findings for psychiatric services are discussed. Women with psychosis or other severe disorders share many of the characteristics that make mentally disordered male prisoners difficult to place, including chronicity, limited compliance and recidivism. Psychiatric surveillance of female prisoners is more efficient but there is considerable variation in standards between institutions. Women will make greater demands for treatment within prison, mainly because of neurotic symptoms and substance abuse. There is a need to increase the availability of counselling and contact with drug treatment agencies. Women's prisons lack a therapeutic community of the Grendon type, which may be of benefit to a substantial minority of inmates. 


\section{CONTENTS}

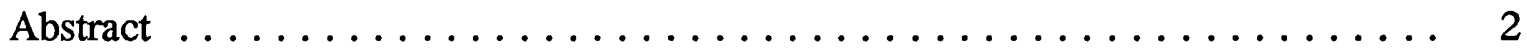

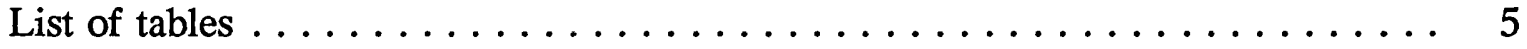

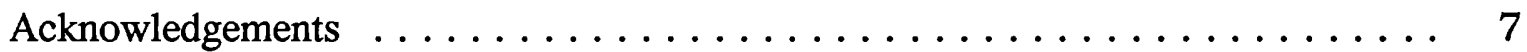

CHAPTER 1: WOMEN, PRISONS AND PSYCHIATRY $\ldots \ldots \ldots \ldots \ldots \ldots$

Psychiatry and women in prison $\ldots \ldots \ldots \ldots \ldots \ldots \ldots \ldots$

Previous studies of female prisoners $\ldots \ldots \ldots \ldots \ldots \ldots \ldots \ldots \ldots \ldots$

1. Studies in the United Kingdom . . . . . . . . . . . . . 10

2. Studies in the United States. $\ldots \ldots \ldots \ldots \ldots \ldots$

3. Studies of mental handicap in prisoners. . . . . . . . . . . 20

Summary: psychiatric disorder in female prisoners . . . . . . . . . . . 25

The structure of the report $\ldots \ldots \ldots \ldots \ldots \ldots \ldots \ldots \ldots \ldots$

CHAPTER 2: SAMPLING, DATA COLLECTION AND CODING $\ldots \ldots \ldots$

Selection of the Initial Sample. . . . . . . . . . . . . . . 27

Interview and data collection $\ldots \ldots \ldots \ldots \ldots \ldots \ldots \ldots \ldots$

Rating and Coding of Data $\ldots \ldots \ldots \ldots \ldots \ldots \ldots \ldots \ldots \ldots \ldots$

Reliability . . . . . . . . . . . . . . . . . . . . . . . 39

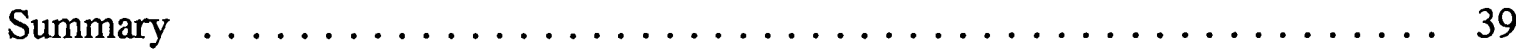

CHAPTER 3: THE SAMPLE $\ldots \ldots \ldots \ldots \ldots \ldots \ldots \ldots \ldots \ldots \ldots \ldots$

The sentenced prison population $\ldots \ldots \ldots \ldots \ldots \ldots \ldots \ldots \ldots \ldots \ldots$

1. The age structure of the prison population $\ldots \ldots \ldots \ldots \ldots$

2. The ethnic origin of prisoners $\ldots \ldots \ldots \ldots \ldots \ldots \ldots \ldots$

3. Implications for the study $\ldots \ldots \ldots \ldots \ldots \ldots \ldots \ldots$

Matching of sample and population. $\ldots \ldots \ldots \ldots \ldots \ldots \ldots \ldots$

1. Sentence length ...................... 45

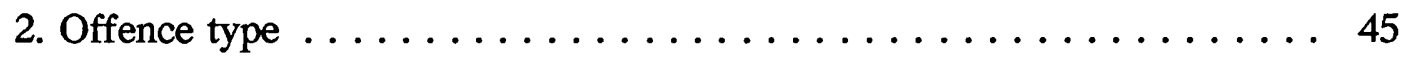

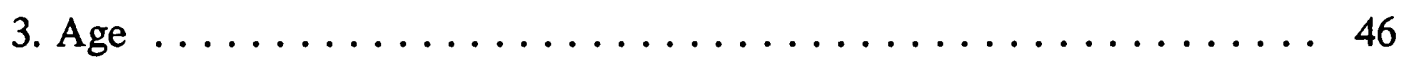

Statistical Techniques $\ldots \ldots \ldots \ldots \ldots \ldots \ldots \ldots \ldots \ldots \ldots \ldots \ldots$

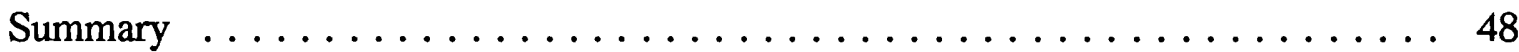

CHAPTER 4: RESULTS I: SOCIAL AND PSYCHOLOGICAL CHARACTERISTICS $\ldots \ldots \ldots \ldots \ldots \ldots \ldots \ldots \ldots \ldots \ldots \ldots . \ldots . \ldots$ 
Social and educational characteristics $\ldots \ldots \ldots \ldots \ldots \ldots \ldots \ldots$

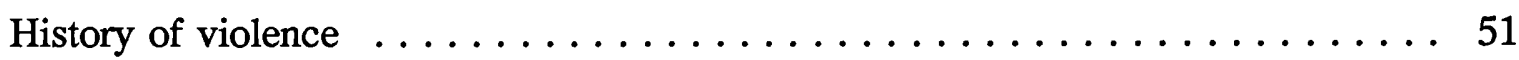

Disciplinary record $\ldots \ldots \ldots \ldots \ldots \ldots \ldots \ldots \ldots \ldots \ldots \ldots \ldots \ldots \ldots \ldots \ldots$

Deliberate self-harm $(\mathrm{DSH}) \ldots \ldots \ldots \ldots \ldots \ldots \ldots \ldots \ldots \ldots \ldots$

Psychiatric treatment prior to imprisonment $\ldots \ldots \ldots \ldots \ldots \ldots \ldots$

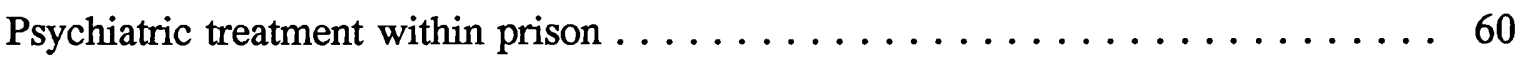

Scores on the Clinical Interview Schedule $\ldots \ldots \ldots \ldots \ldots \ldots \ldots \ldots \ldots$

Attitudes to treatment and recommended treatment $\ldots \ldots \ldots \ldots \ldots$

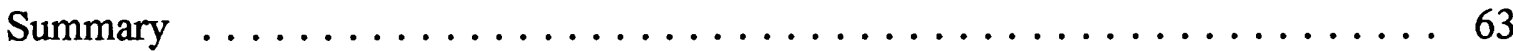

\section{CHAPTER 5: RESULTS II: THE PREVALENCE OF PSYCHIATRIC}

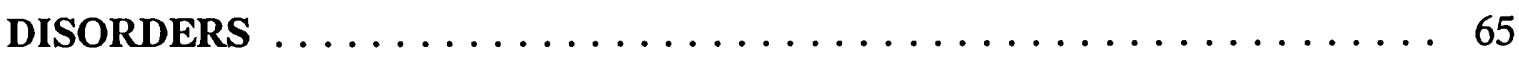

Psychiatric disorder in UK resident women $\ldots \ldots \ldots \ldots \ldots \ldots \ldots$

Psychiatric disorder in women ordinarily resident overseas $\ldots \ldots \ldots \ldots \ldots$

Rates of psychiatric disorder by gender $\ldots \ldots \ldots \ldots \ldots \ldots \ldots$

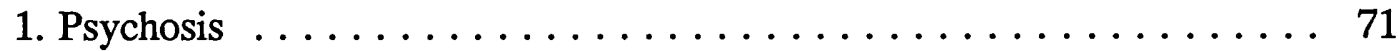

2. Mental Handicap $\ldots \ldots \ldots \ldots \ldots \ldots \ldots \ldots \ldots \ldots \ldots$

3. Personality Disorder $\ldots \ldots \ldots \ldots \ldots \ldots \ldots \ldots$

4. Neurotic Disorders . . . . . . . . . . . . . . . . . . . 93

5. Dependence on Drugs and Alcohol . . . . . . . . . . . . 99

6. Ethnic Origin and Psychiatric Diagnosis . . . . . . . . . . . 112

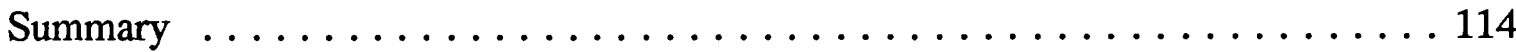

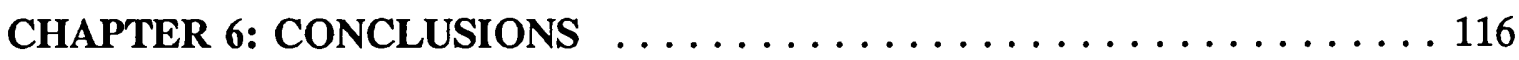

Normal and Abnormal Offenders . . . . . . . . . . . . . 116

1. Is offending by women abnormal? $\ldots \ldots \ldots \ldots \ldots \ldots \ldots \ldots \ldots$

2. The efficacy of medical surveillance and diversion. $\ldots \ldots \ldots \ldots$

3. Gender differences in the Treatment of the Mentally Disordered Offender. ....................... 118

4. Mental disorder outside medical settings. . . . . . . . . . . . . 122

The implications for prison health services $\ldots \ldots \ldots \ldots \ldots \ldots \ldots \ldots \ldots$

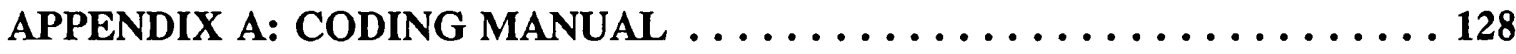

APPENDIX B: LIST OF PRISONS $\ldots \ldots \ldots \ldots \ldots \ldots \ldots \ldots \ldots$

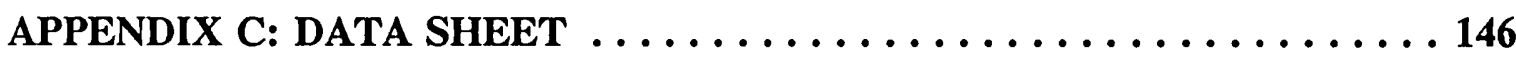






\section{List of Tables}

Table 1.1 Psychiatric disorder in women prisoners, by type of prisoner . . . . . 13

Table 1.2. Psychiatric disorder in prisoners, by gender . . . . . . . . . 18

Table 1.3. Lifetime prevalence of psychiatric disorder in women in prison and in the general population of St. Louis. . . . . . . . . . . . . . . . 20

Table 1.4. Scores on Raven's matrices of sentenced prisoners and the general population. ......................... 23

Table 3.1 Age distribution of the sentenced prison population, by gender . . . . . 40

Table 3.2. Sentenced female prisoners: ethnic origin by country of residence . . . 42

Table 3.3. UK resident female prisoners: previous custodial sentences by ethnic origin $\ldots \ldots \ldots \ldots \ldots \ldots \ldots \ldots \ldots \ldots \ldots \ldots \ldots \ldots \ldots \ldots \ldots \ldots \ldots$

Table 3.4. UK resident female prisoners: index offence by ethnic origin . . . . . 43

Table 3.5 Distribution of sentence lengths in original sample, UK residents and total population of sentenced women . . . . . . . . . . . . 45

Table 3.6 Index offence in original sample, UK residents and total population of sentenced women $\ldots \ldots \ldots \ldots \ldots \ldots \ldots \ldots \ldots \ldots \ldots$

Table 3.7 Age distribution of total sentenced prison population and sample, by

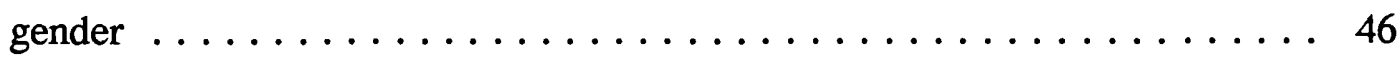

Table 4.1. Social and educational characteristics $\ldots \ldots \ldots \ldots \ldots \ldots$

Table 4.2. Violent offenders by index offence and gender. . . . . . . . . . 52

Table 4.3. Disciplinary record during current imprisonment, by gender. . . . . . . 53

Table 4.4. Lifetime prevalence of deliberate self-harm, by location and gender . . . 55

Table 4.5. Lifetime prevalence of deliberate self-harm by method and by

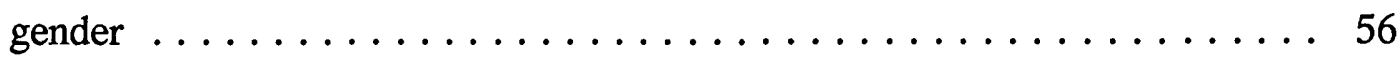

Table 4.6. History of self-cutting, by other social and psychological characteristics

Table 4.7. Female prisoners: lifetime prevalence of deliberate self-harm, by location and ethnic origin

Table 4.8. Male prisoners: lifetime prevalence of deliberate self-harm, by location

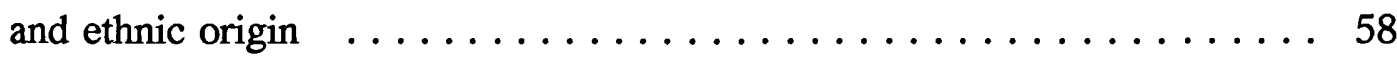

Table 4.9. Previous psychiatric treatment by gender and type of treatment . . . . 59

Table 4.10. Previous psychiatric treatment by gender and type of treatment, excluding all drug dependent prisoners . . . . . . . . . . . . . 60

Table 4.11. Experience of psychiatric treatment during current prison sentence, by gender and type of treatment $\ldots \ldots \ldots \ldots \ldots \ldots \ldots$ 
Table 4.12. CIS scores by gender $\ldots \ldots \ldots \ldots \ldots \ldots \ldots \ldots \ldots \ldots \ldots \ldots$

Table 4.13. Treatment recommendations, by type of treatment and gender . . . . 63

Table 5.1. Female sentenced prisoners: frequency of psychiatric diagnoses, with

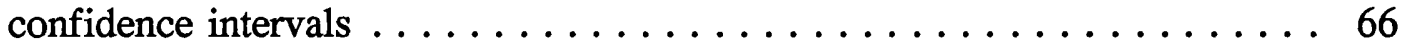

Table 5.2. Female sentenced prisoners ordinarily resident overseas: psychiatric

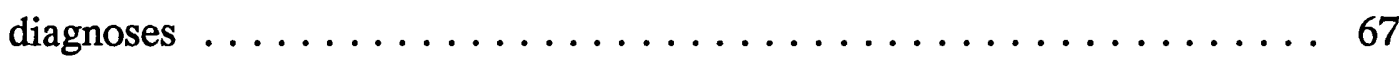

Table 5.3. Rates of psychiatric disorder and odds ratios, UK resident:overseas

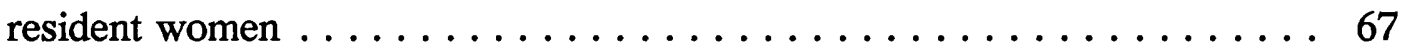

Table 5.4. Psychiatric disorder in sentenced prisoners, by gender . . . . . . . . 69

Table 5.5. Estimated total number of "cases" in the sentenced prison population, by diagnosis and gender . . . . . . . . . . . . . 70

Table 5.6. The relationship between social and criminal history and the diagnosis of personality disorder, by gender $\ldots \ldots \ldots \ldots \ldots$

Table 5.7. Prisoners given a diagnosis of personality disorder: treatment recommendations by gender $\ldots \ldots \ldots \ldots \ldots \ldots \ldots$

Table 5.8. Mean CIS scores by diagnosis of neurotic disorder and by gender. . . 93

Table 5.9. Sentenced prisoners given a diagnosis of neurosis: breakdown by type of neurosis and gender ....................... 94

Table 5.10. Drug dependent prisoners, by gender and main type of drug . . . . . 99

Table 5.11. Female sentenced prisoners: index offence by drug dependence . . . . 100

Table 5.12. Female sentenced prisoners: relationship between social and criminal history and drug dependence . . . . . . . . . . . . . . . . . . . . 101

Table 5.13. Female sentenced prisoners: criminal profile ratings by drug dependence . . . . . . . . . . . . . . . . . . . . . . . . 101

Table 5.14. Female sentenced prisoners: convictions for violence against the person by drug dependence . . . . . . . . . . . . . . . . . . . . . . 102

Table 5.15. Female sentenced prisoners: relationship between social and criminal history and problem drinking . . . . . . . . . . . . . . . 107

Table 5.16. Female sentenced prisoners: criminal profile ratings by problem

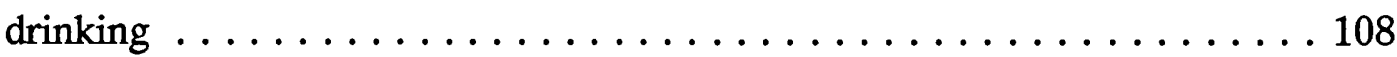

Table 5.17. Female sentenced prisoners: problem drinking by convictions for violence, arson and drunkenness . . . . . . . . . . . . . 108

Table 5.18. UK resident female prisoners: diagnosis by ethnic origin . . . . . . 112

Table 5.19. UK resident male prisoners: diagnosis by ethnic origin $\ldots \ldots \ldots \ldots 113$ 


\section{PSYCHIATRIC DISORDER IN FEMALE PRISONERS}

The work that forms the basis of this thesis was undertaken whilst the author was engaged in preparing a psychiatric profile of the prison population, under the supervision of Professor John Gunn and in cooperation with Dr. Mark Swinton, in the Department of Forensic Psychiatry at the Institute of Psychiatry. The authors cooperated on the design of the instruments used in the project.

The author carried out half of all the interviews for the project as a whole, including half those at three of the women's prisons and all those at the fourth women's prison. The other interviews were carried out by Dr. Swinton.

The comparison of female and male prisoners was carried out entirely by the author, including the selection of the appropriate samples, all analyses and writing-up.

Parts of this thesis were included in the report submitted to the Home Office by the research team ${ }^{1}$.

\section{Acknowledgements}

The author wishes to thank Professor John Gunn and Dr. Mark Swinton. The research panel also included Dr. Pamela Taylor, Dr. David Tidmarsh, Dr. Christine Curle, Mr. Angus Cameron and Mr. Graham Allison.

The work that forms the basis of this thesis was funded by the Directorate of the Prison Medical Service at the Home Office and the Director, Dr. Rosemary Wool, provided valuable encouragement and advice, as did many other members of the DPMS and the Home Office Research and Planning Unit. Thanks are due to all medical officers and prison staff who were interviewed during the study. Particular mention must be made of Dr. Dorothy Speed, principal medical officer at HMP Holloway, who take a great deal of credit for improvements to medical services and the prison regime at Holloway and provided me with many insights into the female prison system.

The author wishes to thank Dr. Graham Robertson, who was a member of the research panel but also read and commented on an earlier draft of this thesis. Mrs. Maureen Bartholomew and Mrs. Carol Double provided secretarial and organisational assistance. Finally, the project could not have been carried out without the cooperation of a large number of women and men serving a prison sentence. 


\section{CHAPTER 1: WOMEN, PRISONS AND PSYCHIATRY}

\section{Introduction}

A statement of the aims of the present study is followed by a brief account of the place of psychiatry in womens' prisons and a review of studies of psychiatric disorder in female prisoners. British and American studies are discussed separately, as are the particular problems of looking at mental handicap in prisoners. The chapter ends with a description of the structure of the report.

\section{The objectives of the study}

The following questions are addressed:

1. What is the prevalence of psychiatric disorder in women serving a prison sentence?

2. How does psychiatric disorder in this population compare to that found in male prisoners and how does it relate to offending?

3. To what extent does the prevalence of psychiatric disorder in women prisoners resemble the prevalence of psychiatric disorder in women in other sections of the community?

The study describes the psychiatric characteristics of a representative, $25 \%$ crosssectional sample of female sentenced prisoners and compares them to a similar five percent sample of male prisoners. In addition to a comparison of prevalence rates, an account is also given of the relationship between psychiatric disorders and offending in these two groups of prisoners.

\section{Psychiatry and women in prison}

Women commit much less crime than men. This has contributed to "a tendency to see girls and women who offend as having medical and social problems rather than as being hardened criminals ${ }^{2}$." The idea that female prisoners are likely to be psychiatrically disturbed gained such wide acceptance that the new Holloway prison was planned to be more like a secure hospital than a prison ${ }^{3}$. The Secretary of State announced, when introducing the rebuilding programme of which Holloway was a part: "Most women and girls in custody require some form of medical, psychiatric or remedial treatment. The main feature of the programme is.....the building of an establishment that is basically a secure hospital to act as the hub of the female prison system. Its medical and psychiatric facilities will be its central feature, and normal custodial facilities will comprise a relatively small part of the establishment."4 To this end, the prison was built without the 
traditional hospital wing (considered unnecessary in view of the therapeutic nature of the whole institution) and a prison doctor was appointed governor.

The experiment was a failure. Holloway received criticism for the nature of its regime and for the conditions under which a minority of severely disturbed women were held ${ }^{5}$. By 1985, the regime had deteriorated to such an extent that self-mutilation and assaults were daily occurrences and dormitories were being put out of use by vandalism at the rate of one a month ${ }^{6}$. Colin Allen, appointed Governor of Holloway in 1985, believed there was a failure by doctors working in Holloway to distinguish mental disorder from other causes of difficult behaviour, resulting in confused messages to other staff. Mentally disordered women were being punished rather than receiving treatment or being transferred to the health service, whilst other women resented being treated as if they were not responsible for their own actions?

Holloway now runs more smoothly. The Governor is not a doctor and the separation of disciplinary and medical services resembles that in male prisons. It remains the case that hospital officers in female prisons must have a nursing qualification, whilst this is not required in male prisons. The oddity here is not that a nursing qualification is required to provide adequate nursing care to sick women but that it should not be considered necessary in order to provide similar care to sick men.

A further example of an unsuccessful attempt to "psychiatrise" a prison for women is contained in Carlen's $s^{8}$ account of Cornton Vale in Scotland and both episodes are discussed in more detail by Dobash et al $^{9}$. The origins of the belief that most female prisoners are psychiatrically abnormal are traced by Sim in his history of the Prison Medical Service ${ }^{10}$, a detailed account which remains useful despite its strong antipsychiatric and anti-medical biases.

In retrospect, the failure of attempts to run womens' prisons as psychiatric hospitals is less surprising than the fact that the schemes were adopted in the first place. The literature review that begins the present study will show that the empirical evidence that female prisoners exhibit more psychiatric disturbance than their male counterparts is limited. None of the following studies attempted seriously to test the proposition that women in prison have higher rates of psychiatric disorder. Instead, some of the studies appear to have been based on this assumption.

\section{Previous studies of female prisoners}

Recent years have seen a rapid expansion in the literature on women and all aspects of the criminal justice system, including prison. Much of this literature is 
sociological in nature. There are few empirical studies of psychiatric disorder in female prisoners and those which do exist are limited in the extent to which they allow comparison with male prisoners.

Many of the studies which report psychiatric disorder in prisoners are concerned with the relationship between crime and mental illness rather than with accurate prevalence rates. Ideally, an account of the prevalence of psychiatric disorder in prisoners would be based on a random sample drawn from a defined population. In this respect, it is important to distinguish remand and sentenced prisoners. Suspected psychiatric disorder is one reason for remanding offenders in custody so it is no surprise that previous studies of male prisoners have shown high rates of psychosis ${ }^{11}$ and suicide ${ }^{12}$ in remand prisoners.

Having defined the study population, criteria for identifying psychiatric disorder must be clearly stated, with cases described according to an accepted diagnostic system. In order to allow any meaningful comparison of male and female prison populations, the same methods and criteria should be applied to both groups.

It will become apparent from the following review that no previous study meets these criteria.

Studies are reviewed under the following headings:

1. Studies in the United Kingdom.

2. Studies in the United States.

3. Studies of mental retardation in prisoners.

Most of the studies describe women in prison. Accounts of men in prison are included for comparison and in order to make general points about the methodology of prison surveys.

\section{Studies in the United Kingdom}

Studies of psychiatric disorder in imprisoned women fall into two groups, those which describe the general prison population and those which describe selected groups of women.

\section{a. Studies of the female prison population.}

The psychiatry of the female prison population is, in large part, the psychiatry of HMP Holloway: few published studies sample other prisons for women.

An exception is the attempt by Epps ${ }^{13}$, then medical officer at a Borstal in Aylesbury, to survey all "girls" sentenced to Borstal training between April 1948 and 
August 1950, a total of 330 women aged between 16 and 21 years. Three hundred were included in the study, 275 being followed up over a prolonged period and the remaining 25 seen once only for an interview and intelligence test. Most of the paper is concerned with social characteristics and an attempt to describe the nature and causes of criminality in this group but some psychiatric data are provided. Four women (1.3\%) were diagnosed as suffering from schizophrenia and were transferred to hospital. Neurotic symptoms were shown by 63 women (21\%) "during the course of the study". Substance abuse was not recorded as a diagnosis but was said to be common in the family histories of the women. The findings on intelligence testing are reported below.

A follow-up study ${ }^{14}$ reports on 100 of the original women who were seen in Holloway prison after being recalled for unsatisfactory behaviour or re-offending. "Emotional instability" was found in $37 \%$ of the recall group, compared to $28 \%$ of the original 300 women. (Significance tests are not given; it appears that the 100 recidivists were not excluded from the group of 300 for comparison purposes, so the true difference between the recidivists and others is likely to be greater than the figures suggest.) Neurotic symptoms were also more common in the recidivist group but there was no apparent difference in the proportion of those with low intelligence or a record of psychiatric treatment. Epps suggests that the recidivist population contains a number of women with personality and neurotic problems who require some form of psychiatric treatment, in addition to Borstal training, if they are to modify their offending behaviour. The study has many methodological flaws (none of the psychiatric terms are defined) but it makes important points. Psychosis is unusual, whereas personality disorder and neurotic symptoms are common and women with the latter problems appear to require some form of help in addition to the ordinary custodial regime.

Epps and Parnel1 ${ }^{15}$ compare 177 of the Borstal women with 123 female undergraduates at Oxford, for both physique and temperament. The paper is of no more than historical interest but contains an early attempt to apply the same measure to female and male prisoners; the "delinquent women" are compared to a group of "delinquent men" described by Sheldon, revealing no major differences on Sheldon's "psychiatric index".

Woodside ${ }^{16}$ describes all women sentenced to six months or longer who were received at HMP Holloway during a six month period in 1961, a total of 139 women. The study was heavily dependent on previous reports (the author is a social worker and did not use a diagnostic interview) and precise diagnoses are not given for the total of 68 women who were identified as "unstable". Fifty-eight (42\%) had a "positive psychiatric history", including in-patient treatment in 26 (19\%). Five women had been "certified 
patients" in the past and a total of twelve women (9\%) were "subnormal" (see below for a fuller discussion of mental handicap). A further ten women were identified as borderline cases, who would warrant further investigation by a psychiatrist.

There is no direct comparison with male prisoners but the survey derived its inspiration and some of its methods from the work of Roper ${ }^{17}$, who surveyed male sentenced prisoners in Wakefield in 1948-49. He found that $18 \%$ had a "positive psychiatric history", a considerably lower figure than the $42 \%$ reported for women. Woodside's results are suggestive of increased rates of psychopathology in women prisoners but detailed psychiatric descriptions are lacking and terms are loosely defined.

Gibbens $^{18}$ carried out a survey of every fourth reception into Holloway during 1967, a total of 638 women. This is the most frequently cited account of psychiatric disorder in female prisoners and is regarded by some authors ${ }^{19}$ as the empirical basis for the psychiatric influences on the rebuilding of Holloway. Despite its preeminent position, this study was never fully written-up and its findings are subject to the reservation that existing accounts do not specify any criteria for the definition of psychiatric problems. The psychiatric findings vary according to the type of prisoner (Table 1.1) but the author concludes that women in prison have high rates of psychiatric disorder. 
Table 1.1 Psychiatric disorder in women prisoners, by type of prisoner (adapted from Gibbens, 1971)

\begin{tabular}{|l|c|c|c|}
\hline & \multicolumn{3}{|c|}{ type of prisoner } \\
\hline & $\begin{array}{c}\text { sentenced } \\
\mathrm{n}=128 \\
8\end{array}$ & $\begin{array}{c}\text { medical } \\
\text { remands } \\
\mathrm{n}=57 \\
8\end{array}$ & $\begin{array}{c}\text { other } \\
\text { remands } \\
\mathrm{n}=485 \\
8\end{array}$ \\
\hline mental illness & 15 & 39 & 25 \\
\hline $\begin{array}{l}\text { inpatient in } \\
\text { last 3y }\end{array}$ & 17 & 26 & 18 \\
\hline $\begin{array}{l}\text { inpatient } \\
>\text { 3y ago }\end{array}$ & 8 & 10 & 6 \\
\hline $\begin{array}{l}\text { past suicide } \\
\text { attempt }\end{array}$ & 22 & 26 & 22 \\
\hline alcoholism & 7 & 7 & 3 \\
\hline
\end{tabular}

\section{Notes to Table 1.1}

All figures are percentages of the total in that category of prisoner. Figures under "other remands" were calculated as the mean of the figures given in the original table under "Remand before conviction" and "Remand after conviction". The raw figures given as n for each category were calculated from the percentages given in the original paper; in total, the percentages add up to $115 \%$, so the raw figures must be regarded as rough estimates.

Comparison of Gibbens' figures with those from a 1971 survey by Gunn et $\mathrm{al}^{20}$ of sentenced men in the South East prison region provides only partial support for this conclusion; $12 \%$ of men gave a history of inpatient psychiatric treatment (compared to $17 \%$ of women reporting such treatment within the last three years and $8 \%$ reporting treatment at an earlier date). On the other hand, $15 \%$ of the men are described as having a drink problem, compared to $7 \%$ of sentenced women described as suffering from alcoholism. Whilst mental health was "a major problem" in $15 \%$ of sentenced women, $34 \%$ of sentenced men were identified as current psychiatric cases ${ }^{21}$.

These studies use very different methods but two particular problems limit the usefulness of direct comparisons between their findings:

\section{i. sampling}

Gibbens used a reception sample whereas Gunn et al studied a cross-section of men serving a sentence. The former method yields a high proportion of prisoners serving short sentences, the second a high proportion of long and medium term prisoners. 


\section{ii. the definition of psychiatric disorder}

The studies used quite different criteria for identifying psychiatric disorder. Some findings are comparable (eg. reports of previous psychiatric treatment) whereas others, such as rates of alcoholism, depend almost entirely on the criteria used.

None of the subsequent studies of women in prison answer these criticisms. A study based on a random sample of 708 receptions to HMP Holloway ${ }^{22}$ found that 125 (18\%) had a history of psychiatric treatment and 195 (28\%) had a history of self-harm. Whilst recognising some limitations of their data, the authors fail to acknowledge the most significant omission, the failure to assign diagnoses; apart from drug and alcohol abuse, none are given. Women with "a history of psychiatric treatment" include those who received brief outpatient treatment for depression alongside those who may have spent many years in a long-stay psychiatric hospital suffering from schizophrenia. A further problem is the use of a reception sample, with no information about criminal characteristics or the mix of sentenced and remand prisoners. The authors make no explicit comparison with male prisoners but state that rates of psychiatric morbidity in women admitted to Holloway are high.

Morris $^{23}$ compares these figures to those for sentenced men in the south east prison region ${ }^{24}$, arguing that rates of disorder are similar. It is more accurate to say that differences in sampling and the definition of psychiatric disorder preclude meaningful comparison.

Eysenck \& Eysenck's study ${ }^{25}$ deserves mention as a rare attempt at systematic comparison of male and female prisoners. As psychologists, the authors avoid diagnosis and use a personality test with "scales...very similar to those contained in the MPI and the EPI". This approach does not prevent them from concluding that "..female prisoners (and male ones to a lesser degree) are psychiatrically ill to a marked degree, a fact which is not always given sufficient recognition".

This conclusion is based on the observation that, whilst both groups of prisoners have higher $\mathrm{P}$ (psychoticism) scores than same-sex controls, female prisoners have higher scores than male prisoners. Respective mean scores are 7.55 and 6.55. Although not given in the paper, the $95 \%$ confidence interval for the difference in population means is readily calculated $^{26}$ as 0.57 to 1.43 . Leaving aside the considerable objections to the use of the $P$ scale as a measure of psychiatric illness, such a small difference in mean scores, even if statistically significant, suggests that "marked" is not the best description of the difference between the populations. 


\section{b. Studies of selected groups of women in prison.}

Published reports on the psychiatric characteristics of particular groups of women in (Holloway) prison are more common than reports on unselected samples of female prisoners. The groups are selected in the expectation that they will be of psychiatric interest and in the knowledge that they are not representative of female prisoners as a whole.

Study groups are defined in one of two ways, by the presence of a particular behavioural or psychiatric problem or by the nature of their offence.

\section{i. Women with particular behavioural or psychiatric problems.}

Imprisoned female drug users (66 cases) were described by d'Orban in $1970^{27}$, two subsequent papers reporting follow-up data four years later ${ }^{28,29}$. This study was concerned with the relationship between drug dependence and offending; prevalence rates are not given. Most of the subjects were remand prisoners during the original study and some entered Holloway on more than one occasion. During the study period, the women faced a total of 96 charges. None were charged with the sale of drugs and 29 cases $(30 \%)$ resulted in a custodial sentence. The sentence length was 12 months and over in three cases and did not exceed 18 months in any of the cases. Seventeen percent of the women had a history of inpatient psychiatric treatment preceding their addiction and fifty percent had received inpatient treatment since becoming addicted. Apart from drug addiction, most admissions were for "personality disorder". Twenty-one of the 96 court disposals (22\%) resulted in hospital admission, six under the Mental Health Act category of psychopathic disorder. This pattern of disposal is noted to be similar to that for male addicts in prison.

The follow-up study found a strong association between continued addiction and continued delinquency, concluding that these findings were in accord with the view that addiction and crime are not causally related but are "parallel effects of underlying factors leading to social deviance". Further reference will be made to this work in a later chapter. It is a useful description of drug dependent women who pass through the prison system.

Cookson ${ }^{30}$ described self-injury by women in Holloway and found that women who injured themselves tended to be younger than average with longer sentences and more violent offences. Incidents occurred in runs or epidemics, suggesting that imitation was important. The rate of self-injury was believed to be high but was not compared to the rate in male prisons. The question of the relationship between self-injury and suicide was not addressed. 
A more recent study by Wilkins and Coid ${ }^{31}$ found that $7.5 \%$ of all remands to Holloway had a history of previous self-injury by cutting. Seventy-four women with a history of self-injury were described in more detail; compared to remanded women with no history of self-mutilation, they were more likely to have had a disturbed and deprived childhood and showed high rates of behavioural disturbance, substance abuse and personality disorder.

\section{ii. Women charged with a particular offence.}

Woodside ${ }^{32}$ described the 26 women admitted to Holloway during February 1960 on drink-related charges. They were found to consist mainly of homeless, alcoholic women with multiple social problems and extensive histories of petty offending.

d'Orban described 13 women remanded to Holloway for stealing a baby ${ }^{33}$ as falling into one of four groups: women of low intelligence who stole a baby to play with ( 2 cases), women suffering from schizophrenia ( 3 cases), "psychopathic personalities" with a history of delinquency and a pre-occupation with the desire to have children ( 4 cases) and a "manipulative" group, where the offence was an attempt to influence the emotions of a third party ( 4 cases). Four women (three from the manipulative group and one from the psychopathic group) were given a prison sentence for this highly unusual offence.

A 1979 paper by d'Orban ${ }^{34}$ describes the 89 women remanded to Holloway over a six year period charged with attempted or actual filicide. Psychiatric disorder was found in 75 women $(84 \%)$, including 14 women (16\%) suffering from psychosis. Rates of psychiatric disorder are high but the selective nature of the sample precludes generalisation to other women in prison. Only nine of the 84 women found guilty (11\%) received a prison sentence and none of these were in the "mentally ill" group. It is not possible to determine the precise psychiatric characteristics of the women who did receive a prison sentence but the results are consistent with a reasonably effective mechanism for screening out mentally ill women for a disposal other than imprisonment. The question remains of how effective such a mechanism may be in detecting and diverting those women charged with more mundane offences.

A 1985 paper, also by d'Orban ${ }^{35}$, describes the 72 women sentenced to imprisonment for contempt of court and received at Holloway prison from 1979 to 1983 (45\% of all women in England and Wales imprisoned for contempt during this period). Psychiatric disorder, according to clinical criteria, was found in 27 women (38\%). The diagnoses were schizophrenia (8 cases), paranoid state (4), personality disorder (9), 
reactive depression (2) and alcoholism (4). As there are no studies of psychiatric aspects of contempt of court in men, it is unclear to what extent the high rates of psychosis are a feature of this uncommon offence in both sexes. Whilst the study shows high rates of psychiatric disorder in a particular group of sentenced prisoners, they were civil prisoners (who accounted for $0.1 \%$ of the sentenced female prison population in 1988) and legislation (since amended) relating to the particular offence of contempt did not allow for a remand for psychiatric reports.

These reports make no claim to being representative of female prisoners in general but it is possible that their presence in the literature contributes to the impression that female offenders have a high level of psychiatric disturbance. Some of the studies appear to have been inspired by the assumption that women in prison are likely to have high levels of disorder and there is a lack of corresponding studies on groups of male prisoners.

\section{Studies in the United States.}

American studies are of limited relevance because of the different ways in which their criminal justice and prison systems are organised. They remain of interest because they demonstrate two features which are absent from studies in the United Kingdom: i. application of the same method to samples of both female and male prisoners. ii. an attempt to relate prevalence rates in prisoners to rates in the community.

Guze $^{36}$ surveyed 223 male and 66 female sentenced prisoners, using a standardised interview ${ }^{37}$. The male sample consisted of all inmates in Missouri becoming eligible for release during the study period (November 1959 to April 1960). The female sample consisted of all women under parole supervision on 1st July 1969, plus seven women released during the course of the study. The ten year gap between collection of the samples means that the male and female samples are not directly comparable but the results are presented in Table 1.2. 
Table 1.2. Psychiatric disorder in prisoners, by gender (from Guze, 1976).

\begin{tabular}{|l|rr|rr|}
\hline & \multicolumn{2}{|c|}{ women } & \multicolumn{2}{c|}{ men } \\
& $\mathrm{n}=6 \mathrm{~N}^{2}$ & 8 & $\mathrm{n}$ & 8 \\
\hline sociopathy & 43 & 65 & 174 & 78 \\
alcoholism & 31 & 47 & 121 & 54 \\
hysteria & 27 & 41 & - & - \\
drug dependence & 17 & 26 & 10 & 5 \\
homosexuality & 9 & 14 & 3 & 1 \\
anxiety neurosis & 7 & 11 & 26 & 12 \\
depression & 1 & 1 & - & - \\
mental deficiency & 4 & 6 & 1 & $<1$ \\
schizophrenia & 1 & 1.5 & 2 & 1 \\
epilepsy/organic & - & - & 4 & 2 \\
uncertain & 8 & 12 & 1 & $<1$ \\
\hline ANY DIAGNOSIS & 66 & 100 & 200 & 90 \\
\hline
\end{tabular}

The authors conclude that "the prevalence of sociopathy, alcoholism and drug dependence was similar to that among male felons". This statement is correct if these diagnoses are combined but masks the significantly greater prevalence of drug dependence in female prisoners (the odds ratio is 7.39 , with a $95 \%$ confidence interval of 3.2 to 17.1). Hysteria (the definition is of somatisation disorder or Briquet's syndrome) was frequent in female prisoners but was not found in any males. The reported differences in the prevalence of mental deficiency are discussed below.

Apart from the recording of homosexuality as a psychiatric disorder, other peculiarities of the study deserve comment. The most frequent index offence, recorded in $21 \%$ of the women, is homicide. The authors do not give population figures but homicide and attempted homicide accounted for less than $2 \%$ of all sentenced female prison receptions in England and Wales during 1988 and the commonest offence was theft. This suggests that the sample may not have been representative of all prisoners.

Another surprising finding is the low frequency of depression. This was noted only when it was a "primary diagnosis" but one case in a total of 289 subjects remains a low prevalence for a disorder which is common in the community ${ }^{38}$. The very high prevalence of hysteria is also unexpected.

Novick $^{39}$ described the 1,300 men and 120 women who comprised all receptions to New York City Correctional Facilities during a two-week period in 1975. Diagnoses 
were derived from the non-standardised, routine interview administered to all receptions by primary care physicians.

A history of drug use (mainly use of heroin or methadone) was given by $48 \%$ of women and $40 \%$ of men. Eight percent of women and nine percent of men were judged by the admitting physician to be in need of psychiatric evaluation. "Psychiatric disorder" was recorded as a "diagnosis or problem listing" in $10 \%$ of women (compared to $5 \%$ of males under 21 years and $7 \%$ of males 21 years and over). Corresponding figures for alcohol abuse were $4 \%$ of women $(0.3 \%$ and $7 \%$ of younger and older men respectively) and for drug abuse $23 \%$ of women (13\% and $17 \%$ of men). Five percent of women and seven percent of men reported previous psychiatric hospitalisation. A history of attempted suicide was given by eight percent of women and five percent of men. Following the medical examination, five percent of the women and seven percent of the men were sent to "mental observation areas".

Sampling in this study was comprehensive and permits comparison of female and male inmates but the absence of precise diagnoses makes it difficult to draw any useful conclusions. The higher prevalence of drug abuse and dependence in women is consistent with the previous study.

A later study of female prisoners in Missouri $^{40}$ examined 100 consecutive sentenced receptions, using the Diagnostic Interview Schedule (Version III) ${ }^{41}$ to generate DSM-III diagnoses. Ninety women received at least one diagnosis on Axis I, with 67 receiving more than one. This study did not examine male prisoners but the authors compare their findings to rates of psychiatric disorder found in the community. Table 1.3 shows the lifetime prevalence of psychiatric disorder in female prisoners compared to rates reported for females in the general population of St. Louis ${ }^{42}$. 
Table 1.3. Lifetime prevalence of psychiatric disorder in women in prison and in the general population of St. Louis. (from Daniel et al, 1988).

\begin{tabular}{|l|c|c|c|}
\hline & $\begin{array}{c}\text { St. Louis } \\
(\mathrm{N}=1802) \\
8\end{array}$ & $\begin{array}{c}\text { prison } \\
(\mathrm{N}=100) \\
8\end{array}$ & $\mathrm{p}$ \\
\hline schizophrenia & 1.1 & 7 & .0003 \\
major depression & 8.1 & 19 & .001 \\
mania & 1.1 & 2 & $\mathrm{~ns}$ \\
alcohol abuse/dep & 4.3 & 36 & .001 \\
drug abuse/dep & 3.8 & 26 & .001 \\
simple phobia & 9.4 & 15 & $\mathrm{~ns}$ \\
agoraphobia & 6.4 & 6 & $\mathrm{~ns}$ \\
panic disorder & 2.0 & 2 & $\mathrm{~ns}$ \\
o-c disorder & 2.6 & 6 & $\mathrm{~ns}$ \\
somatization & .3 & 1 & $\mathrm{~ns}$ \\
antisocial p.d. & 1.2 & 29 & .0001 \\
\hline
\end{tabular}

* $p$ derived from Fisher's exact test or $\mathrm{Chi}^{2}$, as appropriate.

The authors note that for every comparison where the differences are significant, prisoners have higher rates of psychiatric disorder. They go on to demonstrate that these significant differences remain when age-specific prevalence rates are used i.e. they cannot be explained away as the result of the different age structure of the two populations.

Attention is drawn to the high rate of schizophrenia and major depression, compared to most other studies ${ }^{43}$. The high prevalence of depression may be due to the use of a reception sample, as prisoners react to their recently imposed sentence and adjust to loss of liberty. These factors cannot account for the high rate of schizophrenia but the prevalence rate of seven percent derives from a relatively small sample, where it corresponds to seven cases. The $95 \%$ confidence interval is from $3 \%$ to $14 \%$ i.e. the findings are compatible with the possibility that the true rate of schizophrenia in this section of the Missouri prison population is 3\%. The interpretation of the finding must also depend on a knowledge of local practice in respect of mentally disordered offenders.

\section{Studies of mental handicap in prisoners.}

In the light of Bluglass's ${ }^{44}$ assertion that "..more has been written about the association of low intelligence and criminal behaviour than any other factor..", it is ironic that the extent of mental handicap among prisoners remains unclear. In the early part of 
this century, it was widely believed that mental retardation and criminality were directly related. Lewis ${ }^{45}$ emphasised the close relationship between the historical development of the concept of psychopathic disorder and low intelligence. The epidemiology of mental retardation in offender and prison populations remains complicated by confusion between the concepts of low IQ and mental handicap, so that a recent review of studies of psychiatric disorder in sentenced prisoners ${ }^{46}$ was able to quote prevalence rates for mental handicap ranging from less than one percent to $45 \%$.

For this reason, mental handicap is discussed separately from other psychiatric diagnoses whilst referring to many of the same studies. Before reviewing previous findings, two general issues are considered:

a. The definition of mental handicap and ways of estimating its prevalence.

b. The relationship between mental handicap and other psychiatric disorder.

\section{a. The definition and prevalence of mental handicap.}

It is necessary to distinguish the concepts of low IQ and mental handicap:

\section{i. The definition of low IQ (intelligence quotient).}

This is relatively straightforward. If the IQ or Intelligence Quotient is defined as the score on an IQ test, then low IQ is defined as a score falling below an arbitrary cutoff point. Test such as Raven's matrices ${ }^{47}$ are similar measures of intelligence, although they do not use IQ scores.

\section{ii. Mental handicap or mental retardation.}

The definition of mental handicap is more complex. The approach taken in the International Classification of Impairments, Disabilities and Handicaps ${ }^{48}$ has found favour with some specialists in the field ${ }^{49}$ and the definitions used help to illustrate potential sources of confusion:

An impairment is an abnormality or loss of any structure or function.

A disability is any restriction or lack of ability to perform an activity in the manner or within the range considered normal for a human being, resulting from an impairment. A handicap is a disadvantage for a given individual, resulting from a disability, that limits or prevents the fulfilment of a role that is normal for that individual. 
The definition of a handicap contains a social component. Failure to score within the normal range on an IQ test is a disability but it is not a good predictor of other disabilities and it is a poor predictor of handicaps i.e. problems of social functioning ${ }^{50}$.

The social component in handicap is recognised in the ICD9 definition of mental retardation which stresses that an assessment should include information about "adaptive behaviour": IQ levels are provided as a guide, with the proviso that they "should not be applied rigidly".

These distinctions suggest three possible epidemiological measures:

i. The prevalence of low intelligence, as measured by IQ tests.

ii. The prevalence of mental handicap, assessed by standardised measures which take account of social functioning.

iii. The prevalence of mental handicap as defined by presentation to mental handicap services.

This third measure is closely related to the concept of administrative prevalence, defined by Tizard" as "the number for whom services would be required in a community which made provision for all who needed them". In the general population, the prevalence of mental retardation (defined as IQ less than 70) is $20-30 / 1,000$ population, whereas the administrative prevalence is less than $10 / 1.000$, as less than half of all mentally retarded people require services.

\section{b. Mental handicap and psychiatric disorder.}

Mentally handicapped people who come to the notice of psychiatrists generally do so not because of their intellectual deficit but because of some additional undesirable behaviour $^{52}$. This principle was incorporated into the Mental Health Act 1983, which created the categories of mental impairment and severe mental impairment and permits detention only when handicap is "associated with abnormally aggressive or seriously irresponsible conduct". Mentally handicapped people are not excluded from the other provisions of the Act and it has been argued that the terms mental impairment and severe mental impairment will become redundant, as the other categories of mental disorder could be applied to all cases of mentally handicapped people whose psychiatric disorder warrants detention under the $\mathrm{Act}^{53}$.

Populations of mentally handicapped people have increased psychiatric morbidity; rates of psychosis, neurosis and personality disorder are elevated but diagnosis is often difficult, as the manifestations of psychiatric disorder in a mentally handicapped person may fit poorly into diagnostic categories developed in a population of normal 
intelligence ${ }^{54}$. There may be particular difficulties in differentiating disturbed behaviour resulting from situational factors and that caused by psychiatric disorder. Such decisions may require a prolonged multi-disciplinary assessment, which are beyond the scope of most prison surveys.

\section{Previous surveys of mental handicap in prisoners}

The association between delinquency, low IQ and poor educational attainment is a robust finding ${ }^{55}$ and there is good evidence that the association between low IQ and offending remains significant, though less strong, after controlling for social factors ${ }^{56}$. An increased prevalence of low intelligence in the prison population is to be expected, whereas a high prevalence of mental handicap would be a cause for concern at the possibility that existing screening procedures are ineffective.

Many surveys of prison populations measure the prevalence of low intelligence. Using Raven's matrices, Roper ${ }^{57}$ found that $50 \%$ of inmates of Wakefield prison were "below average/dull" and 18\% were described as "intellectually defective/very dull". These results are shown alongside those for the general population in Table 1.4.

Table 1.4. Scores on Raven's matrices of sentenced female prisoners (from Woodside, 1962), sentenced male prisoners (from Roper, 1951 and Bluglass 1966) and the general population.

\begin{tabular}{|c|c|c|c|c|}
\hline & $\begin{array}{l}\text { female } \\
\text { prisoners } \\
\text { (Woodside) } \\
\left(\begin{array}{l}\mathrm{N}=118) \\
8\end{array}\right.\end{array}$ & $\begin{array}{l}\text { male } \\
\text { prisoners } \\
\text { (Roper) } \\
(\mathrm{N}=814) \\
\quad \%\end{array}$ & $\begin{array}{l}\text { male } \\
\text { prisoners } \\
\text { (Bluglass) } \\
(\mathrm{N}=291) \\
\quad 8\end{array}$ & $\begin{array}{l}\text { general } \\
\text { population } \\
\qquad 8\end{array}$ \\
\hline very superior & 11 & 1 & 7 & 5 \\
\hline superior & 16 & 4 & 24 & 20 \\
\hline average & 31 & 45 & 47 & 50 \\
\hline below average & 24 & 32 & 16 & 20 \\
\hline $\begin{array}{l}\text { intellectually } \\
\text { defective }\end{array}$ & 18 & 18 & 6 & 5 \\
\hline
\end{tabular}

Whilst the figures for the prison population are skewed towards the lower end of the range, it is apparent that the "below average" categories cannot be considered synonymous with mental handicap. Roper did not consider social functioning in relation to the test results although, elsewhere in the paper, he states that half a percent of his sample were "profoundly intellectually defective" and were therefore excluded from his analysis.

$\mathrm{Epps}^{58}$ tested 289 women in Borstal using Raven's matrices but does not report the results in full. She describes 144 women (50\%) as falling in the "average" category 
with $134(46 \%)$ of "subnormal" and 11 (4\%) of "superior" intelligence. Assuming that these figures result from merging the two lowest and two highest categories respectively, they resemble Roper's findings and justify Epps' assertion that "the intelligence of the average delinquent is less than that of the average delinquent". The relevance to mental handicap is uncertain.

Woodside ${ }^{59}$ reports the results of testing with Raven's matrices in 118 sentenced women (also shown in Table 1.4) and concludes that they show a "slight loading towards the lower intelligence grades". In her total sample of 139 women, she identifies 12 (9\%) as subnormal. The author accepts that her diagnostic criteria are "rough and ready" but she notes that five of these women have a history of inpatient psychiatric treatment, another three had been "certified patients in institutions" and a further two had been recommended for a disposal under Section 60 of the Mental Health Act, 1959.

Wooodside's study reports a relatively high percentage of "true" mental handicap in a prison population. The two case histories cited suggest that the diagnosis of mental retardation may not have been applied to all the cases today (one had an IQ of 80) but that they did reflect psychiatric practice at that time (one had two recommendations for sentencing under the Mental Health Act, the other had spent five years as a compulsory patient in an institution for the "mentally defective"). It is unfortunate that more information is not given about the other patients, as this paper provides an interesting glimpse of psychiatric practice in relation to mental handicap in the early months of the operation of the 1959 Act.

Robinson $^{60}$ surveyed 566 consecutive male receptions to HMP Belfast and concluded that $24 \%$ were "of subnormal intelligence to a degree which merited consideration by the Special Care Authority". The author does not say how this decision was reached but does note that only nine $(1.6 \%)$ of these inmates had ever received treatment by the Authority.

Bluglass $^{61}$ combined Raven's matrices, the Mill Hill vocabulary test ${ }^{62}$ and a clinical assessment in his survey of 300 male inmates in Perth prison. The scores on Raven's matrices are included in Table 1.4 and approximate to the distribution for the general population.

His criteria for mental handicap resemble the second type of prevalence measure described above i.e. a standardised measure which also takes account of social function. The categories were "Borderline Subnormal", requiring a score in the "below average" range on Raven's matrices and the Mill Hill vocabulary test, plus evidence of impaired social function (11.6\% of the sample) and "Subnormal", requiring a score within the 
"intellectually defective" range on both tests in addition to social impairment ( $2.6 \%$ of the sample).

Guze's $^{63}$ survey of 223 male prisoners identified $7 \%$ as "below normal intelligence" on the basis of school history and mental state, plus test results when these were available from records. IQ scores were available for three of these subjects and fell between 80 and 85; only one subject was thought to have a degree of impairment that would preclude a normal, self-sufficient life in the community. Of the 66 women in this study, four (6\%) were considered "mildly retarded" though "none seriously enough to interfere with daily life". Only one woman had test results, an IQ of 60 .

In summary, these studies are consistent with an increased prevalence of low intelligence in most prison populations compared to the general population but only one study, by Woodside, provides evidence that the prevalence of mental handicap is higher than two or three percent.

\section{Mental handicap in the present study}

The diagnosis was made on clinical criteria, supplemented by test results when available. This method corresponds most closely to a measure of administrative prevalence. Additional diagnoses were only given when it was felt that the clinical features of the case would warrant the diagnosis in the absence of mental handicap. This issue is discussed further when considering the results of the present study.

\section{Summary: psychiatric disorder in female prisoners}

Most studies of prisoners, irrespective of gender, reveal a similar pattern. The prevalence of substance abuse, personality disorder and neurotic symptoms is high but psychosis is less common. Variation in rates of mental handicap can be accounted for by the use of different criteria and the confounding of low intelligence and mental handicap. Prison studies in the UK do not allow a direct comparison of rates of psychiatric disorder in women and men but suggest that personality disorder and behavioural disturbance may be more common in women. American studies suggest higher rates of personality disorder, substance abuse and neurotic disorder in female prisoners but are equivocal in respect of psychosis and mental handicap. Even if the differences in prevalence rates are valid, there is no evidence to justify the assumption that most women in prison are in need of psychiatric help. The failed attempt to make Holloway prison a secure hospital was not based on sound empirical evidence. 
The structure of the report

Chapter Two - Sampling, Data Collection and Coding describes the selection of the samples of female and male prisoners, the interview and data collection and the rating and coding of data.

Chapter Three - The Sample describes the characteristics of the sample of female prisoners and compares it to the female prison population as described in the Prison Statistics, 1988. Differences in the ethnic composition of the female and male samples are described and related to the presence within the female population of a signicant minority of foreign nationals serving long sentences for the importation of drugs. This potential source of bias is dealt with by a separate analysis of overseas women. The chapter ends with a description of the statistical techniques used to compare the women and men.

Chapter Four - Results $I$ describes the results of a comparison of social characteristics of the female and male samples, including indicators of childhood disturbance, educational attainment and marital status. The prison disciplinary records of the female and male samples are compared, followed by a description of the lifetime prevalence of deliberate self-harm in the female sample and a comparison with the prevalence and nature of deliberate self-harming behaviour in the male sample. The chapter ends with an account of previous psychiatric treatment and the treatment recommendations made in the present study.

Chapter Five - Results II contains descriptions of the prevalence of psychiatric disorders in women prisoners who are normally resident in the UK and those who are normally resident overseas. Rates of psychiatric disorder in female and male sentenced prisoners are then compared.

Chapter Six - Conclusions places the findings in the context of other work on mentally disordered offenders and looks at the implications for prison health services. 


\section{CHAPTER 2: SAMPLING, DATA COLLECTION AND CODING}

\section{Introduction}

This chapter describes selection of the original sample of prisoners, the sources of information used and the way in which data were collected, including a description of the research interview. This is followed by a description of the rating and coding of data and an account of the way in which diagnoses and treatment recommendations were made.

The chapter is divided into three sections:

1. Selection of the Initial Sample

2. Interview and Data Collection

3. Rating and Coding of Data

\section{Selection of the Initial Sample.}

\section{The sentenced prison population}

On 30th June 1988, the prisons of England and Wales held 1,776 women ${ }^{64}$. Five hundred and fifteen of these were remand prisoners awaiting trial or sentence and 1,256 were serving a sentence of imprisonment. In 27 cases, the sentence was being served in default of payment of a fine; the remaining 1229 women, sentenced by the court to immediate imprisonment, form the basis of the study.

By contrast, the male prison population on the same date contained 37,292 male adult and young offenders serving a sentence, of whom 549 were fine defaulters and 36,743 had been sentenced to immediate imprisonment ${ }^{65}$. The ratio of men to women is $30: 1$.

\section{The initial sample}

At the time of the study, sentenced women were held in eight prisons. The larger survey of which this study is a part also required visits to some 25 male prisons so it was impractical to visit all prisons for women. Instead, four were chosen to represent different areas of the country, levels of security and offence types. The prisons are described in Appendix B.

At each of the four prisons, subjects were chosen from an alphabetical list of inmates on each wing. Every second inmate was selected from this list, approached by the interviewer and asked to take part in the study. It was explained that the study was being conducted by doctors from outside the prison system and would enquire about "medical, psychiatric, drink and drug problems and the need for treatment." The woman was reassured that the interview was to be conducted in confidence, none of the information 
was to be made available to the prison authorities and the study would have no effect on the way in which she was managed within the prison system. Women who agreed to take part were required to sign a consent form.

In those few cases where the inmate left prison before being approached, the next name on the list, from the same wing, was substituted. Prisons are highly organised institutions, with inmates allocated to particular wings on the basis of various characteristics which include disciplinary problems and difficult behaviour. This method of sampling by wing or unit was designed to ensure that no pockets of disturbed inmates were overlooked. The permission of the prison authorities was required before inmates could be approached but this was never refused and inmates were selected from all parts of the prison, including disciplinary and segregation units.

Of 301 women approached, only eight (2.7\%) refused, leaving 293 subjects. (In three of the eight "refusers", the women were from overseas and language difficulties made it impossible to explain the nature of the project or conduct the interview. It will be seen in the next chapter that only four UK resident women refused to take part.) The sample constitutes $24.5 \%$ of the total population of 1,229 sentenced women.

Sampling of sentenced male adults and young offenders and matching with the male sentenced population are described elsewhere ${ }^{66}$. A total of 1884 male prisoners were approached and 1769 agreed to be interviewed, a refusal rate of $6 \%$.

For the purposes of comparing the prevalence of psychiatric disorder in women and men, these samples were subject to further modification, for reasons which will be discussed in the next chapter.

\section{Interview and data collection}

The aim was to provide a demographic, criminological and behavioural description of each woman interviewed and then to identify and describe in more detail those who fulfilled the criteria for one or more of the psychiatric diagnoses in ICD9.

Data on each subject were collected from five sources:

1. Prison discipline records and prison medical records.

2. Semi-structured interview with the inmate, including a standardised assessment of mental state using the Clinical Interview Schedule.

3. Informal interviews with prison staff familiar with the interviewee.

4. Notes or reports from NHS hospitals when a history of previous treatment was obtained.

5. The woman's criminal record, obtained from the Criminal Record Office. 
This information was used to complete a data sheet which had been designed for the study (Appendix C).

Each of these sources of information will now be described in more detail.

\section{Prison records.}

In prison, every woman has a discipline record and a medical record.

The discipline record should always contain the following information:

date of birth

occupation

last known address

date and place of sentence

nature of offence

length of sentence

earliest date of release (EDR)

latest date of release (LDR)

disciplinary offences during sentence

loss of remission

record of transfers between prisons

warning if inmate presents management problems due to:

- violent behaviour

- escape potential

- vulnerability to abuse by other inmates.

The discipline record may also contain:

detailed account of the index offence

social enquiry reports

psychiatric reports

parole reports by:

- prison officers

- the Governor

- probation officer

- education officer

- chaplain

full criminal record 
Data from the discipline record were used to complete pages one to three of the data sheet (Appendix C).

The prison medical record contains the initial screening and medical examination carried out on every inmate plus details of any contact with the doctor since then, including a record of past and current treatment. When mental disorder is suspected, the record may contain an extensive psychiatric history, copies of psychiatric reports prepared for the trial or relating to previous treatment and correspondence with psychiatrists outside the prison concerning possible transfer to hospital.

\section{The semi-structured interview.}

The aim was to screen the maximum number of women in the shortest time whilst collecting as much information as possible on those subjects who were identified as psychiatric cases. Time constraints were very important as access to prisoners is generally possible for only two hours in the morning and two hours in the afternoon.

For this reason, the basic screening interview was short. One of two trained psychiatrists conducted each interview and asked additional questions as necessary. The interview was carried out after extracting information from the discipline record, in order to make maximum use of historical information that could suggest the presence of psychiatric disorder. Further implications of this approach to data collection are discussed below in the section on ratings and diagnostic criteria.

Depending on the facilities available, the interview was conducted in an office on a prison wing or in the prison hospital. Only interviewer and interviewee were present in the room and it was not possible for the interview to be overheard.

The basic interview is contained in the data sheet, beginning on page 4 . The format is a set of screening questions asked of all subjects. Supplementary questions follow when the response to the screening question is positive or when information from the prison record suggests problems in a particular area. The interview was designed to resemble a shortened version of a clinical psychiatric interview and the psychiatrist conducting the interview was given the freedom to add whatever questions he felt appropriate. Criteria for ratings made by the interviewer are described in more detail below.

Information was collected in the following areas: 


\section{i. Background/demography}

Place of birth, ethnic origin, education, marital status and social circumstances, location within the prison.

\section{ii. Medical and psychiatric history}

Specific medical conditions, substance abuse, any contact with psychiatric services inside or outside prison, any current or past psychiatric problems.

\section{iii. Standardised mental state examination}

This was carried out using the Clinical Interview Schedule (CIS) ${ }^{67}$, a standardised psychiatric interview. Originally developed for use in identifying psychiatric disorder in General Practice, it consists of a number of stem questions leading on to more detailed questions when the response is positive. The questions concern mainly neurotic symptoms e.g. "do you ever find that you get anxious or frightened for no good reason?", "do you worry a lot about things?".

Prior to beginning the study, both interviewers were trained in the use of the CIS and ratings are made according to the criteria in the CIS manual. The standard interview was modified by omitting the "Depersonalisation" item which proved difficult to explain to subjects in a pilot study and was of limited relevance to a prison population.

The CIS was also used as a convenient starting point for enquiry about other symptoms, including abnormal experiences and beliefs, when appropriate.

\section{iv. Schonnelt ${ }^{8}$ reading age}

This brief test provides an estimate of reading ability, expressed as a reading age. It was administered whenever there was doubt over a subject's intellectual ability. Whilst a low score may be due to poor education, a high or reasonable score is strong evidence against a significant degree of mental retardation.

\section{v. Criminal Profile ${ }^{69}$}

A summary of a subject's criminal career, used in a previous prison survey ${ }^{70}$.

Criteria for rating are contained in the questionnaire.

\section{vi. Attitude towards treatment}

Current attitude towards psychiatric treatment was assessed on a five-point scale used in a previous prison survey ${ }^{71}$. The rating is arrived at by a process of negotiation between psychiatrist and interviewee, replicating a similar situation in the psychiatric clinic. 


\section{Interviews with prison staff}

In specific cases, with the consent of the inmate, interviews with staff provided supplementary information to aid diagnosis. People in regular daily contact with the inmate were able to give useful descriptions of behaviour and relations with others. One difficulty with making psychiatric assessments in prison is the lack of a social context and information about the subject's behaviour outside the interview setting. In hospital psychiatry the family would be used as informants to supply this information; an attempt was made to use prison staff in a similar way.

\section{Reports from outside hospitals.}

Whenever information was obtained about previous psychiatric contact, the woman concerned was asked for permission to contact the relevant hospital. This was never refused and attempts were made to obtain copies of notes or reports. Some women had notes documenting many years of psychiatric contact or a full assessment by a consultant from a special hospital.

\section{The criminal record}

A record of each woman's past convictions (CRO data) was obtained from the Home Office. This information was recorded on pages 27 and 28 of the coding manual.

Having assembled as much information as possible, the final part of the data sheet is completed. This records ICD9 diagnoses, if any, and an assessment of the possible role for medical services. Decisions on diagnoses and treatment recommendations are described in the following section. 


\section{Rating and Coding of Data}

Data coding was recorded on the data sheet (Appendix C) according to the guidelines in the coding manual (Appendix A). Many items were coded at interview and require no discussion beyond that contained in the manual. Others record assessments and opinions which may be coded later after obtaining further information. The judgements required in making these assessments vary in complexity. Whenever possible, the manual describes operational definitions.

The criteria for rating substance abuse and gambling illustrate this approach. The manual contains operational guidelines and it is expected that the rating will be made during or immediately following the interview, possibly after considering a medical or social enquiry report. Note that the frequency of particular behaviours has also been recorded, without making any judgement about their significance e.g. in addition to coding drug dependency, frequency of use of individual drugs is also coded.

\section{Psychiatric Diagnosis and Treatment Recommendations}

The aim of each assessment was to assign a diagnosis according to an accepted classification system and to make a decision on the most appropriate management.

\section{The diagnostic classification.}

The diagnostic system used was the Mental Disorders Glossary of ICD9, part of the World Health Organization's International Classification of Diseases, Ninth Revision $^{72}$. It is the most widely used psychiatric diagnostic system in Europe. It consists of a booklet providing brief descriptions of the features of each disorder and a four-digit code number. The definitions are widely accepted and both interviewers had previously used the system in their clinical practice. The diagnosis was based on clinical criteria, with reference to "present state" rather than lifetime diagnoses. The exceptions were alcohol and drug abuse, where the reference period was the six months prior to arrest for the index offence.

The equivalent diagnostic system in North America is the Diagnostic and Statistical Manual of Mental Disorders, Revised 3rd Revision (DSM-III-R) ${ }^{73}$. ICD9 was preferred for the present study as it is more widely accepted in Europe. However, a noted shortcoming of ICD9 is in its categories for personality disorder; they are not comprehensive and are to be extensively revised in the next edition of the International Classification of Diseases. To compensate for this shortcoming, subjects believed to have a personality disorder were also assigned to one of the DSM-III-R categories for 
personality disorder, using clinical criteria rather than a standardised instrument (see below).

\section{Making a diagnosis.}

Neither the interview designed for the study nor the CIS generate diagnostic labels. The latter is concerned only with neurotic symptoms (although psychotic phenomena that become apparent during the interview are noted and recorded in the "manifest abnormality" section of the Schedule).

The decision to use the CIS, rather than an interview such as the Present State Examination (PSE) ${ }^{74}$ which can generate diagnoses, was taken for several reasons:

- Constraints on time and the large number of subjects made a longer interview impractical.

- It was predicted that psychotic symptoms would be of low frequency and routine enquiry as to their presence would offend some prisoners and lead to an increased refusal rate.

- Both interviewers were trained psychiatrists. By using their discretion in conjunction with information already gleaned from the prison record, they could reduce the time spent with prisoners who showed no evidence of mental disorder. When psychotic symptoms were suspected or evident, a clinical psychiatric interview was conducted to determine their nature and content. It was possible to return for a subsequent interview in doubtful or complicated cases.

- In making a diagnosis, the interview was only one of a number of sources of information. In an attempt to simulate good clinical practice, full weight was given to historical information.

- For the purposes of the present study, it was less important to assign a precise diagnosis than to identify cases within broad diagnostic categories eg. psychotic or neurotic disorders. 


\section{Difficult diagnoses and decisions on management of cases.}

The approach described above is more efficient than administering a long standardised interview to all subjects. Its disadvantage is that individual symptoms are not routinely recorded and hence cannot be analysed as such. It could be argued that the validity of this method has not been established. It was important to ensure that the decisions taken were not simply the result of biases in the psychiatrists conducting the interviews. One aim of the study is to describe service needs, so it is essential that decisions on diagnosis and management should reflect current clinical opinion within forensic psychiatry.

For this reason, a project steering committee was set up to advise on questions of diagnosis and management.

\section{The project steering committee}

This consisted of the three psychiatrists intimately involved with the study, two senior lecturers in forensic psychiatry (one of whom was also a Special Hospital consultant), two psychologists working in the forensic field and a probation officer. At monthly meetings, this group considered all cases suspected of suffering from a psychotic illness in addition to any other cases felt by the interviewers to present diagnostic or management problems. Information considered included interview data and all available reports e.g. past psychiatric and social enquiry reports, the disciplinary record in prison and detailed statements regarding the index offence.

All cases selected as above were debated by the group and a consensus was usually reached. In the rare cases of unresolved disagreement, the interviewer made the final ratings in the light of the points raised during discussion.

\section{Decisions made by the steering committee}

Decisions made by the committee fell into two categories:
i. Diagnosis
ii. Recommended treatment

\section{i. Diagnosis.}

The criteria used were those specified in ICD $9^{75}$. 


\section{ii. Recommended treatment.}

Decisions on the role of the prison psychiatric services and nature of treatment were guided by the application of current standards of clinical practice in an ideal world i.e. in the light of present medical knowledge but not constrained by the availability of resources.

There are no generally accepted criteria for assessing treatment needs. In the present study, an attempt has been made to replicate the process by which such decisions are reached in the clinical practice of forensic psychiatry i.e. by discussing each case as a clinical problem, within a multidisciplinary team.

\section{The treatment recommendations.}

Six treatment recommendations were possible:

\section{i. None}

This was automatically applied to subjects with no diagnosis, also given to those with a diagnosis but felt to be untreatable because of lack of motivation, unless the nature and degree of mental disorder was such as to require involuntary treatment under the Mental Health Act 1983.

\section{ii. Treatment within prison}

Treatment which an average General Practitioner or psychiatrist could provide on a mainly outpatient basis e.g. supportive psychotherapy and/or medication. A brief period of special supervision or admission to a prison "hospital" may be required but with the expectation that most of the sentence could be completed under the normal prison regime without undue risk to the health of the inmate or to staff. 


\section{iii. Therapeutic Community}

The type of contract-based regime found within the prison system at HMP Grendon and outside prison at the Henderson hospital and drug or alcohol rehabilitation centres. Allocation to this category does not require a judgement as to where the treatment is provided but does imply that the inmate is capable of entering into a therapeutic contract.

This category was included as it proved in pilot studies to be a form of treatment with which many drug or alcohol dependent prisoners were familiar. Some inmates were aware of the regime at Grendon but many more had heard of Phoenix House or Clouds House, therapeutic communities which cater for substance abusers. As this form of treatment is rare within the health service, the consequence was that the potential users of the service often knew more about this form of therapy than the medical officers or psychiatrists responsible for their care. For subjects with a diagnosis of drug dependence, this category was used rather loosely to indicate that the subject was motivated to undergo some form of "psychological" (i.e. not prescribed) treatment aimed at reducing or avoiding future drug use.

\section{iv. Further Assessment}

This category acknowledges that an accurate diagnosis or treatment decision may be impossible in the prison setting, whether because of lack of information or mixed motives in an environment where "illness" is one of the few officially sanctioned expressions of distress, anger or discontent. Where there is uncertainty over diagnosis, treatment or motivation, it is assumed that at least the initial stages of assessment would take place in prison, some cases requiring no more than a further interview. The outcome of assessment may range from no treatment to hospital transfer. This category was used only when there was a high degree of suspicion that mental disorder was present and of such a degree as to require intervention.

\section{v. Hospital}

Inpatient treatment outside the prison system, either within the NHS or a special hospital. This category includes all cases requiring compulsory treatment and inmates willing to accept treatment voluntarily but suffering from psychiatric disorder which cannot be managed adequately or safely in a prison setting. The implication is that the inmate is not correctly placed at present, so an attempt was made to determine how these women reached prison, whether their disorder was recognised within the prison and what arrangements were being made for transfer or management within the prison. 


\section{The Diagnosis of Personality Disorder}

The diagnosis of personality disorder presents two specific problems for a prison survey:

i. It is heavily dependent on historical information, particularly from independent informants. This will be documented for some cases but will be unavailable for others.

ii. Prisoners are, by definition, criminal. Criminality features in many definitions of personality disorder and the diagnosis can be criticised as a re-labelling of criminality that has no relevance to psychiatric practice.

In this study, the diagnosis was based on present mental state and behaviour, using historical information when available. Particular note was taken of persistent interpersonal difficulties and social ineptitude, whether this emerged at interview or from other accounts. Inevitably, behaviour within the penal system is given added weight as problems within prison are more likely to be documented than those seen only outside.

Whilst this approach is likely to result in under-diagnosis of personality disorder, it should detect those personalities who are problematic within prison, along with the more severe manifestations of personality disorder outside prison. These factors must be taken into account when comparing the present findings with other studies and this point will be discussed at greater length when the results are presented.

With regard to the second point, criminal behaviour, self-harm and substance abuse were recorded and coded separately. Presence of these behaviours was not sufficient to justify a diagnosis of personality disorder which was added only when indicated by additional features of the case. Standardised instruments for diagnosing personality disorder were not used because of the weight which they give to criminality and substance abuse. Many of these instruments are subject to the criticism that they re-define offending in psychiatric terms and a clinical approach, despite problems of reliability, seemed more likely to guarantee relevance to psychiatric practice. 


\section{Reliability}

Inter-rater reliability for other items on the questionnaire was checked in a pilot study when twenty volunteer prisoners were interviewed by both interviewers on separate occasions. The information obtained was used to compile the coding manual (Appendix A). A few items were dropped from the questionnaire when it proved impossible to establish adequate reliability.

During the course of the study, a number of measures were taken to ensure that reliability was maintained. The interviewers discussed many of the cases informally or at larger meetings of the research steering committee (see below). Periodically, a small number of prisoners (approximately five percent of female subjects and two percent of males) was interviewed by both interviewers and results compared.

\section{Summary}

A sample of women, comprising $25 \%$ of the sentenced prison population, was selected from four prisons. Using data from prison and hospital records and a semistructured psychiatric interview, each woman was assigned an ICD9 diagnosis and a decision was made as to the most appropriate psychiatric management of each case. A 5\% sample of the male sentenced population forms a comparison group.

The following chapter describes the sample of female prisoners in more detail and attempts to establish that it forms a valid comparison group for the group of male prisoners. 


\section{CHAPTER 3: THE SAMPLE}

\section{Introduction}

This chapter describes the sample of female prisoners, establishes that it is representative of the population of sentenced women and that it is a valid comparison group for the sample of male prisoners.

The chapter begins with a brief description of the demographic characteristics of the female and male sentenced populations and draws attention to marked differences in the ethnic composition of the female and male prison populations. These differences are described and explained by the presence within the female prison population of a large number of foreign drug couriers, mainly from West Africa. It is argued that a more useful comparison of female and male prisoners can be made by excluding overseas residents from both samples and describing separately the psychiatric disorder found in women from overseas. The demographic and criminological features of the sample and the prison population are compared to establish that the sample is representative. The chapter ends with a description of the statistical techniques used.

\section{The sentenced prison population}

Demographic information provided in the Prison Statistics ${ }^{76}$ is limited to age and ethnic origin.

\section{The age structure of the prison population}

Table 3.1 compares the age distribution of the female and male prison populations $\mathbf{s}^{77}$.

Table 3.1 Age distribution of the sentenced prison population, by gender.

\begin{tabular}{|l|c|c|}
\hline age $(\mathrm{y})$ & $\begin{array}{c}\text { women } \\
8\end{array}$ & $\begin{array}{c}\text { men } \\
8\end{array}$ \\
\hline$<17$ & 0.7 & 1.5 \\
$17-20$ & 12.4 & 19.2 \\
$21-29$ & 45.6 & 44.0 \\
$30-49$ & 36.8 & 31.2 \\
$50 \&$ & 4.4 & 4.1 \\
\hline
\end{tabular}


The female prison population has a greater proportion of inmates in the 25-29 years and 30-39 years age groups, whereas the male prison population has a higher proportion in the younger age groups.

\section{The ethnic origin of prisoners}

\section{Background}

Monitoring of ethnic origin is carried out at various stages of the criminal justice system. Since 1984, prison department statistics have assigned inmates to one of five ethnic categories, as assessed by a prison officer with the inmate's agreement. The first figures were published in $1986^{78}$ and relate ethnicity to offence, type of prison and length of sentence.

Welcoming the appearance of hitherto unavailable data, Walker ${ }^{79}$ noted that the figures reveal a statistical over-representation of black people in the prison population. She stressed that the significance of this finding was unclear and interpretation must depend on information about ethnicity in offenders outside prison.

Despite such reservations, data on ethnicity has become a feature of the annual Prison Statistics. From the 1988 figures, it is apparent that people from ethnic minorities are unevenly distributed within the prison population and that one of the most striking concentrations is among women ${ }^{80}$. Twenty-five percent of sentenced women are from ethnic minorities. Women of West Indian/African origin account for $20 \%$ of the female prison population compared to nine percent of males.

The proportion of women from ethnic minorities also varies greatly by offence group. Five percent of women serving a sentence for burglary are of West Indian/African origin whilst they make up $40 \%$ of women sentenced for drug offences. By way of qualification, it is pointed out in the Prison Statistics that these figures have "...limited explanatory value...in providing conclusive evidence, both as regards the involvement of particular ethnic groups in crime and in relation to the practice of the courts"81. However, the statistical over-representation of women from ethnic minorities in certain parts of the prison population remains unexplained and has been ignored in most writing on women and the criminal justice system ${ }^{82}$.

\section{The ethnic origin of women in the study sample}

The published statistics suggest that the female sentenced population differs from the male sentenced population in containing an increased number of black women who have committed drug offences. Before comparing rates of psychiatric disorder in the two 
populations, it would be useful to know more about this obvious difference in demographic characteristics. In the course of the interviews, it became apparent that many black women serving a prison sentence were drug couriers, usually from West Africa. They had no address in this country and were due for deportation at the end of their sentence. A description of drug couriers by $\mathrm{Green}^{83}$ covers their background, motivation and problems within prison but does not address the question of their impact on prison ethnicity data.

The Prison Statistics do not allow the identification of foreign nationals. The categories of ethnic origin used in the present study correspond to those in the Prison Statistics, labelled according to the terms adopted by Walker ${ }^{84}$. As information about last address was also collected, women from overseas could be readily identified and table 3.2 relates country of residence to ethnic origin.

Table 3.2. Sentenced female prisoners: Ethnic origin by country of residence.

\begin{tabular}{|c|c|c|c|c|c|c|c|}
\hline & \multicolumn{2}{|c|}{$\begin{array}{l}\text { overseas } \\
\text { residents } \\
n \quad \& \quad\end{array}$} & \multicolumn{2}{|c|}{$\begin{array}{l}\text { UK } \\
\text { residents }\end{array}$} & \multicolumn{2}{|c|}{ total } & $\begin{array}{c}\text { prison } \\
\text { stats. } \\
1988 \\
8\end{array}$ \\
\hline white & 5 & 13 & 219 & 84 & 224 & 74 & 72 \\
\hline black & 27 & 69 & 33 & 13 & 60 & 20 & 20 \\
\hline Asian & 5 & 13 & 6 & 2 & 11 & 4 & 2 \\
\hline other & 2 & 5 & 4 & 1 & 6 & 2 & 6 \\
\hline total & 39 & 100 & 262 & 100 & 301 & 100 & 100 \\
\hline
\end{tabular}

The ethnic composition of the original sample of women is representative of the sentenced population as a whole. In total, 39 women (13\% of the sample) were ordinarily resident overseas, including 27 black and five Asian women who were serving sentences for the importation of drugs (usually heroin) and were to be deported at the end of their sentences. Considering only the 262 women ordinarily resident in the United Kingdom, the proportion of black women falls to $13 \%$ and that of Asian women to $2 \%$.

Only 18 of the 1769 men interviewed (1\%) were ordinarily resident outside the UK. The ethnic origin of the remaining 1751 men was white 1485 (85\%), black 186 (10.5\%), Asian $62(3.5 \%)$ and other $18(1 \%)$. 
In the sections which follow, the criminological characteristics of women ordinarily resident in the United Kingdom are described in more detail. Asian women are included in the "other" category as their numbers are so small.

\section{Criminological characteristics by ethnic origin}

In those women for whom the information was available, Table 3.3 shows that $67 \%$ of white and $61 \%$ of black women were serving their first custodial sentence. This difference is not statistically significant. Eighteen percent of both groups had served two or more previous sentences.

Table 3.3. UK resident female prisoners: number of previous custodial sentences by ethnic origin.

\begin{tabular}{|l|c|c|c|c|}
\hline \multirow{2}{*}{} & \multicolumn{4}{|c|}{ Previous custodial sentences. } \\
\cline { 2 - 5 } & None & 1 & 2 & $3+$ \\
\hline white & 144 & 33 & 25 & 14 \\
black & 20 & 7 & 5 & 1 \\
other & 10 & 0 & 0 & 0 \\
\hline total & 174 & 40 & 30 & 15 \\
\hline
\end{tabular}

There is now no particular concentration of black women among those convicted of drug offences (Table 3.4). The seven black women were sentenced for offences involving cannabis only. Ten of the white women were sentenced for offences involving cannabis but 33 cases involved opiates or amphetamines.

Table 3.4. UK resident female prisoners: index offence by ethnic origin

\begin{tabular}{|l|rr|rr|rr|rr|}
\hline & \multicolumn{2}{|c|}{$\mathrm{n}^{\text {white }}$} & \multicolumn{2}{c|}{ black } & \multicolumn{2}{c|}{ other } & \multicolumn{2}{c|}{ total } \\
& 112 & 84 & 18 & 13 & 4 & 3 & 134 & 51 \\
theft/ & 11 & & & & & & \\
robbery & & & & & & & \\
drugs & 43 & 83 & 7 & 13 & 2 & 4 & 52 & 20 \\
violence & 43 & 80 & 7 & 13 & 4 & 7 & 54 & 21 \\
other & 21 & 95 & 1 & 5 & 0 & - & 22 & 8 \\
\hline all & 219 & 84 & 33 & 13 & 10 & 4 & 262 & 100 \\
\hline
\end{tabular}

By contrast, none of the foreign nationals had any previous convictions. All but one (who had been convicted of spying) were serving a sentence for drug offences. None 
of these women had a history of criminality in their families and all were employed in "middle-class" occupations. Typically, they were businesswomen or traders who travelled regularly between their own country and London.

\section{Implications for the study}

The ethnic composition of the female prison population is affected by the presence of a number of women who are not ordinarily resident in the United Kingdom. They account for a significant part of the over-representation of black women in the sentenced female population compared to the male prison population. They differ from UK resident women in a number of ways, including the specialised nature of their offending, their lack of any criminal history and the nature of their lifestyle. It is reasonable to assume that the pattern of psychiatric disorder in these women may be different from that of UK resident women.

Only one percent of the sample of male prisoners was ordinarily resident overseas. A more valid and useful comparison of rates of psychiatric disorder may be obtained by excluding overseas residents from both samples. Psychiatric disorder in women resident overseas will be described separately in Chapter 5.

This approach requires one further adjustment. Later, estimates will be made of the total number of women with a particular diagnosis in the prison population. They will depend on the size of the sentenced population and, in particular, on the size of the population normally resident in the United Kingdom. To include overseas residents when calculating these figures would inflate the apparent number of psychiatric cases in the population.

The simplest, rough estimate of the total number of sentenced women ordinarily resident in the UK is obtained by multiplying the number in the present $25 \%$ sample by four, yielding a figure of 1048 . This will be used as a notional total sentenced population throughout the remainder of the study, unless otherwise specified.

Four of the 262 women approached did not consent to be interviewed, a refusal rate of $1.5 \%$. Two hundred and fifty-eight UK resident women were interviewed.

As only a small number of men are resident outside the $\mathrm{UK}$ it is unnecessary to make any correction to estimates of numbers in the total population. The male sample consists of 1751 adults and young offenders, representing approximately $5 \%$ of the male sentenced population. 


\section{Matching of sample and population.}

The distribution of sentence length, nature of current offence and age in the sample of women and the female prison population are now compared. Matching of the male sample with the sentenced population is described elsewhere ${ }^{85}$.

\section{Sentence length}

In the original sample, medium-term prisoners are under represented and long-term prisoners over represented, relative to the population figures for $1988^{86}$ (Table 3.5).

Table 3.5 Distribution of sentence lengths in original sample, UK residents and total population of sentenced women

\begin{tabular}{|c|c|c|c|c|c|c|}
\hline & & $\begin{array}{l}\text { inal } \\
\text { le }_{8}\end{array}$ & $\begin{array}{l}\text { UK } \\
\text { re } \\
\text { n }\end{array}$ & $\underset{8}{d e n t s}$ & $\begin{array}{l}\text { to } \\
\text { po }\end{array}$ & ation \\
\hline $\begin{array}{l}\text { short } \\
<18 \mathrm{~m}\end{array}$ & 128 & 43 & 127 & 49 & 512 & 41 \\
\hline $\begin{array}{l}\text { medium } \\
18-36 \mathrm{~m}\end{array}$ & 59 & 20 & 56 & 21 & 336 & 27 \\
\hline $\begin{array}{l}\text { long } \\
>36 \mathrm{~m}\end{array}$ & 91 & 30 & 56 & 21 & 332 & 26 \\
\hline life & 23 & 8 & 23 & 9 & 76 & 6 \\
\hline total & 301 & 100 & 262 & 100 & 1256 & 100 \\
\hline
\end{tabular}

Life sentence prisoners are over-represented but the discrepancy between the predicted $6 \%$ and actual $8 \%$ in the sample represents only five individuals. Overall, the original sample is a reasonable reflection of sentence lengths in the total population. The main effect of excluding overseas residents is to decrease the proportion of long sentence prisoners in the sample, as many of the women convicted of smuggling drugs are serving sentences of between five and ten years.

\section{Offence type}

The original sample is similar to the population figures, despite an overrepresentation of "theft" and "drug" offences in the sample (Table 3.6). The large "other" and "unrecorded" categories in the population figures arise because official statistics are compiled from the front sheet of prison records, which are not always complete. In the course of the study, it was possible to identify offences for all subjects. It was noted that many offences involving drugs were described as "customs evasion" on the front sheet, 
presumably leading to their placement in the "other" category in official statistics. In the present study, they were coded as drugs offences and this may account for some of the discrepancy in this category.

Table 3.6 Index offence in original sample, UK residents and total population of sentenced women.

\begin{tabular}{|c|c|c|c|c|c|c|}
\hline & \multicolumn{2}{|c|}{$\begin{array}{l}\text { original } \\
\text { sample } \\
n\end{array}$} & \multicolumn{2}{|c|}{$\begin{array}{l}\text { UK } \\
\text { residents }\end{array}$} & \multicolumn{2}{|c|}{$\begin{array}{l}\text { total } \\
\text { population } \\
\mathbf{N}\end{array}$} \\
\hline violence & 54 & 18 & 54 & 21 & 247 & 20 \\
\hline robbery & 24 & 8 & 24 & 9 & 73 & 6 \\
\hline burglary & 18 & 6 & 18 & 7 & 57 & 5 \\
\hline theft & 92 & 31 & 92 & 35 & 313 & 26 \\
\hline drugs & 90 & 30 & 52 & 20 & 314 & 26 \\
\hline other & 23 & 8 & 22 & 9 & 185 & 15 \\
\hline unrecorded & - & - & - & - & 40 & 3 \\
\hline total & 301 & 100 & 262 & 100 & 1229 & 100 \\
\hline
\end{tabular}

N.B. "theft" includes handling, fraud and forgery offences.

"other offences" is defined only by exclusion in Home Office figures. In the table, this category includes all offences not included under the specified headings

\section{Age}

Table 3.7 compares the ages on 30 June 1988 of the sentenced prison population $^{87}$ with the ages at time of interview of the female and male samples. There are no major discrepancies between the samples and the total population.

Table 3.7 Age distribution of total sentenced prison population and sample, by gender

\begin{tabular}{|l|c|c|c|c|}
\hline & \multicolumn{2}{|c|}{ women } & \multicolumn{2}{c|}{ men } \\
\hline age (y) & $\begin{array}{c}\text { pop. } \\
8\end{array}$ & $\begin{array}{c}\text { sample } \\
8\end{array}$ & $\begin{array}{c}\text { pop. } \\
8\end{array}$ & $\begin{array}{c}\text { sample } \\
8\end{array}$ \\
\hline$<17$ & 0.7 & 0.8 & 1.5 & 1.0 \\
$17-20$ & 12.4 & 14.0 & 19.2 & 20.8 \\
$21-29$ & 45.6 & 49.2 & 44.0 & 45.7 \\
$30-49$ & 36.8 & 31.8 & 31.2 & 28.3 \\
$50 \& \&$ & 4.4 & 4.3 & 4.1 & 4.3 \\
\hline Over & & & & \\
\hline
\end{tabular}




\section{Statistical Techniques}

The samples of UK resident and overseas women represent $25 \%$ of their respective populations and the male sample represents $5 \%$ of sentenced men. SPSS- $X^{88}$ is used for most analyses. In addition, confidence intervals for proportions ${ }^{89}$, differences and odds ratios $^{90}$ are given where appropriate.

\section{Confidence intervals}

Confidence intervals provide an estimate of population values derived from measurements on the sample. The $95 \%$ confidence interval is used throughout this project. It indicates that the chances of the true value of the population statistic concerned falling outside the range of values given is not greater than $5 \%$. Confidence intervals can be calculated for many statistics, including proportions, the difference between proportions and odds ratios.

\section{The finite population correction}

The formula for calculating the confidence interval for a proportion ${ }^{91}$ takes account of sample size but makes no reference to the population size; the assumption is that the population is infinite or of unknown size. When a population is of known and finite size it is possible to use a finite population correction ${ }^{92}$. In practice, this is only worthwhile when the sample is large relative to the total population - a condition which applies to the sample of the female prison population in the present study. The population estimate of 1048 (see above) has been used to calculate the finite population correction for UK resident women serving a prison sentence; in fact, the effect of substituting the original population figure of 1229 is negligible.

\section{Odds ratios}

Odds ratios are used as a test for the difference between proportions in a $2 \times 2$ table, as an alternative to the $\mathrm{Chi}^{2}$ test. The odds ratio is an estimate of relative risk. A result of 1.0 indicates that the proportion of each of two groups with a particular condition is identical. The greater the deviation from 1.0, the greater the difference in proportions. Unlike the $\mathrm{Chi}^{2}$ test, this statistic describes the magnitude of the difference between proportions; with large samples, a $\mathrm{Chi}^{2}$ test may show statistical significance when the magnitude of the difference between proportions is quite small. $\mathrm{Chi}^{2}$ tests are used occasionally, when the magnitude of a difference is of less importance. 
Confidence intervals are calculated for odds ratios. If the $95 \%$ confidence interval for the population odds ratio does not include the value 1.0, the null hypothesis (that the population proportions are in fact equal) can be rejected and it can be assumed that a $\mathrm{Chi}^{2}$ test would have been significant at the $\mathrm{p}<.05$ level or higher. In the tables which follow, odds ratios for which the $95 \%$ confidence interval for the population odds ratio does not include the value 1.0 are presented in bold type.

\section{Summary}

Comparison of the demographic characteristics of female and male sentenced prisoners reveals differences in the age structure of the populations and in the ethnic origin of women and men in prison. The higher proportion of black inmates in the female population is due to the presence of women not ordinarily resident in the UK who have been sentenced for the importation of drugs. They differ in a number of ways from UK resident women and may bias a comparison of rates of psychiatric illness in women and men. Overseas residents are therefore excluded from the comparison of female and male prisoners and will be described separately. The criminological characteristics of the sample have been described and compared to the population, to establish adequate matching. The statistical techniques used to describe the women and compare them to men in prison have been described.

The following two chapters present the main results of the study, describing women serving a prison sentence and comparing them to male prisoners. Chapter 4 presents an account of social and psychological characteristics and Chapter 5 describes the prevalence of psychiatric disorder. 


\section{CHAPTER 4: RESULTS I:}

\section{SOCIAL AND PSYCHOLOGICAL CHARACTERISTICS}

\section{Introduction}

The chapter begins with a comparison of social characteristics of the female and male samples, including indicators of childhood disturbance, educational attainment and marital status. Gender differences in the prevalence of violent offending within the sample are described, followed by a comparison of the disciplinary records of women and men in prison. Violence against the self is described with reference to deliberate self-harm both outside and within prison.

The prevalence and type of previous psychiatric treatment is described in the two samples, before and after entering prison. Finally, scores on the Clinical Interview Schedule and the treatment recommendations made in the present study are described and compared. For the reasons given in the previous chapter, this account is limited to UK resident women.

Prevalence rates for specific psychiatric disorders are described in the following chapter.

\section{Social and educational characteristics}

In Chapter 3, attention was drawn to the limited demographic information contained in the Prison Statistics. The emphasis of the present study is psychiatric but some background data were collected. This information is presented with the qualification that it is self-reported and retrospective, in some cases by many years.

Table 4.1 shows that, compared to male prisoners, a smaller proportion of women had experience of local authority care or residence in children's homes. Women were more likely to have completed their education in ordinary schools and were more likely to have obtained a qualification of CSE level or above. 
Table 4.1. Social and educational characteristics of sentenced prisoners, by gender.

\begin{tabular}{|c|c|c|c|c|c|c|c|}
\hline & \multicolumn{3}{|c|}{$\begin{array}{c}\text { women } \\
\mathrm{N}=258\end{array}$} & \multicolumn{3}{|c|}{$\begin{array}{c}\text { men } \\
\mathrm{N}=1751 \\
\end{array}$} & \multirow{2}{*}{$\begin{array}{c}\text { odds } \\
\text { ratio } \\
(958 \mathrm{ci})\end{array}$} \\
\hline & $\mathrm{n}$ & 8 & $\mathrm{NK}$ & $\mathrm{n}$ & 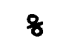 & NK & \\
\hline $\begin{array}{l}\text { history of L.A. } \\
\text { care }\end{array}$ & 53 & 21 & 5 & 458 & 28 & 88 & $\begin{array}{c}0.7 \\
(0.5 \\
.96)\end{array}$ \\
\hline $\begin{array}{l}\text { history of } \\
\text { children's home }\end{array}$ & 36 & 14 & 5 & 365 & 22 & 89 & $\begin{array}{c}0.6 \\
(0.4 \\
0.9)\end{array}-$ \\
\hline $\begin{array}{l}\text { obtained CSE or } \\
\text { above }\end{array}$ & 119 & 46 & 1 & 651 & 37 & 7 & $\begin{array}{c}1.5 \\
\left(1.1^{-9}\right. \\
1.9)\end{array}$ \\
\hline $\begin{array}{l}\text { received special } \\
\text { education }\end{array}$ & 23 & 9 & 2 & 364 & 21 & 6 & $\begin{array}{c}0.4 \\
(0.2 \\
0.6)\end{array}-$ \\
\hline
\end{tabular}

$\mathrm{NK}=$ information not known. Percentages and odds ratios in this table are calculated after subtracting NK from $\mathrm{N}$.

\section{Marital Status}

Eighty-six women (33\%) and 633 men (36\%) reported that they were married or had been living with a partner before entering prison (O.R. $=0.9,95 \%$ c.i. $=0.7$ to 1.2$)$. One hundred women (39\%) reported that they had never married, compared to 914 men (52\%: O.R. $=0.6,95 \%$ c.i. $=0.4$ to 0.7$)$. A higher proportion of women $(62,24 \%)$ than men $(187,11 \%)$ reported that they were divorced or widowed $(O . R .=2.7,95 \%$ c.i. $=1.9$ to 3.7). Ten women (4\%) and 15 men (1\%) were serving a sentence for killing their spouse (O.R. $=4.7,95 \%$ c.i. $=2.1$ to 10$)$.

\section{Discussion}

The measures of childhood disturbance and deprivation are rather crude but they suggest that a slightly higher proportion of male prisoners experienced social and family disruption in childhood. Similar proportions of men and women reported that they were co-habiting before entering prison. The finding that a greater proportion of men had never married may reflect the general tendency of men to marry later, exaggerated by the higher proportion of young inmates in the male prison population (see Chapter 3, Table 3.7). These data provide no clear evidence for differences in social adjustment between female and male inmates before imprisonment. The statistically significant difference in the proportions of women and men serving a sentence for killing their spouse serves as a reminder of the criminological differences between the two groups but must be regarded 
as a poor index of social adjustment. This observation is more relevant to a consideration of violent offending in the two groups (see below).

There is little published information about the social characteristics of prisoners and it is difficult to draw conclusions from the limited self-report data described above. It is safe to say that the scanty information available provides no evidence to suggest that the female prison population contains an increased proportion of inmates with a high level of social or educational disruption in childhood or a low level of social adjustment as adults.

\section{History of violence}

A comprehensive account of gender differences in offending falls outside the scope of this study. Violent offending will be described in more detail as it may, in some cases, be a manifestation of psychiatric disorder. Also, it serves to illustrate some gender differences in prisoners that are not readily apparent from official statistics.

Violent offending is much less common in women than in men and this is reflected in the prison population. Percentages can be misleading in this respect. In 1988, $23 \%$ of male sentenced prisoners were serving a sentence for violence, compared to $21 \%$ of female prisoners. The absolute numbers were 247 and 8,586 respectively ${ }^{93}$, one woman for every 35 men.

Of the 258 women interviewed in the present study, 53 (21\%) were serving a sentence for violent offences, compared to $22 \%$ of the male sample.

In order to identify a group of inmates with a more pronounced record of violence, a stricter criterion can be adopted, requiring a record of three or more convictions for minor violence or a single conviction for severe, life-threatening violence. This information is readily available in the Criminal Profile rating for each subject, which takes account of both the index and previous offences.

Forty-three women (17\%) and 439 men (25\%) meet these criteria, emphasising the greater prevalence of violent offending among male inmates (O.R. $=1.7,95 \%$ c.i. $=1.2$ to 2.4). Even using this stricter criterion, the difference in prevalence is not great. Gender differences become more apparent if the nature of the index offence is considered in more detail. Table 4.2 shows that the pattern of index offences is quite different in women and men. 
Table 4.2 . Violent offenders by index offence and gender.

\begin{tabular}{||l|c|c|c|c||}
\hline index offence & \multicolumn{2}{|c|}{ women } & \multicolumn{2}{c|}{ men } \\
\hline & $\mathrm{n}$ & 8 & $\mathrm{n}$ & 8 \\
\hline murder or attempt & 26 & 60 & 154 & 35 \\
\hline assault/wounding & 6 & 14 & 95 & 22 \\
\hline theft/robbery & 6 & 14 & 141 & 32 \\
\hline sex offences & - & - & 22 & 5 \\
\hline arson & 3 & 7 & 6 & 1 \\
\hline other & 2 & 5 & 21 & 5 \\
\hline total & 43 & 100 & 439 & 100 \\
\hline
\end{tabular}

The 26 women sentenced for "murder or attempt" includes 22 serving a life sentence for murder, none of whom had served a previous sentence. By contrast, the male sample included 120 men sentenced for murder, including $39(33 \%)$ who had served at least two previous prison sentences.

The 22 female murderers can be compared to 22 male murderers, matched for age at time of sentence. The victims of the women were husband or co-habitee in 16 cases, other family (two), a dependent adult (two) and a stranger (two). The victims of the men were a stranger (11), a male acquaintance (nine) and wife or co-habitee (two).

As assessed from reports of the trial, the circumstances of the killing in the case of the women were a triangular sexual relationship (ten cases), domestic violence (eight), financial gain (three) and terrorism (one). The circumstances of the killings by men were rows or disputes (ten cases), financial gain (five), sexual (four), domestic violence (two) and a triangular sexual relationship (one).

\section{Discussion}

The Prison Statistics disguise enormous quantitative and qualitative differences between female and male prisoners in terms of their history of violence. It would be wrong to draw conclusions about the nature of offending based on the figures presented here, as sentenced prisoners have passed through a process of "filtering" by both criminal justice and psychiatric systems. Nevertheless, they serve to emphasise the very different nature of the female and male prison populations. As far as serious violence is concerned, these results provide no evidence to suggest that the women had been imprisoned for less "rational" offences. 


\section{Disciplinary record}

The preceding section described one aspect of behaviour outside prison. A potentially useful index of inmates' behaviour within the custodial setting is provided by their prison disciplinary record. Table 4.3 shows that women are more likely than men to have at least one disciplinary offence on record during the three months preceding the interview.

Table 4.3. Disciplinary record during current imprisonment, by gender.

\begin{tabular}{|c|c|c|c|c|c|c|c|}
\hline & \multicolumn{3}{|c|}{$\begin{array}{c}\text { women } \\
\mathrm{N}=258\end{array}$} & \multicolumn{3}{|c|}{$\begin{array}{c}\text { men } \\
\mathrm{N}=1751 \\
\end{array}$} & \multirow[t]{2}{*}{$\begin{array}{l}\text { odds ratio } \\
(958 \mathrm{ci})\end{array}$} \\
\hline & $\mathrm{n}$ & 8 & NK & $\mathrm{n}$ & $q$ & $\mathrm{NK}$ & \\
\hline $\begin{array}{l}\text { disciplinary } \\
\text { offence in last } \\
\text { three months }\end{array}$ & 83 & 32 & 1 & 361 & 20 & 10 & $\left(1.4^{1.8}-2.4\right)$ \\
\hline $\begin{array}{l}\text { disciplinary } \\
\text { transfer during } \\
\text { present sentence }\end{array}$ & 36 & 14 & 5 & 365 & 22 & 89 & $\left(0.2^{0.5}-0.9\right)$ \\
\hline $\begin{array}{l}\text { any loss of } \\
\text { remission during } \\
\text { present sentence }\end{array}$ & 19 & 7 & 1 & 651 & 37 & 7 & $\begin{array}{c}0.1 \\
(.08-0.2)\end{array}$ \\
\hline
\end{tabular}

$\mathrm{NK}=$ information not known. Percentages and odds ratios in this table are calculated after subtracting NK from $\mathrm{N}$.

Eight women $(3 \%)$ had a record of five or more disciplinary offences during this period, compared to 19 men (1\%). However, women were less likely to have been transferred to another prison for disciplinary reasons or to have lost remission during the present sentence (this analysis was limited to those serving a determinate sentence and therefore eligible for loss of remission).

\section{Discussion}

Within prison, a significantly greater proportion of women had disciplinary offences recorded against them during the preceding three months. Women in prison have been notorious for a high level of disturbed behaviour since $1862^{94}$ and a report in $1910^{95}$ comments on the need for higher staffing levels to manage the women's section of Millbank prison. Dobash et $\mathrm{al}^{96}$ review the historical development of prison regimes for women, drawing attention to the "conventional wisdom" that women, whilst less violent outside prison behave more violently than men once locked up.

Some evidence from other institutions supports this view and a survey of violent incidents in Rampton hospital ${ }^{97}$ found that women, who account for only $25 \%$ of the 
patient population, were involved in $75 \%$ of incidents. The authors note that a small number of highly disturbed patients accounted for most incidents with one woman being responsible for $12 \%$ of violent incidents. This uneven distribution emphasises the pitfalls inherent in generalising about the nature of "women in custody" from figures of this type.

It remains the case that women within prison are punished for disciplinary offences more often than men ${ }^{98}$. The rate of offences per 100 prison population for all female establishments in 1985 was 335, whereas for men it was 160 but the majority of these offences were disobedience or disrespect.

The findings presented in Table 4.3 suggest that women are much less likely to be disciplined by loss of remission, the punishment for more serious offences within prison. They are also less likely to have been transferred for disciplinary reasons. Transfer was most commonly used as a sanction against inmates who absconded from prison (or home leave) or intimidated other inmates. In both cases, the response was a move to a higher level of security.

These results do not suggest that women in prison are generally more disturbed or violent than men. It appears that the management of men within prison presents more serious disciplinary problems but women are more likely to be disciplined for trivial offences. This point has been made by Carlen ${ }^{99}$, who cites it as evidence that prison regimes for women are more oppressive than those for men and require a higher standard of behaviour. Mandaraka-Sheppard argues that aggressive offences by female prisoners can best be explained as "..a function of their response to the particular negative aspects of institutions ${ }^{100 "}$. Her study of three open and three closed female prisons found institutional rather than individual characteristics to be more important in accounting for violent incidents. She criticised the trivial nature of many recorded offences, the vague nature of some rules and the consequent inconsistency in their application. It has also been suggested that the nature of female prison officers is partly responsible for the high number of trivial offences recorded in women's prisons ${ }^{101}$.

All these factors may be important. The comparison with male prisoners is complicated by the difference in regimes. In the prisons visited for the present study, it was apparent that women had a much greater degree of physical freedom within prison than men with a similar security classification. The long lock-up periods that characterise male prisons, even those for long-term inmates ${ }^{102}$, are much less common in female prisons. Styal provided considerable freedom of movement within a secure perimeter for the majority of its inmates. This allows more interaction with prison officers and increases the potential for transgressing minor prison rules. For the same reason, many male inmates 
stated that they found "open" prisons more oppressive; the increased freedom meant increased regulation of behaviour and some chose to return to closed prisons. MandarakaSheppard's description of an open prison regime ${ }^{103}$ brings out the paradox whereby (conditional) freedom of movement increases the opportunities to breach regulations.

\section{Deliberate self-harm (DSH)}

Eighty-two women (32\%) reported deliberate self-harm on at least one occasion; $31(12 \%)$ had harmed themselves more than once. Two hundred and ninety-seven men (17\%) reported self-injury, $131(8 \%)$ on more than one occasion. Table 4.4 compares the prevalence of deliberate self-harm in male and female prisoners.

Table 4.4. Lifetime prevalence of deliberate self-harm, by location and gender

\begin{tabular}{|c|c|c|c|c|c|}
\hline & \multicolumn{2}{|c|}{$\begin{array}{l}\text { female } \\
N=258\end{array}$} & \multicolumn{2}{|c|}{$\begin{array}{l}\text { male } \\
\mathrm{N}=1748\end{array}$} & \multirow[t]{2}{*}{$\begin{array}{l}\text { odds ratio } \\
\text { (958 c.i.) }\end{array}$} \\
\hline & $\mathrm{n}$ & 8 & $\mathrm{n}$ & 8 & \\
\hline $\begin{array}{l}\text { any history of self- } \\
\text { harm }\end{array}$ & 82 & 32 & 297 & 17 & $\left(1.7^{2.3}-3.0\right)$ \\
\hline self-harm in custody & 13 & 5 & 81 & 5 & 1.0 \\
\hline self-harm outside & 78 & 30 & 236 & 14 & $\left(2.1^{2.8}-3.7\right)$ \\
\hline
\end{tabular}

\section{Method of deliberate self-harm}

Reported methods of dsh are shown in Table 4.5; an individual may report more than one method. "Other methods" consisted of jumping from high places, fire (reported by seven men and no women) and gassing. The only significant gender difference is the higher prevalence of overdoses in women. 
Table 4.5. Lifetime prevalence of deliberate self-harm by method and by gender

\begin{tabular}{|c|c|c|c|c|c|}
\hline & \multicolumn{2}{|c|}{$\begin{array}{c}\text { female } \\
\mathrm{N}=258\end{array}$} & \multicolumn{2}{|c|}{$\begin{array}{l}\text { male } \\
\mathrm{N}=1748 \\
\end{array}$} & \multirow[t]{2}{*}{$\begin{array}{l}\text { odds ratio } \\
\text { (958 c.i.) }\end{array}$} \\
\hline & $\mathrm{n}$ & 8 & $\mathrm{n}$ & 8 & \\
\hline overdose & 64 & 25 & 156 & 97 & $\left(2.4^{3.4}-4.7\right)$ \\
\hline cutting & 25 & 10 & 151 & 9 & $\left(0.7^{1.1}-1.8\right)$ \\
\hline hanging & 7 & 3 & 22 & 1 & $\left(0.9^{2.2}-5.2\right)$ \\
\hline other & 6 & 2 & 48 & 3 & $\left(0.4^{0.8}-2.0\right)$ \\
\hline
\end{tabular}

\section{Self-cutting}

A total of 25 women reported cutting, thirteen on more than one occasion. Seventeen of these women reported dsh only outside prison. Twelve women who reported cutting also reported overdosing and three reported hanging or self-strangulation. Table 4.6 compares women with and without a history of self-cutting. Women who have been in care have a lifetime prevalence of DSH of $19 \%$, compared to $8 \%$ in those who have not. The prevalence in the 36 women with a drink problem (see Chapter 5 for definition) is $22 \%$, compared to $8 \%$ in others, and the prevalence in women with a history of violent offending (defined as at least one conviction for violence against the person) is $15 \%$, compared to $6 \%$ in those with no history of violence. Drug dependent women (see Chapter 5) have a lifetime prevalence of deliberate self harm of $13 \%$, compared to $9 \%$ in non-dependent women, a difference which is not statistically significant. 
Table 4.6. History of self-cutting, by other social and psychological characteristics

\begin{tabular}{|c|c|c|c|c|}
\hline & \multicolumn{2}{|c|}{ self-cutting } & $\begin{array}{l}\text { odds ratio } \\
\text { (958 c.i.) }\end{array}$ \\
\hline \multirow{2}{*}{$\begin{array}{l}\text { in } \\
\text { care }\end{array}$} & $\mathrm{n}$ & 185 & 15 & \multirow{2}{*}{$\left(1.2^{2.9}-6.9\right)$} \\
\hline & $y$ & 43 & 10 & \\
\hline \multirow{2}{*}{$\begin{array}{l}\text { problem } \\
\text { drinking }\end{array}$} & $n$ & 205 & 17 & \multirow{2}{*}{$\left(1.4^{3.5}-8.9\right)$} \\
\hline & $y$ & 28 & 8 & \\
\hline \multirow{2}{*}{$\begin{array}{l}\text { drug } \\
\text { dependence }\end{array}$} & $\mathrm{n}$ & 178 & 17 & \multirow{2}{*}{$\left(0.6^{1.5}-3.7\right)$} \\
\hline & $\mathrm{Y}$ & 55 & 8 & \\
\hline \multirow{2}{*}{$\begin{array}{l}\text { violent } \\
\text { offending }\end{array}$} & $\mathrm{n}$ & 147 & 10 & \multirow{2}{*}{$\left(1.1^{2.6}-6.0\right)$} \\
\hline & $\mathrm{Y}$ & 84 & 15 & \\
\hline
\end{tabular}

\section{Deliberate self-harm by ethnic origin}

The black women in the sample reported a lower prevalence of deliberate selfharm both outside and within custody (Table 4.7) but the $95 \%$ confidence interval for the population odds ratios included the value 1.0 , so the possibility that the population prevalences of dsh are in fact the same cannot be excluded. (Table 4.7 includes only women from white and black/Afro-Carribean groups, as other numbers are too small to analyse.)

Table 4.7. Female prisoners: lifetime prevalence of deliberate selfharm, by location and ethnic origin

\begin{tabular}{|c|c|c|c|c|c|}
\hline & \multicolumn{2}{|c|}{$\begin{array}{l}\text { white } \\
\mathrm{N}=216\end{array}$} & \multicolumn{2}{|c|}{$\begin{array}{l}\text { black } \\
\mathrm{N}=33\end{array}$} & \multirow[t]{2}{*}{$\begin{array}{l}\text { odds ratio } \\
\text { (958 c.i.) }\end{array}$} \\
\hline & $\mathrm{n}$ & 8 & $\mathrm{n}$ & 8 & \\
\hline $\begin{array}{l}\text { any history of self- } \\
\text { harm }\end{array}$ & 73 & 34 & 7 & 21 & $\begin{array}{l}2.0 \\
(0.8-5)\end{array}$ \\
\hline self-harm in custody & 13 & 6 & 0 & 0 & --- \\
\hline self-harm outside & 69 & 32 & 7 & 21 & $\left(0.7^{1.6}-5\right)$ \\
\hline
\end{tabular}

The sample of men shows more marked differences in the same direction (Table 4.8, again including only men from the two largest ethnic groups). White men are more likely to report any history of self-harm and self-harm outside custody. For dsh within prison, the confidence interval for the population odds ratio includes the value 1.0. 
Table 4.8. Male prisoners: lifetime prevalence of deliberate self-harm, by location and ethnic origin

\begin{tabular}{|l|c|c|c|c|c||}
\hline & \multicolumn{2}{|c|}{$\begin{array}{c}\text { white } \\
\mathrm{N}=1460\end{array}$} & \multicolumn{2}{|c|}{$\begin{array}{c}\text { black } \\
\mathrm{N}=183\end{array}$} & $\begin{array}{c}\text { Odds ratio } \\
\text { (958 c.i.) }\end{array}$ \\
\hline & $\mathrm{n}$ & 8 & $\mathrm{n}$ & 8 & \\
\hline $\begin{array}{l}\text { any history of self- } \\
\text { harm }\end{array}$ & 278 & 19 & 11 & 6 & $\begin{array}{c}3.7 \\
(2.0-7)\end{array}$ \\
\hline $\begin{array}{l}\text { self-harm in custody } \\
\text { self-harm outside }\end{array}$ & 76 & 5 & 4 & 2 & $\begin{array}{c}2.5 \\
(0.9-7)\end{array}$ \\
\hline
\end{tabular}

\section{Discussion}

Women in prison have a higher lifetime prevalence of deliberate self-harm than men. This suggests a higher lifetime prevalence of psychological disturbance in the women but clear-cut differences are limited to overdosing outside prison. Prevalence rates for DSH during the current period in custody are the same for both sexes.

The lifetime prevalence of dsh by cutting in women is $10 \%$ (the $95 \%$ c.i. is 7 $13 \%$ ). This is the same as the rate in males and not significantly different from the $8 \%$ prevalence rate found in Wilkins \& Coid's survey of remanded women ${ }^{104}$. This finding is surprising as self-cutting in male prisoners has received less attention in the literature.

Wilkins and Coid found self-mutilation to be associated with violence and arson and regard it as an indicator of severe psychopathology. The Holloway study by Cookson $^{105}$ does not give prevalence rates but found an association of self-injury with violent offending. The present study confirms that women with a history of self-cutting are more likely to have been in care, to have a history of violent offending and a drink problem but finds no significant association with drug dependence. The same pattern of associations is found in the male sample.

Black women in the sample had lower prevalence rates of deliberate self-harm but the difference in rates was not sufficiently great as to exclude the possibility that population rates for black and white women are the same. The pattern is similar in male prisoners, where the difference between the rates in white and black prisoners does appear to reflect a characteristic of the population. 


\section{Psychiatric treatment prior to imprisonment}

Previous psychiatric contact was reported by $45 \%$ of women, compared to $36 \%$ of men (Table 4.9). Women were less likely to report no psychiatric contact and more likely to report previous out-patient or in-patient treatment. Men are more likely to report treatment only at a child guidance clinic.

Table 4.9. Previous psychiatric treatment by gender and type of treatment

\begin{tabular}{|c|c|c|c|c|c|}
\hline \multirow{2}{*}{ type of treatment } & \multicolumn{2}{|c|}{ women } & \multicolumn{2}{|c|}{ men } & \multirow{2}{*}{$\begin{array}{l}\text { odds ratio } \\
\text { (958 c.i.) }\end{array}$} \\
\hline & $\mathrm{n}$ & 8 & $\mathrm{n}$ & 8 & \\
\hline none & 143 & 55 & 1125 & 64 & $\left(0.5^{0.7}-0.9\right)$ \\
\hline child guidance only & 22 & 9 & 291 & 17 & $\left(0.3^{0.5}-0.7\right)$ \\
\hline adult outpatient & 61 & 24 & 199 & 11 & $\left(1.8^{2.4}-3.3\right)$ \\
\hline adult inpatient & 32 & 12 & 136 & 8 & $\left(1.1^{1.7}-2.5\right)$ \\
\hline TOTAL & 258 & 100 & 1751 & 100 & \\
\hline
\end{tabular}

It became apparent during the study that the commonest single reason for psychiatric contact was drug dependence and women had particularly high rates (see Chapter 5). Table 4.10 shows the results of the same analysis when drug dependent inmates are excluded. The difference in the proportion reporting no psychiatric contact is no longer significant but it remains true that women are more likely to report in- or outpatient psychiatric contact as adults and men are more likely to report treatment at a child guidance clinic only. 
Table 4.10. Previous psychiatric treatment by gender and type of treatment, excluding all drug dependent prisoners

\begin{tabular}{||l|c|c|c|c|c||}
\hline type of treatment & \multicolumn{2}{|c|}{ women } & \multicolumn{2}{c|}{ men } & $\begin{array}{c}\text { odds ratio } \\
\text { (958 c.i.) }\end{array}$ \\
\hline none & $\mathrm{n}$ & 8 & $\mathrm{n}$ & 8 & \\
\hline child guidance only & 124 & 64 & 1062 & 68 & $\begin{array}{c}0.8 \\
(0.6-1.1)\end{array}$ \\
\hline adult outpatient & 19 & 10 & 250 & 16 & $\begin{array}{c}0.6 \\
(0.4-0.9)\end{array}$ \\
\hline adult inpatient & 31 & 16 & 150 & 10 & $\begin{array}{c}1.8 \\
(1.2-8.7)\end{array}$ \\
\hline TOTAL & 21 & 11 & 97 & 6 & $(1.1-3.0)$ \\
\hline
\end{tabular}

\section{Discussion}

A greater proportion of men report treatment only at a child-guidance clinic. Most of these contacts were for conduct disorder and this finding is in line with other indicators of disturbed behaviour in childhood (see Table 4.1) and with gender differences in the prevalence of conduct disorder ${ }^{106}$. Women are more likely to have had in- or out-patient psychiatric treatment after the age of 15 years. When drug-dependent prisoners are excluded from this comparison, the overall proportion of men and women reporting any psychiatric contact is approximately equal but the differences in type of contact remain. Before considering the meaning of these results, differences in psychiatric contact within prison are described.

\section{Psychiatric treatment within prison}

The issue of psychiatric treatment within prison is an emotive one, raising two conflicting concerns. On the one hand, there is concern that patients whose liberty is restricted may not be free to refuse medication. On the other, prisoners have restricted access to treatment and may be deprived of the appropriate treatment for their clinical condition. It will be argued here that the use of psychotropic medication in prison cannot be understood without considering both the prevalence of psychiatric disorder in prisoners and the use of non-pharmacological treatments. A full account of gender differences in this respect must also be placed in the context of psychiatric treatment outside prison.

Treatment with psychotropic medication during the current period of imprisonment was reported by 68 women $(26 \%)$ and 131 men (8\%: O.R. $=4.4,95 \%$ c.i. $=3.2$ to 6.2$)$. 
Table 4.11. Experience of psychiatric treatment during current prison sentence, by gender and type of treatment

\begin{tabular}{|c|c|c|c|c|c|}
\hline \multirow[t]{2}{*}{ type of treatment } & \multicolumn{2}{|c|}{$\begin{array}{c}\text { women } \\
N=258\end{array}$} & \multicolumn{2}{|c|}{$\begin{array}{c}\text { men } \\
\mathrm{N}=1751\end{array}$} & \multirow[t]{2}{*}{$\begin{array}{l}\text { odds ratio } \\
\text { (958 c.i.) }\end{array}$} \\
\hline & $\mathrm{n}$ & 8 & $\mathrm{n}$ & 8 & \\
\hline neuroleptics & 16 & 6 & 57 & 3 & $\left(1.1^{2.0}-3.5\right)$ \\
\hline antidepressants & 41 & 16 & 54 & 3 & $\left(4.0^{6.2}-9.6\right)$ \\
\hline anxiolytics & 41 & 16 & 88 & 5 & $\left(2.5^{3.7}-5.6\right)$ \\
\hline any medication & 68 & 26 & 131 & 8 & $\left(3.2^{4.4}-6.1\right)$ \\
\hline $\begin{array}{l}\text { psychological } \\
\text { treatments }\end{array}$ & 21 & 8 & 60 & 3 & $\left(1.5^{2.5}-4.2\right)$ \\
\hline
\end{tabular}

It was common for interviewees to report that some other inmates were "drugged up" or treated with large doses of medication but the author did not encounter a single case of a woman reporting that she herself had been given medication against her will, despite asking this specific question of all inmates who reported taking medication at any time during their imprisonment. The same was found in the male sample. The most frequent complaint in relation to medication was that the doctor refused to prescribe for minor neurotic symptoms and insomnia. These symptoms were common, especially among those who had been taking large quantities of alcohol or drugs before entering prison.

\section{Discussion}

Women are more likely to have received treatment in prison with any one of three types of psychotropic medication. This finding is consistent with prison department statistics $^{107}$ which show only the total number of doses of psychotropic medication dispensed but reveal that the rate per 100 inmates is higher for female prisons.

The greater use of psychotropic medication in female prisons has been criticised $^{108}$, some authors suggesting that it is a way of controlling difficult prisoners ${ }^{109}$. An alternative explanation is that women prisoners have a higher prevalence of conditions requiring psychiatric treatment ${ }^{110}$ and this question will be addressed below and in the following chapter.

Table 4.11 shows that women also had significantly higher rates of treatment by psychological methods, usually counselling or psychotherapy. This suggests a greater demand for treatment in womens' prisons. Together with the data on psychotropic medication, it is consistent with figures for the utilisation of psychiatric services outside 
prison. For all mental illness, the rate of GP contacts for the age group 15 - 44 years in 1989 was 15,308 per 100,000 for women compared to 6,298 per 100,000 for men, a ratio of $2.4: 1^{111}$. First hospital admission rates were 110.7 per 100,000 in women and 102.6 per 100,000 in men $(1.1: 1)$.

The missing link in this argument is the prevalence of psychiatric disorder in women, which will be described in Chapter 5. First, the prevalence of self-reported psychiatric symptoms will be described.

\section{Scores on the Clinical Interview Schedule (CIS)}

If more women in prison receive psychiatric treatment because they request it, then they would be expected to report a higher level of psychiatric symptoms. Scores on the CIS serve as a useful measure of neurotic symptomatology.

Mean CIS scores are 4.8 for men and 7.1 for women $(t=-5.26 . p<.001)$. In addition, a greater proportion of women have high or intermediate CIS scores (Table 4.12).

Table 4.12 . CIS scores by gender

\begin{tabular}{||l|c|c|c|c||}
\hline CIS SCORE & \multicolumn{2}{|c|}{ Women } & \multicolumn{2}{c|}{ men } \\
\hline Iow $(0-10)$ & $\mathrm{n}$ & 8 & $\mathrm{n}$ & 8 \\
\hline intermediate $(11-15)$ & 191 & 74 & 1526 & 87 \\
\hline high (16+) & 32 & 12 & 113 & 7 \\
\hline Total & 35 & 14 & 103 & 6 \\
\hline
\end{tabular}

$\operatorname{chi}^{2}(d f=2)=34.74 \quad p<.001$

This result is not surprising and is in accord with gender differences found in other settings. 


\section{Attitudes to treatment and recommended treatment}

The picture is completed by looking at womens' attitudes to psychiatric treatment as a response to the problems they report and the researchers' assessment of whether treatment is appropriate.

On the five-point rating scale for "Attitude to treatment", 76 women (29\%) were rated 3 or 4 , compared to 273 men $(16 \%$ : O.R. $=2.3,95 \%$ c.i. $=1.7$ to 3.0$)$.

Psychiatric intervention was recommended for $44 \%$ of women and $34 \%$ of men (Table 4.13). All types of treatment were recommended more often for women but only the differences in "treatment in prison" and "further assessment" reached statistical significance.

Table 4.13. Treatment recommendations, by type of treatment and gender

\begin{tabular}{|c|c|c|c|c|c|}
\hline & \multicolumn{2}{|c|}{ women } & \multicolumn{2}{|c|}{ men } & \multirow{2}{*}{$\begin{array}{l}\text { odds ratio } \\
(958 \text { c.i.) }\end{array}$} \\
\hline & $\mathrm{n}$ & 8 & $\mathrm{n}$ & 8 & \\
\hline none & 145 & 56 & 1334 & 76 & $\left(0.3^{0.4}-0.5\right)$ \\
\hline $\begin{array}{l}\text { "outpatient" } \\
\text { treatment in prison }\end{array}$ & 56 & 22 & 179 & 10 & $\left(1.8^{2.4}-3.4\right)$ \\
\hline $\begin{array}{l}\text { therapeutic } \\
\text { community }\end{array}$ & 20 & 8 & 96 & 6 & $\left(0.9^{1.5}-2.4\right)$ \\
\hline $\begin{array}{l}\text { transfer to } \\
\text { hospital }\end{array}$ & 12 & 5 & 52 & 3 & $\left(0.8^{1.6}-3.0\right)$ \\
\hline further assessment & 25 & 9 & 90 & 5 & $\left(1.2^{2.0}-3.2\right)$ \\
\hline total & 258 & 100 & 1751 & 100 & \\
\hline
\end{tabular}

\section{Summary}

The limited social and educational data collected do not suggest higher rates of psychopathology in women entering prison. Violent offending is less common than in male prisoners and of a different nature, though these differences are not easily explained in terms of individual psychopathology. Within prison, women are more likely to have been disciplined but their offences are less serious and this observation may be better explained by reference to the prison regime rather than to characteristics of the women.

Women are more likely to have taken an overdose outside prison but prevalence rates of self-cutting and self-harm within prison are similar to those found in male prisoners. Women are more likely to have had psychiatric treatment before entering prison 
and whilst there. They report higher rates of neurotic symptoms, are more likely to express a wish for psychiatric treatment and to be rated as being in need of treatment. These findings are in accord with patterns of service utilisation outside prison.

Female sentenced prisoners have a higher prevalence of psychological problems for which treatment is seen as appropriate by both doctors and the women themselves. The following chapter describes the prevalence of particular psychiatric diagnoses. 


\section{CHAPTER 5: RESULTS II:}

\section{THE PREVALENCE OF PSYCHIATRIC DISORDERS}

\section{Introduction}

The prevalence of psychiatric disorders is described separately for women who are normally resident in the UK and women resident overseas. A comparison is made of the pattern of psychiatric disorder in these two groups of women serving a prison sentence. Rates of psychiatric disorder in female and male sentenced prisoners are then compared, excluding all overseas residents. Psychiatric disorder in women is described in greater detail under the diagnostic headings of Psychosis, Mental Handicap, Personality Disorder, Neurotic Disorder and Substance Abuse. The chapter ends with an account of the relationship between ethnic origin and psychiatric diagnosis in both women and men serving a prison sentence.

\section{Terminology}

Diagnostic terms have been taken from ICD $9^{112}$ and are combined and modified as follows:

Psychosis includes categories 295 (schizophrenia), 296 (affective psychoses) and 297 (paranoid states).

Neurotic Disorder includes categories 300 (here referred to as neurosis) and 309 (adjustment reaction).

Personality Disorder is category 301.

Substance Abuse includes categories 303 (alcohol dependence), 304 (drug dependence) and 305 (non-dependent abuse of drugs).

Organic disorder includes categories 317 (here referred to as mental handicap) and 345 (epilepsy). The latter is included as a neurological disorder that may have psychiatric complications.

Sexual deviation is category 302.

Any other uses of diagnostic terms will be explained at the appropriate point in the text.

\section{Psychiatric disorder in UK resident women}

One hundred and forty seven women $(57 \%)$ were given at least one diagnosis. Thirty-nine of these women also received a second diagnosis and four were given a third. The prevalence of all the diagnoses given to UK resident women (i.e. including second 
and third diagnoses) is shown in Table 5.1. The decision as to which diagnosis is primary is somewhat arbitrary. In the following account all references will be to the total prevalence rates i.e. including second and third diagnoses. The total, including subjects with no diagnosis, will therefore exceed $100 \%$.

Table 5.1. Female sentenced prisoners: frequency of psychiatric diagnoses, with confidence intervals

\begin{tabular}{|l|c|c|c||}
\hline diagnosis & $\mathrm{n}$ & 8 & $\begin{array}{c}958 \text { C.i. } \\
(8)\end{array}$ \\
\hline psychosis & 4 & 1.6 & \pm 1.3 \\
\hline neurotic disorder & 40 & 16 & \pm 3.8 \\
\hline personality disorder & 46 & 18 & \pm 4.1 \\
\hline $\begin{array}{l}\text { alcohol } \\
\text { abuse/dependence }\end{array}$ & 24 & 9 & \pm 3.1 \\
\hline drug abuse/dependence & 67 & 26 & \pm 4.7 \\
\hline mental handicap & 6 & 2.3 & \pm 1.6 \\
\hline other disorders & 2 & 0.8 & - \\
\hline epilepsy & 1 & 0.4 & - \\
\hline no diagnosis & 111 & 43 & - \\
\hline
\end{tabular}

The commonest second diagnosis was personality disorder and most of the cases with multiple diagnoses consist of permutations of substance abuse, personality disorder and neurosis. Five women with mild mental handicap and one woman with epilepsy also received a second diagnosis of personality disorder.

\section{Discussion}

The broad pattern of diagnoses is consistent with the results of most surveys of sentenced prisoners, with low rates of psychosis and high rates of personality disorder, substance abuse and neurosis. A similar pattern was found in the men interviewed for the present study, whose diagnoses are reported in section 3 below and described in more detail elsewhere ${ }^{113}$.

\section{Psychiatric disorder in women ordinarily resident overseas}

Table 5.2 shows the diagnoses given to women from overseas, excluding three women in whom the interview was not completed because of language difficulties. No overseas women received secondary diagnoses. 
Table 5.2. Female sentenced prisoners ordinarily resident overseas: psychiatric diagnoses

\begin{tabular}{|l|c|c|}
\hline diagnosis & $\mathrm{n}$ & \% \\
\hline $\begin{array}{l}\text { NEUROTIC DISORDERS } \\
\text { neurosis }\end{array}$ & 10 & 28 \\
adjustment reaction & $(6)$ & $(17)$ \\
\hline DRUG DEPENDENCE/ABUSE & $(4)$ & 3 \\
\hline NO DIAGNOSIS & 1 & 69 \\
\hline TOTAL & 25 & 100 \\
\hline
\end{tabular}

Thirty-one percent of overseas women received a diagnosis, compared to $57 \%$ of women resident in the UK. Table 5.3 compares the frequency of particular diagnoses.

Table 5.3. Rates of psychiatric disorder and odds ratios, UK resident:overseas resident women

\begin{tabular}{|c|c|c|c|}
\hline diagnosis & $\begin{array}{c}\text { UK } \\
\text { residents } \\
(\mathrm{N}=258) \\
\frac{8}{8}\end{array}$ & $\begin{array}{c}\text { overseas } \\
\text { residents } \\
\left(\begin{array}{c}\mathrm{N}=36) \\
8\end{array}\right.\end{array}$ & $\begin{array}{c}\text { odds ratio } \\
\text { (958 c.i.) }\end{array}$ \\
\hline any diagnosis & 57 & 31 & $\left(1.4^{3.0}-6.4\right)$ \\
\hline neurotic disorder & 16 & 28 & $\begin{array}{c}0.48 \\
\left(0.2^{-1.1)}\right.\end{array}$ \\
\hline personality disorder & 18 & - & - \\
\hline drug abuse/dependence & 26 & 3 & $\begin{array}{c}12.3 \\
\left(1.7^{-9} 91\right) \\
\end{array}$ \\
\hline alcohol abuse/dependence & 9 & - & - \\
\hline psychosis & 1.6 & - & - \\
\hline
\end{tabular}

\section{Criminological characteristics}

None of the overseas women had a record of previous convictions.

\section{Discussion}

Rates of psychosis, substance abuse and personality disorder were higher in women resident in the UK. Overseas women in the sample had a higher rate of neurotic disorder but the confidence interval for the odds ratio (which includes the value 1.0) suggests that this may not apply to the population as a whole. The different pattern of psychiatric disorder in the two groups validates the decision to analyse them separately (see Chapter 3) and to exclude overseas residents from the comparison of rates of psychiatric disorder by gender. 
Apart from a single case of drug dependence, the only diagnosis found in overseas women was neurotic disorder, mainly depression or an adjustment reaction. The likelihood of developing depression is increased by adverse social circumstances and a lack of social supports - two characteristics of overseas women in prison, who often have language difficulties and rarely receive visitors.

These women are not the central focus of the present report but they form a substantial minority within the female prison population and present a challenge to prison psychiatric services. The social isolation and language problems that contribute to their high rate of neurotic disorder may also act as obstacles to their receiving the counselling help and medical care that they need ${ }^{114}$.

\section{Rates of psychiatric disorder by gender.}

The following comparison is restricted to inmates ordinarily resident in the UK, for the reasons given in Chapter 3.

Five hundred and ten men (38\%) received at least one diagnosis, compared to $57 \%$ of women. The female:male odds ratio is 3.2 , the $95 \%$ confidence interval being from 2.5 to 4.2. Women are more likely to receive a psychiatric diagnosis and Table 5.4 shows the relative frequencies of different groups of disorders. 
Table 5.4 The prevalence of psychiatric disorder in sentenced prisoners, by gender

\begin{tabular}{|c|c|c|c|c|c|}
\hline \multirow[t]{2}{*}{ DIAGNOSIS } & \multicolumn{2}{|r|}{$\begin{array}{c}\text { WOMEN } \\
\mathrm{N}=258\end{array}$} & \multicolumn{2}{|r|}{$\begin{array}{c}\text { MEN } \\
\mathrm{N}=1751 \\
\end{array}$} & \multirow[t]{2}{*}{$\begin{array}{l}\text { ODDS RATIO } \\
(958 \text { c.1.) }\end{array}$} \\
\hline & $\mathrm{n}$ & 8 (958 c.i.) & $\mathrm{n}$ & $8 \quad(958$ c.1. $)$ & \\
\hline PSYCHOSIS & 4 & $1.6 \pm 1.3$ & 34 & $1.9 \pm 0.6$ & $\left(0.3^{0.8}-2.3\right)$ \\
\hline NEUROSIS & 40 & $16 \pm 3.8$ & 104 & $6 \pm 1.1$ & $\left(2.0^{2.9}-4.3\right)$ \\
\hline $\begin{array}{l}\text { PERSONALITY } \\
\text { DISORDER }\end{array}$ & 46 & $18 \pm 4.1$ & 177 & $10 \pm 1.4$ & $\left(1.4^{1.9}-2.8\right)$ \\
\hline $\begin{array}{l}\text { ALCOHOL ABUSE/ } \\
\text { DEPENDENCE }\end{array}$ & 24 & $9 \pm 3.1$ & 203 & $12 \pm 1.5$ & $\left(0.5^{0.8}-1.2\right)$ \\
\hline $\begin{array}{l}\text { DRUG ABUSE/ } \\
\text { DEPENDENCE }\end{array}$ & 67 & $26 \pm 4.7$ & 203 & $12 \pm 1.5$ & $\begin{array}{c}2.7 \\
\left(2.0^{2}-3.7\right) \\
\end{array}$ \\
\hline $\begin{array}{l}\text { MENTAL } \\
\text { HANDICAP }\end{array}$ & 6 & $2.3 \pm 1.6$ & 11 & $0.6 \pm 0.4$ & $\left(1.4^{3.8}-10\right)$ \\
\hline $\begin{array}{l}\text { SEXUAL } \\
\text { DISORDERS }\end{array}$ & 1 & $0.4-$ & 38 & $2.2 \pm 0.7$ & 0.2 \\
\hline $\begin{array}{l}\text { EATING } \\
\text { DISORDERS }\end{array}$ & 1 & $0.4-$ & - & - & - \\
\hline EPILEPSY & 1 & $0.4-$ & 4 & $0.2 \pm 0.2$ & - \\
\hline $\begin{array}{l}\text { DIAGNOSIS } \\
\text { UNCERTAIN }\end{array}$ & - & $-\quad-$ & 7 & $0.4 \pm 0.3$ & - \\
\hline
\end{tabular}

The prevalence of psychosis is approximately equal in the two samples. The diagnoses of neurosis, personality disorder, drug abuse and mental handicap are more common in women and the odds ratios suggest that these differences reflect population characteristics. The difference between the samples is greatest for mental handicap but the $95 \%$ confidence interval for the population odds ratio is wide, with a minimum value of 1.4. This diagnosis is discussed in more detail below.

Odds ratios have not been calculated where the number of cases is very small. The single case of a woman diagnosed as suffering from a sexual disorder had started life as a man but had undergone a sex change operation and lived as a woman. The single case of eating disorder was a young woman suffering from bulimia.

Prevalence rates can be translated into estimates of the total number of cases in the sentenced prison population. The number of cases in the sample of women is multiplied by four and the number of cases in the sample of men is multiplied by 20 , to take account of the difference in sampling rates. 
Table 5.5. Estimated total number of "cases" in the sentenced prison population, by diagnosis and gender

\begin{tabular}{||l|c|c||}
\hline DIAGNOSTIC GROUP & women & men \\
\hline psychosis & 16 & 680 \\
\hline neurotic disorder & 160 & 2,080 \\
\hline personality disorder & 184 & 3,540 \\
\hline alcohol abuse/dependence & 268 & 4,060 \\
\hline drug abuse/dependence & 268 & 4,060 \\
\hline mental handicap & 24 & 220 \\
\hline other disorders & 8 & 900 \\
\hline epilepsy & 4 & 80 \\
\hline
\end{tabular}

The figures shown in Table 5.5 are rough estimates. Confidence limits for some of them will be referred to in the following discussion. For now, they serve to make a point that is central to any comparison of the women and men in prison. The difference in size of the two populations means that, even for diagnoses which are more common in women, the number of male cases is far greater than the corresponding number of women.

This finding has two implications. First, it serves to warn against drawing unwarranted conclusions about the operation of the criminal justice system from percentage figures e.g. the high percentage of women with a drug problem cannot be seen as evidence of the courts' greater willingness to imprison women with a drug problem, compared to similar men. Second, the figures have implications for the provision of a psychiatric service to prisoners. The logistic problems in assessing and possibly transferring to hospital 16 women with a diagnosis of psychosis are of a different order of magnitude from the task of dealing with 680 men with a similar diagnosis.

Reference will be made to both these factors during the course of the following discussion. The results are considered in more detail under the following diagnostic headings:

1. Psychosis.

2. Mental Handicap.

3. Personality Disorders.

4. Neurotic Disorders.

5. Dependence on Drugs and Alcohol. 


\section{Psychosis}

Further statistical analysis is precluded by the fact that only four cases were identified. Whilst this study is based on a representative sample of sentenced prisoners, the number suffering from psychosis is low and they cannot be regarded as representative of mentally ill offenders at other points in the criminal justice system. By definition, these are the cases for whom the screening system did not function effectively and they illustrate some of the problems arising within current provision for offender-patients.

The cases are described below. All four of these women were located in some form of special regime, two in a prison "hospital", one in a disciplinary segregation unit and one in Durham H Wing. By contrast, 19 of the 34 men suffering from psychosis were in normal prison accommodation, although most had been identified by the prison authorities as mentally disordered.

\section{Case histories}

Case no. 133: A 37 year old woman who had served two weeks of a twelve month sentence for the possession of cannabis with intent to supply. The police found her flat to be in a chaotic state, containing fifty grams of cannabis and a note from a friend asking for some of the drug.

Born in Jamaica but resident in London for at least twenty years. Details of early life unavailable. Known to social services as a socially isolated woman with an eccentric lifestyle. Two of her children were in local authority care, the other three with their estranged father. Three previous psychiatric admissions were characterised by persecutory and bypochondriacal delusions, auditory hallucinations and prominent affective disturbance. She made a partial response to depot neuroleptics for six months but defaulted from outpatient treatment.

On remand, she was floridly psychotic with persecutory delusions, auditory hallucinations, restlessness, anorexia and disturbed sleep. She responded to treatment with neuroleptic medication, which was accepted willingly. A psychiatric report, prepared by the NHS consultant from her catchment area after she had spent four months on remand, did not recommend a psychiatric disposal on the grounds that her psychosis had improved. This report made reference to drug abuse and suggested that this was the cause of all her symptoms. 
At interview, she was irritable and suspicious with ideas of reference and the belief that people were laughing at her. She was reluctant to discuss her beliefs in detail and appeared moderately depressed. Despite continuing treatment with neuroleptic medication, the severity of her symptoms required that she was located in the prison hospital because of her excessive suspiciousness, hostility and quick temper.

Primary diagnosis - schizophrenia, schizoaffective type (295.7).

Comment: Cannabis may have exacerbated the psychosis but it was equally likely that her psychotic symptoms had led to increased use of cannabis and had contributed to her being apprehended by the police. The delay between arrest and the NHS psychiatric report appears to have contributed to the failure to recommend a psychiatric disposal, as her condition had improved by the time she was seen. Her present mental state left plenty of scope for psychiatric intervention; her symptoms prevented her being on normal location in prison and cannabis abuse and past failure to comply with treatment suggested likely problems on release from prison.

Case no. 137: A 23 year old woman who had served three months of a 36 month sentence for burglary and deception. Together with another woman, she had committed a series of burglaries over two months, then used stolen credit cards. She had previous convictions for similar offences and saw her offending as "....a way of getting money. I couldn't survive on benefits".

Her parents had separated soon after her birth and her brother suffered from schizophrenia. Raised by her grandfather, she was always a difficult child, jealous of her siblings, attention-seeking and prone to tantrums. Frequent truancy from secondary school and thefts from home and shops resulted in referral to child guidance clinic. She obtained one "A" level.

She had previous psychiatric admissions aged 21 and 22 years, the first following a serious suicide attempt. Despite depressive symptoms, schizophrenia was thought to be most likely diagnosis and she was discharged on neuroleptic medication but failed to attend for follow-up.

Shortly after beginning her sentence, her behaviour became disturbed, resulting in several attacks on prison officers, attempts to barricade herself in her 
cell and set fire to it. Thought disorder, auditory hallucinations and bizarre and persecutory delusions had been noted.

At interview, symptoms included profound depression, prominent suicidal ideation, retarded movements, poverty of speech, persecutory delusions and second and third person auditory hallucinations. She was contained in the prison hospital, accepting treatment with neuroleptic and antidepressant medication and awaiting transfer to hospital under Section 47 of the Mental Health Act 1983.

Primary diagnosis - schizophrenia, schizoaffective type (295.7).

Comment: There was no evidence that psychiatric illness played a part in the index offences. Following her relapse and despite prompt referral by the prison doctor to the catchment area, she had spent at least a month in the prison "hospital" awaiting assessment and transfer, representing a considerable suicide risk. Had it not been for delays in the NHS, she would have been transferred before the date of the study.

Case no. 378: A 37 year old woman who had served one month of a six month sentence for shoplifting.

Few details of early life were available. Onset of schizophrenia in late adolescence, resulting in multiple hospital admissions. A difficult patient, often absconding and not compliant with treatment but with no history of violence. Reports note few delusions or hallucinations in recent years but prominent negative symptoms including poor self-care, social withdrawal and lack of motivation. One report notes "borderline subnormal intelligence" but has worked in sheltered employment as a typist.

She lived in hostel for psychiatric patients and was reported to shoplift "every day" in a blatant manner, resulting in many convictions. The index offence occurred less than two months after release from prison following a similar offence. The psychiatric report prepared for the court by the NHS consultant responsible for her care mentioned her history of schizophrenia but stressed the current absence of delusions and hallucinations. Her prominent negative symptoms were described in the report but were not referred to as features of schizophrenia. It was suggested that she needed long-term secure care but she was not felt to warrant medium security and local facilities for long-term inpatient care did not 
exist. The report then went on to stress her non-compliance, her persistent petty theft and her responsibility for her actions, before stating that there was no psychiatric recommendation in this case.

At interview, she was located on a segregation unit and receiving treatment with depot neuroleptics. Prominent negative symptoms included poor self-care, flattened affect, poor social skills and of poverty of speech: she repeatedly asked "am I fat? Do you think I am fat?" and made rather vague and uninformative replies to many questions. No delusions or hallucinations were apparent.

Primary diagnosis - residual schizophrenia (295.6).

Comment: This woman showed prominent, classical features of chronic schizophrenia but her persistent shoplifting made her unsuitable for community care and reports suggested that there was no long-term "asylum" care available.

Case no. 2099: A 38 year old woman who had served two years of an eight year sentence for arson with intent to endanger life. Having formed a dependent relationship with a woman who had helped her, she became very demanding and when the woman wished to reduce contact, perceived this as rejection and threatened her, developing the delusion that the woman was her true mother. A series of threatening letters culminated in an arson attack on her home, when she was asleep upstairs.

Born into a family of travellers and brought up in a caravan, she never attended school and learned to read and write in prison.

First hospital admission aged 19 years, hospital order following a conviction for theft, said to have been "depressed and of low intelligence". Two subsequent admissions following suicide attempts, given a diagnosis of personality disorder. History of alcohol abuse some years previously - no evidence of recent dependence.

Previous offences included a life-threatening assault on her 4 year old daughter and an arson attack on her husband's home which was motivated by pathological jealousy. Her relationship with her husband and with several other people is said to have been stormy and characterised by violent outbursts, usually on her part.

At interview, showed limited social skills and appeared of low intelligence but was literate $(\mathrm{IQ}=75$ ). Stated that offence had been motivated by her belief 
that victim was her mother - still suspected this to be true but was now less certain. Moderately depressed but not suicidal. No other abnormal beliefs or hallucinations apparent. She was located in a "hospital" unit and was being treated with neuroleptic medication. She was regarded as highly vulnerable and a potential suicide risk.

Primary diagnosis - paranoia, unspecified (297.9).

Secondary diagnosis - personality disorder, unspecified (301.9).

Comment: Psychiatric evidence did not appear to have been presented at her trial, when she pleaded not guilty. She did not disturb the running of the prison and had not been referred for transfer.

\section{Discussion.}

The precise diagnosis in these complex cases may be debatable but there is little doubt that all suffer from serious and disabling psychiatric conditions. They were voluntarily taking neuroleptic medication and one was on a waiting list for transfer to hospital. It appears that prisoners suffering from psychosis do not blend in with other inmates but require some form of special management, whether this is provided in a prison "hospital" or a disciplinary or segregation unit. The methodology of the present study is biased towards detection of cases that present management problems within prison. It is possible that "silent" cases went undetected but this would mean that they were also overlooked in the numerous social enquiry and medical reports surveyed.

The fact that all the women with psychosis were subject to some form of special regime in prison, whereas a substantial proportion of the male cases were on normal location, is consistent with the argument advanced in Chapter 6, that psychiatric surveillance is more effective in the smaller, female prison population.

It has been suggested that the loss of beds in psychiatric hospitals since 1954 has resulted in many psychotic patients going to prison ${ }^{115}$. The work of Penrose ${ }^{116}$, showing an inverse relationship across countries between the size of the mental hospital and prison populations, is often cited in support of this suggestion. The notion that the populations of yesterday's asylums and today's prisons are somehow equivalent ignores the fact that at least half of the patients in psychiatric hospitals were women, whereas the female:male ratio in prisons is about 1:30.

Furthermore, the results of the present study suggest that the absolute number of sentenced female prisoners suffering from psychosis is 16 , with a possible range, derived from the $95 \%$ confidence interval, of four to 31 . Given that more than 70,000 mental 
illness beds for people aged 18 - 64 were lost between 1954 and 1984, sentenced female prisoners suffering from psychosis are numerically insignificant in any explanation of where the chronically mentally ill are now located. It is estimated that there are 150,000 people suffering from schizophrenia in England and Wales ${ }^{117}$. Assuming that half are women, then less than $.05 \%$ of women suffering from schizophrenia are serving a prison sentence at any one time.

The corresponding figure for male sentenced prisoners is 680 individuals suffering from psychosis, with a possible range from 478 to 919 . A similar rough calculation suggests that this is around $1 \%$ of all men suffering from schizophrenia.

For both men and women, these proportions are approximate and are likely to be overestimates. The figure for psychotic prisoners is not restricted to those suffering from schizophrenia but includes all those with symptoms of psychosis. Despite the inaccuracies, they serve to make a point about the relative contribution of prison to the accommodation of women and men suffering from psychotic illnesses.

Low numbers should not obscure the tragic situation of these women. Two were recognised as serious suicide risks, one of whom remained in prison simply because of delays in achieving transfer (Case no. 137) and the other because her minimal interference with the prison regime was not felt to warrant referral for transfer (no. 2099). Case no. 113 can also be seen as a victim of delays in the NHS, in that her mental state improved on treatment, whilst awaiting assessment, to such an extent that hospital admission was no longer believed to be necessary. An additional factor in this case was cannabis abuse, put forward in the psychiatric report as a cause of her symptoms, despite evidence of chronic mental disorder. The diagnosis of cannabis psychosis contributed to the rejection of this woman by her catchment area consultant.

Case no. 378 was imprisoned for petty theft, despite suffering from a chronic schizophrenic illness so classical in its features that it could have been taken from one of Kraepelin's accounts. This was the clearest example of someone who did not fit readily into existing treatment services and was therefore rejected.

Health service delays or refusal to accept patients have been stressed but the characteristics of these patients also deserve emphasis. Chronic illness, non-compliance, substance abuse and recidivism increase the chances of rejection by psychiatric services $^{118}$ and suggest a need for specialised provision. The problems of patients who are difficult to place have received increasing attention in the literature ${ }^{119}$, without any noticeable easing of the situation. 
The delay in transfer from prison to health service care has been recognised as a significant factor increasing the length of time which mentally disordered offenders spend in prison. A study of prison transfers to one special hospital ${ }^{120}$ showed that the mean time from medical recommendation to admission in 1960 was 1.3 months, whereas by 1983 it was 7.6 months, an increase of 6.3 months.

The hospital beds which have disappeared over the last three decades were not occupied only by patients suffering from psychosis, and many offender patients would not receive this diagnosis. The final chapter will return to a discussion of prison in relation to psychosis and other mental disorders in the community. First, it is necessary to consider the prevalence of other psychiatric disorders in the female prison population, beginning with mental handicap. 


\section{Mental Handicap}

The small number of cases again precludes statistical analysis. The six women found to be mentally handicapped are described below. The problem of additional psychiatric diagnoses in relation to mental handicap was discussed in Chapter 1 and will be mentioned in the comment following each case.

\section{Case histories}

Case no. 382: A 29 year old woman who had served two months of a twelve month sentence for arson. Under various social pressures, including further sexual advances from her brother, she set a fire in her own flat, then informed her neighbour. She had a previous conviction for arson in similar circumstances.

In care from two to eleven years of age, she attended special schools, having an IQ of 58. A victim of long-term sexual abuse by her brother and father, she had three children, all adopted shortly after delivery. She had several previous psychiatric admissions, usually following overdoses precipitated by social stresses and had cut herself on many occasions, in and out of prison. She was a long-term attender at a mental handicap clinic and a social services day centre. One psychiatric report mentioned "voices telling her to set fires" but found "no other evidence of psychosis".

On remand, she set fire to her own mattress and cut herself repeatedly. A medical report from a prison doctor described her as "mentally impaired" with "intellectual functioning below normal" but made no medical recommendation on the grounds that the patient "would quickly arrange for a Mental Health Review Tribunal" and "no Tribunal would agree to keep her in hospital".

At interview, she was slow to respond and had poor social skills. Her reading age was seven years, she reported no delusions or hallucinations and was not on regular medication.

Primary diagnosis - mild mental retardation (317).

Comment: There was insufficient evidence to justify a diagnosis of psychosis as the arson and self-destructive behaviour could be explained as a response to social stresses in a person of limited intellectual and coping ability. The research panel agreed with the prison medical officer that the patient was mentally impaired, as defined in the Mental Health Act 1983, but believed that hospital transfer would be the best treatment. 
Case no. 452: A 23 year old woman who had served one month of a five month sentence for shoplifting. She had several previous convictions and one previous sentence, all for theft. Born into a large, deprived and criminal family, she attended special schools but had no psychiatric history. She had never worked and remained dependent on mother, who was the main care-giver to her 18 month old baby. She coped well on normal location in prison, with the help and protection of her older sisters who were also serving sentences. She had been disciplined for intimidating other inmates, along with her sisters.

At interview, her speech was slow and inarticulate and she was unable to read any words on the Schonnell test.

Primary diagnosis - mild mental retardation (317).

Comment: There was insufficient evidence to justify an additional diagnosis of personality disorder as her violent behaviour could be seen as resulting from social or other situational factors.

Case no. 494: A 23 year old woman who had served 18 months of a 30 month sentence for aggravated burglary, entering the home of a 70 year old man in the company of another woman, tying him up and assaulting him in the course of a robbery. Her accomplice had worked for the man and was the instigator of the offence. She had previous minor theft convictions but this was her first time in prison. She was from a chaotic family and had attended a special school. She had no history of psychiatric treatment but reported one overdose as a child and many episodes of self-cutting, mainly within prison. Exploited and bullied by other women in prison, she was placed on a segregated (Rule 43) unit for her own protection.

At interview she was over-familiar and socially inappropriate in manner. She expressed no remorse for the index offence and minimised its seriousness but was angry at the length of her sentence. She described hitting out at anyone who annoyed her within prison and was pre-occupied with lesbian approaches from other women, although without delusions or hallucinations. Reading age six years.

Primary diagnosis - mild mental retardation (317).

Second diagnosis - personality disorder (301.7).

Comment: In this case, the extent of the violence, self-harm and relationship difficulties was thought to justify the additional diagnosis. 
Case no. 496: A 44 year old woman who had served 14 months of a four year sentence for offences of indecent assault against her son (aged 8years) and daughter (15 years). This was her first conviction; she was found guilty of being a willing partner in her husband's more serious sexual offences against the children. She had attended special school and was known to mental handicap services, working at an adult training centre. Her husband was also mentally handicapped and both received support from mental handicap and social services. She had no psychiatric history. Reports at trial noted low intelligence but concluded hospital treatment was not required and recommended probation. She had been bullied in prison (because of her obvious vulnerability, in addition to the nature of her offence) and was segregated for her own protection.

At interview, she appeared slow, nervous and ineffectual. Her reading age was six years and four months. She denied any role in her husband's offences, describing him as violent and forceful; "I didn't know what he was up to but I couldn't have stopped him anyway.". She was going through a divorce. She had no major problems coping with the prison regime on the segregation unit but felt she could not survive on normal location.

Primary diagnosis - mild mental retardation (317).

Comment: No evidence for an additional diagnosis.

Case no. 497. A 23 year old women who had served five months of a nine month sentence for arson. She had many previous convictions and had served two previous sentences for criminal damage and assault.

She attended special school and showed difficult and aggressive behaviour from an early age. She had many psychiatric admissions, often compulsory, for episodes of bizarre and violent behaviour and was given provisional diagnoses of personality disorder, mental handicap, depression and, on one occasion, schizophrenia. Her IQ was meausured at 66 . She suffered from mild diabetes but was unable to conform to dietary restrictions. Repeated assaults on staff and low intelligence led to rejection by local hospitals and hostels. Local psychiatrists agreed treatment was necessary and suggested referral to special hospital. She had carried out many assaults on prison staff, some of them serious.

This woman was interviewed in a special disciplinary unit, where she had spent the whole of her sentence. She was obese with poor social skills and mild 
disinhibition but no delusions or hallucinations. She accepted neuroleptic medication, which was prescribed to reduce her aggression; she reported that it made her calmer and helped control her temper. Reading age six years.

Primary diagnosis - mild mental retardation (317).

Second diagnosis - personality disorder (301.9).

Comment: Despite obtaining extensive reports on her psychiatric history, there was insufficient evidence for a firm diagnosis of psychosis, though it remains a possibility. Reports suggested she needed long-term care at a level of security intermediate between local and special hospital. A special hospital opinion was not obtained and no efforts were being made to secure her transfer, as the prison medical officer did not believe that this was warranted and had opposed earlier attempts to secure a hospital placement, on the grounds that the patient "would soon convince a tribunal that she could not be detained in hospital".

Case no. 499: A 29 year old woman who had served two and a half years of a five year sentence for arson, having set fire to the hostel where she was living. She had served five previous custodial sentences, all short, for offences of arson (1), criminal damage (3), burglary (1) and theft (1).

Abandoned by her mother at nine months, several foster placements proved unsatisfactory, partly due to her behavioural problems. She attended special schools, where her behaviour was always difficult. Her IQ was assessed at 73 when aged seven years. Aged 16 to 18 years, she lived in a hostel for the mentally handicapped but had difficulty forming relationships.

Brief psychiatric admissions dated from age 17 years, with numerous episodes of self-harm by cutting of her arms and attempted hanging, both in and out of custody. She showed aggression towards property (originally breaking windows, progressing to arson) and people (kicking, punching, often directed towards hostel or prison staff). Possible short psychotic episodes, with suspected auditory hallucinations, responded rapidly to medication. Difficult behaviour resulted in rejection by local psychiatric facilities. Admission to a regional secure unit was felt to be inappropriate because of her low intelligence and probable need for long-term care. During the present sentence, many episodes of violence and self-harm resulted in periods of solitary confinement. 
At interview, she was placed in a special disciplinary unit within the prison. She had very limited social skills and a child-like manner. Symptoms included depression and anxiety, accompanied by frequent (at least daily) impulses to injure or kill herself and difficulty in controlling her temper when frustrated. She was unable to attempt the Schonnell reading test. No delusions or hallucinations were apparent but she was being treated with long-term neuroleptic medication which she said helped her keep calm.

Her release date was approaching and she had been referred to a special hospital and accepted for transfer, under Section 47 of the Mental Health Act 1983, on the grounds of psychopathic disorder.

Primary diagnosis - mild mental retardation (317).

Second diagnosis - personality disorder (301.9).

Comment: Despite extensive records of previous admission, the evidence was not felt to justify a present-state diagnosis of schizophrenia or other psychosis. Followup information was obtained later; the assessment in hospital concluded that schizophrenia was a likely additional diagnosis. One year after transfer, she killed herself in the special hospital.

\section{Discussion.}

All cases meet the criteria for mental handicap described in Chapter 1 . They show evidence of low intellectual ability in association with a significant degree of social handicap. As was the case for psychotic inmates, the mentally handicapped women detected in the survey did not blend in with the "normal" prison population. They required some form of special management and a high proportion were also suffering from psychiatric disorders that required treatment.

Three of the cases (nos. 382, 497 and 499) received diagnoses of schizophrenia or another psychosis when assessed elsewhere, either before or after assessment in the study, and two were receiving neuroleptic medication. It is apparent from the case histories that in many respects they were more disturbed and socially disabled than inmates who did receive a diagnosis of psychosis.

This degree of diagnostic uncertainty is relevant to the findings on psychosis. If all three of these women had been given a diagnosis of a psychotic disorder in addition to mental handicap, the total number of psychotic women would have increased to seven ( $2.7 \%$ of the sample). This would not be a significant difference from the $1.9 \%$ of men 
with this diagnosis, even before allowance is made for the fact that some of the men with a diagnosis of mental handicap may also warrant an additional diagnosis.

At least three of these women would have been more appropriately placed in a psychiatric hospital. In fact, one was transferred to special hospital after our study but the referral to special hospital was not made until late in her sentence. The practice of hospital referral as the prisoner's Earliest Date of Release (EDR) approaches has been criticised elsewhere ${ }^{\mathbf{1 2 1}}$ and is difficult to justify in the present case, where the woman's behaviour appeared to have been worse during the early part of her imprisonment. A suggested referral at the remand stage had been opposed by at least one doctor working in the remand centre, for the reasons given in the case history.

Two of these cases illustrate the point made by $\mathrm{Allen}^{122}$, that prison medical officers are sometimes reluctant to recommend psychiatric treatment, even when severe disorder is apparent. Allen refers to reports that end with "....the implicitly damning conclusion: 'This offender is fit for any penalty that the court may impose'". This phrase appeared in the reports prepared by medical officers on cases 382 and 497, where it serves also as a damning reflection on the standard of some psychiatric reports prepared on mentally disordered offenders. Allen believed that this type of report was generally confined to male offenders; the present study confirms that it is not.

All six women with a diagnosis of mental handicap were held in one prison and had passed through a single remand centre (the eleven men with a similar diagnosis were contained in seven different prisons). The three most disturbed women were held on the same unit for inmates who present control problems and two of them were the responsibility of the same health region. As the female prison population is so small, the policies of a single prison, health region or even an individual doctor can exert a disproportionate influence on the proportion of mentally disordered inmates in the prison system. It is possible that the policies of doctors at one prison contributed to the high proportion of mentally handicapped inmates found in sentenced female prisoners. Evidence for this is found in the reports expressing active opposition to proposed hospital referral and transfer; this was a very unusual occurrence, most prison doctors being glad to be relieved of the responsibility of looking after mentally disordered inmates.

A study of male remand prisoners ${ }^{123}$ found considerable variation in the frequency of hospital disposal both between health regions and between individual psychiatrists. The same study also found that mentally handicapped inmates were particularly likely to be rejected by their catchment area psychiatrist. This may be related 
to a perceived need for long-term care, which was a factor in the rejection of psychotic patients also.

If the figures in the current study are accepted at face value, as representative of the female prison population, they suggest that the total number of mentally handicapped women serving a prison sentence is approximately 24 , with a wide $95 \%$ confidence interval from 8 to 42 . The equivalent figure for the sentenced male population is 220 (95\% c.i. from 73 to 367 ). These numbers are very small compared to the number of mentally handicapped people in the community, or the number of beds lost in mental handicap hospital closures over the last thirty years.

The small number of cases limits the conclusions that can be drawn but it did appear that the presence of mental handicap had complicated the previous psychiatric treatment of some patients and obstructed attempts to secure a hospital disposal in relation to the index offence. Mental handicap facilities were unable to cope with a high level of disturbed behaviour, whereas mental illness hospitals stressed the chronic nature of the patient's condition and were unable to offer long-term inpatient care.

Robertson ${ }^{124}$ describes a decline in the use of the criminal provisions of the Mental Health Act in relation to mentally handicapped offenders since the 1960's. He argues that mental handicap hospitals are concentrating their resources on the care of severely mentally handicapped patients and are less likely to admit the mildly handicapped. It is suggested that most mildly handicapped offenders have not been disadvantaged by this change; in the past, it is likely that many were hospitalised unnecessarily. This may be true in most cases. However, the present findings suggest that these changes have left a gap in provision, for the mildly mentally handicapped offender with marked social deficits and a requirement for hospitalisation because of a behavioural or psychiatric disorder. Women with this type of problem fall uncomfortably between mental handicap and mental illness services. 


\section{Personality Disorder}

Personality disorder was the only diagnosis given to 18 women (7\%) and 104 men $(6 \%)$ but it was given as an additional diagnosis to 28 women (11\%) and 73 men (4\%). Table 5.4 confirms that the gender difference is statistically significant.

Further discussion of the relative prevalence of personality disorder must first address the question of how the diagnosis was used in the present study. The subcategories of personality disorder in ICD9 were not found to be useful and most subjects were described as "unspecified". Also using clinical criteria, a DSM-III-R diagnosis was given to all subjects considered to have a personality disorder and "borderline" was the label most used, given to 24 women (9\%). In fact, the DSM-III-R categories were of limited use, as most cases could be placed in several categories, a problem that also applies when standardised instruments are used to make these diagnoses.

More information about the way the diagnosis was used is provided by a description of some of the characteristics associated with a diagnosis of personality disorder.

\section{Associations with personality disorder}

\section{Other diagnoses, social and criminal characteristics}

Personality disorder was most commonly used as an additional diagnosis in combination with substance abuse and neurosis. Clinical criteria were used in preference to standardised tests, with the intention of ensuring relevance to psychiatric practice. This approach emphasises the importance of psychiatric symptoms in making the diagnosis. Typical complaints included a repeated desire to self-injure (inside and outside prison), feelings of tension or depression, low self-esteem, poor control of anger and difficulty relating to other people. Feelings of isolation and loneliness were common, together with a recognition that substance abuse had been used to "treat" these feelings when at liberty. The diagnosis of personality disorder, rather than neurotic disorder, also required evidence that these problems were of long duration, rather than being the short-lived manifestation of depression or situational stresses.

The cost of relying on non-standard criteria is loss of reliability and the introduction of bias. Whilst standard criteria were not used in making the diagnosis, it is possible to describe some associations between personality disorder and other characteristics that were defined in a more or less operational way. This information is relevant to the important question of whether the diagnosis was used in a different way in women and men. 
Table 5.6 describes the relationships between the clinical diagnosis and social, criminal and psychiatric characteristics which may have been expected to be related to personality disorder. In fact, there is a significant positive relationship between a diagnosis of personality disorder and all the variables except drug addiction and there is considerable overlap in the confidence intervals for the odds ratios in women and men.

Table 5.6. The relationship between social and criminal history and the diagnosis of personality disorder, by gender

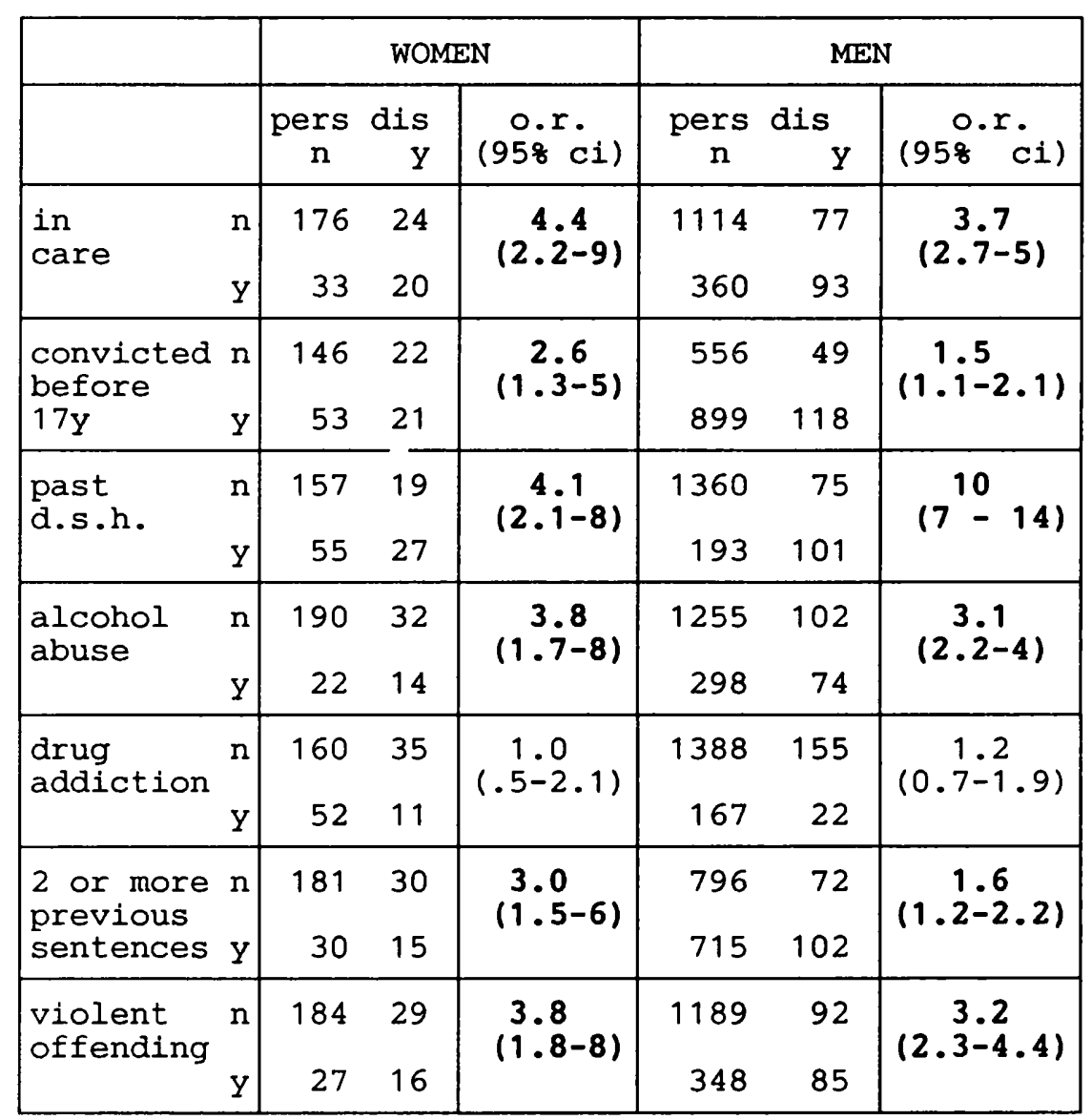

"violent offending" is defined by a score of 3 or 4 on the criminal profile "violence" scale.

\section{Psychiatric treatment and personality disorder}

If the diagnosis has relevance to psychiatric practice, then it would be expected that some cases would have received psychiatric treatment in the past. Current attitudes to treatment also serve as a guide to the extent to which the women themselves believe that they have problems that may appropriately be presented to a psychiatrist.

Of the 46 women given the diagnosis, $30(65 \%)$ had a history of psychiatric contact before entering prison, including nine of the 18 in whom this was the only diagnosis. Eight $(17 \%)$ were judged to have no desire for treatment at present but 22 
(48\%) were judged to have a strong desire for treatment, with little interest in side benefits. The others had an intermediate level of motivation but stated that they would accept treatment voluntarily, if it was offered.

The researchers' recommendations for psychiatric treatment are shown in Table 5.7. "Prison care" denotes various forms of treatment that could be provided within prison, including psychotherapy (see Chapter 2 for full definition); it does not imply that the treatment must be given in prison. Most women with a diagnosis of personality disorder were recommended for treatment of this type.

Table 5.7. Prisoners given a diagnosis of personality disorder:

treatment recommendations by gender

\begin{tabular}{|l|c|c|c|c||}
\hline & \multicolumn{2}{|c|}{$\begin{array}{c}\text { women } \\
\text { N=258 }\end{array}$} & \multicolumn{2}{c||}{ men } \\
& $\mathrm{n}$ & 8 & $\mathrm{n}$ & 8 \\
\hline $\begin{array}{l}\text { "outpatient" } \\
\text { treatment within } \\
\text { prison }\end{array}$ & 15 & 6 & 44 & 2 \\
\hline $\begin{array}{l}\text { therapeutic } \\
\text { community }\end{array}$ & 9 & 3 & 46 & 3 \\
\hline $\begin{array}{l}\text { further assessment } \\
\text { transfer to } \\
\text { hospital }\end{array}$ & 12 & 5 & 35 & 2 \\
\hline none & 8 & 3 & 9 & $<1$ \\
\hline total & 2 & 1 & 43 & 2 \\
\hline
\end{tabular}

The eight women with personality disorder recommended for hospital transfer include three with an additional diagnosis of mental handicap (see discussion above). None of the other women or men with a diagnosis of personality disorder had additional diagnoses other than substance abuse or neurosis. When these three special cases were excluded, personality disordered women were still more likely than men to be rated as needing hospital transfer but the difference was likely to be a chance one (O.R. $=3.0$, 95\% c.i. from 0.9 to 9 ).

\section{Case histories}

Case no 95: a 24 year old woman who had served four months of a 15 month sentence for theft and robbery. She grew up in children's homes, her first conviction at 13 years being followed by many convictions for petty theft and three for violence, resulting in two previous prison sentences. Her drinking began 
at the age of 12 years and she reported drinking "until I'm paralytic, if I've got the money". She described symptoms of withdrawal when she entered prison, when she was treated in the prison hospital. She also used heroin every day and cocaine, amphetamines and benzodiazepines "on most days" and saw drug use as a major problem. She had been in a drug treatment centre but could not tolerate the regime and left after a few days. Her index offence was a street robbery of another woman, accompanied by gratuitous violence: "I'm sorry now but I don't really remember it, I was so out of my head on drink and drugs. That's where the money went".

At interview, she was softly spoken and intelligent, revealing long-standing feelings of depression, tension and irritability and a history of overdosing on numerous occasions. She described herself as having no friends, frequently arguing with staff and other inmates, often thinking that other people were looking at her or trying to annoy her.

Primary diagnosis - drug dependence (304.7).

Secondary diagnosis - alcohol dependence (303).

Third diagnosis - personality disorder (301.9).

(DSM-III-R diagnosis of borderline personality disorder).

Comment: The history of relationship difficulties, violence and persistent psychiatric symptoms were judged to warrant a diagnosis of personality disorder in addition to the substance abuse diagnoses.

Case no 143: A 26 year old woman who had served 9 months of a 42 month sentence for robbery, having entered a flat and stolen a ring from the female occupant before hitting her over the head with a glass ashtray. Her parents were unknown and her early life had been spent in children's homes, foster placements breaking down because of aggressive behaviour which resulted in two referrals to a child guidance clinic. She absconded repeatedly from residential schools, becoming involved in prostitution and drug use. She had many convictions from age 15 for theft, deception, burglary and assault, often accompanied by heavy drinking which she said was "no longer a problem". She described herself as having been "obsessed with shoplifting, just for its own sake, taking things to throw away". 
At interview, she was located on the mother and baby unit with her seven month old daughter, born during the present sentence. Two previous children had been adopted away and a third was permanently in the care of the father as "I don't want to see him or it". Her manner was aggressive and confrontational and she complained of many physical problems and of her temper and irritability, which caused her problems "every day", both in and out of prison. She reported other people making her angry "all the time. It's been a problem all my life, though it's not as bad right now, in here." She attributed her previous convictions for assault to her loss of control, which meant that "rows get out of hand", and to other people provoking her. Previous relationships had ended because of her outbursts. She accepted no responsibility for the index offence, claiming that she had been "forced to do it", by financial necessity. She believed the victim had provoked the violence.

Primary diagnosis - personality disorder (301.7).

Comment: She denied that alcohol abuse was a current problem and there was insufficient evidence to support this additional diagnosis.

Case no 117: A 19 year old woman who had served one month of a six month sentence for burglary and assault. Brought up in a middle class family, she was described as "wild and uncontrollable" from childhood, requiring special schooling. Her conviction began at the age of 16 years and included five thefts and three assaults, resulting in four previous prison sentences, all marked by repeated offences against discipline, including assaults on staff.

At interview, her manner was loud and she was verbally aggressive. She described long-standing problems with her temper and outbursts of violence "for no reason. People just say something and it winds me up." She described difficult relationships with staff and inmates, saying that this was partly her temper but also their own fault "for provoking me". She was not currently depressed but described past episodes of depression and tension when she would cut her arms repeatedly, both inside and outside prison.

Primary diagnosis - personality disorder (301.7)

Comment: the extent and nature of violence towards others and the self and difficulty relating to others were the main reasons for the diagnosis. 


\section{Discussion}

Previous studies of psychiatric disorder in male prisoners report rates of "psychopathy" or "sociopathy" ranging from $5 \%^{125}$ through $8 \%^{126}$ to $78 \%^{127}$. The best explanation of this variation is the use of different criteria and, in particular, variation in the extent to which criminality is used as a criterion for antisocial personality disorder.

The tangled relationship between personality disorder and criminality is not a new problem. Maudsley ${ }^{128}$ spoke of a mental disorder with "...so much the look of vice or crime that many persons regard it as an unfounded medical invention" and Lewis ${ }^{129}$ describes Kraepelin as having been defeated in his prolonged struggle to classify these disorders. The question remains unresolved and some authors regard it as insoluble in principle $^{130}$.

Unfortunately, the relationship between criminality and personality disorder remains of great importance for any attempt to compare female and male prisoners. Women have much lower levels of criminality than men and this difference extends to female prisoners, who have lower levels of previous offending than their male counterparts. The results of any attempt to compare prevalence rates for personality disorder will depend on the extent to which criminality is used a criterion. If criminality had been a criterion in the present study, many more males would have been given the diagnosis. By disregarding criminality per se, whilst taking account of the nature of the offending, greater weight has been given to the presence of psychiatric symptoms and to borderline personality disorder.

The problem of choosing criteria for the definition of personality disorder is also encountered in studies outside prisons and is not solved by using standardised instruments. The prevalence rates for antisocial personality disorder in the ECA study ${ }^{131}$ of $0.2 \%$ for women and $0.8 \%$ for men are, at least in part, a re-statement of the observation that women offend less frequently than men. The terms criminality and sociopathy are sometimes used synonymously ${ }^{132}$.

A further problem is the possibility that many of the reported differences between male and female offenders are a result of "labelling", in that similar characteristics or actions are evaluated differently, according to the gender of the subject ${ }^{133}$. The diagnosis of personality disorder depends partly on judgements of the social acceptability of behaviour and this is likely to vary with the gender of the subject. This alleged "psychiatrisation" of behaviour is a central theme of Sim's critique of the function of psychiatry in prisons for women ${ }^{134}$. At a philosophical level, the point is unanswerable; research in psychiatry is based on the labelling of patterns of behaviour or experience. On 
a pragmatic level, it is possible to look in more detail at the way in which the labels are applied.

The present study found that the researchers applied the diagnosis of personality disorder more frequently to women than to men. Operational criteria were not used, leaving plenty of scope for bias. Nevertheless, other findings suggest that gender bias cannot account fully for this result.

First, it is argued that the symptoms documented in the case histories above were not construed as "normal" when encountered in male subjects. It is difficult to see how this level of disturbance, recognised as problematic by both interviewer and subject, could be regarded as normal.

Second, the diagnosis of personality disorder showed a similar association with a number of operational or semi-operational measures in both men and women. In all the comparisons in Table 5.6, the confidence intervals for the odds ratios show considerable overlap. These measures are rather crude and the rating of characteristics as present or absent provides no quantitative information about individuals. Limited though they are, they provide no evidence of large discrepancies between the way in which the diagnosis was applied to men and women. This cannot exclude the possibility of bias related to variables that were not identified.

One contribution to the higher rate of personality disorder in women may be the fact that the descriptive criteria for "borderline personality disorder" include "impulsiveness in.......substance abuse" and "recurrent suicidal threats, gestures and behaviour"135. Both drug abuse and deliberate self-harm were significantly more common in women. As the historical information available to the interviewer was limited, it is likely that these salient features were influential in making the diagnosis.

Despite problems with the reliability and validity of the diagnosis, there is evidence that the findings have clinical and practical relevance. Most women given the diagnosis reported that they would accept psychiatric treatment if it were offered, including many who expressed a strong desire for treatment. These women may have resented the label and may not have construed their problems in the same terms as a psychiatrist but their willingness to accept medical intervention suggests a degree of common ground. Over half of these women had already received psychiatric treatment outside prison. Any comprehensive psychiatric service to prisoners would be required to respond to the problems these women present.

A high rate of personality disorder in female prisoners is in accord with the findings of Gibbens' study, which refers to many women suffering from "personality or 
behaviour disorders". Dobash et al, in a critique of his study, argue that this was one of the reasons for the failure of the Holloway project ${ }^{136}$. When Gibbens spoke of a high rate of psychiatric disorder, he was actually referring to a high rate of personality disorder rather than other diagnoses. The response of psychiatry to these patients is ambivalent at best and another study in which Gibbens was involved ${ }^{137}$ found that only $9 \%$ of women remanded to Holloway for medical reports were accepted for treatment whilst $53 \%$ of those identified as suffering from personality disorder were rejected. A psychiatric approach to these patients was unlikely to prove successful when psychiatry did not have clear and generally accepted ways of approaching their treatment.

Carlen $^{138}$ criticises the concept of personality disorder on the grounds that it attributes disturbed behaviour to the individual. An alternative is to see the behaviour as a reaction to prison life, which can best be explained by analysing the prison regimes which "are enough to drive any woman crazy ${ }^{139 " . ~ T h e ~ p r e s e n t ~ s t u d y ~ c a n n o t ~ a n s w e r ~}$ questions about the cause of psychiatric disorder but Carlen's explanation cannot account for the findings. The diagnosis of personality disorder was not given to inmates whose disturbed behaviour was confined to prison. It was unusual for behaviour such as deliberate self-harm to be manifest only within prison and the case histories described above reveal chronic symptoms. The nature of prison regimes is an important determinant of inmate behaviour but the diagnosis of personality disorder, unsatisfactory though it may be, remains useful in a full account of the psychiatric symptoms reported by inmates.

In a more cogent criticism, Carlen also draws attention to the contradictions inherent in psychiatry's use of the concept of personality disorder, the "simultaneous identification of psychopathic personality disorder and its refusal to recognise it as a category of treatable mental illness ${ }^{140 "}$. An important finding of the present project, whatever the problems of diagnosis, is that most of the women so labelled were judged to require some form of psychiatric help, ranging from hospital transfer to counselling (Table 5.7). Much of this help could be provided, and is provided, by non-medical personnel. The contradiction identified by Carlen would be largely resolved if psychiatrists were to acknowledge the treatment needs of these women and abandon "therapeutic nihilism ${ }^{141 " .}$ 


\section{Neurotic Disorders}

As with personality disorder, the question of observer bias can be addressed by looking at the relationship between the diagnosis and other measures. The most appropriate reference measure in the case of neurosis is the score on the Clinical Interview Schedule. Whilst neurotic disorder, like the other diagnoses, was diagnosed according to clinical criteria, the researchers had each subject's score available to them.

Table 5.8 compares mean CIS scores for cases and controls.

Table 5.8. Mean CIS scores by diagnosis of neurotic disorder and by gender.

\begin{tabular}{||l|c|c||}
\hline & women & men \\
\hline $\begin{array}{l}\text { with a diagnosis of } \\
\text { neurosis }\end{array}$ & $\begin{array}{c}17.2 \pm \\
5.2\end{array}$ & $\begin{array}{c}17.9 \pm \\
5.0\end{array}$ \\
\hline $\begin{array}{l}\text { without a diagnosis of } \\
\text { neurosis }\end{array}$ & $\begin{array}{c}5.3 \pm \\
5.2\end{array}$ & $3.9 \pm 4.0$ \\
\hline$t$ & 13.3 & 33.6 \\
\hline$p$ & .001 & .001 \\
\hline
\end{tabular}

The difference between the means for female prisoners is 11.9 (the 95\% confidence interval for this difference is 11.1 to 12.7$)$. The difference between the means for males is 14.0 (95\% confidence interval 13.6 to 14.4 ).

The difference between mean CIS scores for female and male "cases" of neurosis is only 0.7 (the $95 \%$ confidence interval is -0.1 to +1.5 ). The difference between mean CIS scores for non-cases is 1.4 (the $95 \%$ confidence interval is 1.1 to 1.7 ). Whilst the mean CIS score for cases is roughly equal in both sexes, the mean CIS score for noncases is lower in males.

Neurosis was the only diagnosis in 24 women (9\%) and 57 men (3\%); it was given as an additional diagnosis to 16 women $(6 \%)$ and 47 men (3\%).

A breakdown by type of neurosis is shown in Table 5.9, women having higher prevalence rates in all categories. 
Table 5.9. Sentenced prisoners given a diagnosis of neurosis: breakdown by type of neurosis and gender

\begin{tabular}{||l|c|c|c|c||}
\hline & \multicolumn{2}{|c|}{$\begin{array}{c}\text { women } \\
\mathrm{N}=258\end{array}$} & \multicolumn{2}{c|}{$\mathrm{men}$} \\
& $\mathrm{N}=1751$ \\
\hline & $\mathrm{n}$ & 8 & $\mathrm{n}$ & 8 \\
\hline neurotic depression & 15 & 6 & 37 & 2 \\
\hline adjustment reaction & 13 & 5 & 34 & 2 \\
\hline anxiety state & 9 & 4 & 23 & 1 \\
\hline other & 3 & 1 & 10 & $<1$ \\
\hline total & 40 & 16 & 104 & 6 \\
\hline
\end{tabular}

\section{Psychiatric treatment}

Four of the 13 women with a diagnosis of adjustment reaction had a history of psychiatric treatment before their present sentence, as did 18 of the 27 women with other neurotic disorders.

Only three of the 40 women with a diagnosis of neurotic disorder expressed no desire for psychiatric treatment at present and 24 had a strong desire for treatment. The treatment recommnendations were none (three women), further assessment (four), therapeutic community (two), treatment within the prison (29) and transfer to hospital (two). For most women, treatment within prison referred to counselling or support. The women recommended for therapeutic community treatment had other diagnoses (substance abuse) which influenced this decision. The cases recommended for hospital transfer were women with neurotic depression which had not responded to drug therapy. They were unable to cope with the prison regime and were thought to represent a suicide risk.

\section{Associations with neurotic disorder}

The diagnosis of neurosis had no significant association with most criminological and social variables. One exception was the finding that neurotic disorder was diagnosed in $15(28 \%)$ of the 53 women with a violent index offence (O.R. $=2.8,95 \%$ c.i. from 1.4 to 5.9). Seven of these women were serving a life sentence for murder.

\section{Case histories.}

Case no 128: An 18 year old woman who had served six days of a nine month sentence for assault. This was her first conviction, arising from a fight with a female acquaintance, over approaches to her husband. "Things just got out of hand, she was just as much to blame. I've been on bail since the offence, I never 
thought I would get sent down". She had attended normal schools but was assessed by an educational psychologist at the age of 14 because of disruptive behaviour following rows between her parents; she did not require treatment and was never suspended or expelled from school. At the time of her offence, she was a housewife. There was no history of drug or alcohol abuse.

At interview, she was articulate and pleasant but tearful and very distressed, terrified of prison and what she feared might happen to her there. She reported poor concentration, sleep and appetite but was not suicidal. She had never experienced symptoms like this before and attributed them to her situation. She was appealing against her sentence and saw an early release as the best solution to her problems, although she felt desperate for someone she could talk to about her fears. Her CIS score was 24.

Primary diagnosis - adjustment reaction (309.0).

Comment: The experience of imprisonment precipitates anxiety and depression in a woman with no previous psychiatric history. This type of reaction is likely to be more common in remand prisoners; most sentenced prisoners have already spent time on remand and have worked through their initial reactions to prison.

Case no 458: A 20 year old woman who had served nine months of a 36 month sentence for theft of electricity and arson. Together with her husband, she had accumulated electricity arrears of over $£ 1,000$, tried to disguise this by interfering with the meter then set fire to the house in order to destroy the meter. At the time of the offence, she had a two year old baby and was pregnant .(her second child was now eight months old and was with her on the Mother and Baby Unit). The index offences were her first convictions.

She had been brought up in a poor but close-knit family. Neurotic complaints as a child led to several child guidance attendances but no psychiatric contact as an adult. There was no history of drug or alcohol abuse. Her husband was unemployed and they had constant difficulty making ends meet.

At interview, she reported symptoms beginning shortly after the birth of her child: multiple physical complaints, fatigue, poor concentration, sleep and appetite, she was easily upset and would burst into tears for no particular reason. She felt depressed all the time with pronounced guilt and self-blame, thinking that she would never be able to cope with the baby. She was anxious and uncertain of the 
future but expressed no suicidal ideas. Not currently receiving treatment, she would have liked some but "didn't know how to ask for it, or what to say". Her CIS score was 25.

Primary diagnosis - neurotic depression (300.4).

Comment: In this case, contributory factors to her depression included her difficult social circumstances before entering prison and the birth of a baby, with imprisonment playing a lesser role.

Case no 478: A 27 year old woman who had served four and a half years of a life sentence for murder. Together with her husband, she had plotted the murder of an acquaintance for insurance money; the husband had carried out the act. She had one juvenile conviction for theft and said the offence had been her husband's idea. She had no previous psychiatric history but had taken an overdose whilst on remand awaiting trial.

At interview she was depressed, anxious and irritable, reporting disturbed sleep, appetite and concentration nut no suicidal thoughts. She reported depression and anger throughout her sentence, believing her conviction was unjust. She had been treated with antidepressants but had stopped them because she feared dependence, although she still saw the visiting psychiatrist for supportive psychotherapy. Her depression had been worse recently, following bad news about her tariff. Her CIS score was 19.

Primary diagnosis - neurotic depression (300.4).

Comment: Her depression can be seen as a reaction to circumstances and a failure to adjust to her conviction and sentence. Her present state was exacerbated by a frequent stress in prisoners, bad news about tariff or parole dates.

Case no 1615: A 47 year old woman who had served one year of a life sentence for murder. She had stabbed her husband in the course of a drunken argument.

Born into a large and poor family, she had suffered physical abuse from both parents and left home at the age of 13 years. She had received little schooling and was illiterate. She had three children aged 12, 14 and 17 with her husband of 20 years. Both she and her husband had been alcoholics "for as long as I remember" but had the children living with them. Her husband was regularly 
violent towards her and this was often reciprocated. She had several psychiatric admissions in the past, associated with alcoholism, depression and self-harm.

At interview, she was depressed and pessimistic, with occasional suicidal thoughts. She felt her actions had been justified by her husband's behaviour but regretted his death and missed her children.

Primary diagnosis - neurotic depression (300.4).

Secondary diagnosis - alcohol dependence (303).

Comment: An early life that provided a poor basis for coping with adversity was followed by a violent marriage, alcoholism and episodes of depression which preceded her imprisonment. Factors contributing to her present state include the fact that she is a short way into a life sentence, has lost her husband and children and is getting over alcohol dependence.

\section{Discussion.}

A community survey of minor affective disorder in London ${ }^{142}$ found prevalence rates for minor affective disorder of $6.1 \%$ for men and $14.9 \%$ for women. Reviewing similar studies, the authors note that, despite the use of different instruments, most "report figures of the same order: $4-8 \%$ in men, and $8-15 \%$ in women."

Neurotic symptoms can be seen on a continuum of severity, from normal unhappiness through to severe and incapacitating depression. The choice of a threshold for "caseness" is fairly arbitrary. Many of the comments made about personality disorder would also apply to neurosis. Most neurotic disorder in the community does not come to the attention of psychiatrists ${ }^{143}$ and may not be regarded by the sufferer as pathological or requiring medical treatment. A psychiatric interview and the use of clinical criteria will tend to detect those cases that are regarded by the doctor and the patient as the appropriate concern of medicine.

The results of the present study fall within the range described above. They provide no evidence to suggest that the relative prevalence of neurotic disorder in men and women serving a prison sentence differs significantly from that found in community surveys. It is not possible to draw conclusions about the relative prevalence of neurotic disorder in prisoners compared to people outside prison but our findings are certainly of the same order of magnitude as those emerging from community surveys. A definitive answer to this question would require the use of identical instruments for the prison and community samples and an adjustment to take account of the unusual age structure of the prison population. 
In general, there was little relationship between a diagnosis of neurotic disorder and the extent or nature of offending, although the diagnosis of neurosis was more common in violent offenders. In a sentenced prison population, the meaning of this association is unclear. A significant number of women with a violent index offence and a diagnosis of neurosis were serving a life sentence for murder and their symptoms may be a reaction to the length of their sentence or the loss of the victim, who was usually someone with whom they had a long and ambivalent relationship.

Neurotic disorder is the only diagnosis that was also common in women from overseas (Table 5.2). It has been argued above that these women have few social characteristics in common with other women serving a prison sentence. None had previous convictions or a history of psychiatric treatment and most were middle-class traders. This finding is in line with the suggestion that neurotic disorder can be seen as a reaction to circumstances, rather than having any particular association with offending. 


\section{Dependence on Drugs and Alcohol}

\section{i. Drug dependence}

The figures given in Tables 5.4 and 5.5 combine the ICD9 diagnoses of "drug dependence" and "non-dependent abuse of drugs". The descriptions given in ICD9 could be criticised as over-inclusive and the following analyses use a stricter, operational definition of drug dependence (see coding manual, Appendix A). This requires selfreported daily use of the relevant drug throughout the six-months prior to the index offence, symptoms of withdrawal on entering custody and an acceptance by the interviewee that s/he was drug-dependent at the time of the index offence. Cannabis was excluded from this definition of drug dependence, on the grounds of its limited clinical importance.

According to these operational criteria, 63 women (24\%, with a $95 \%$ cconfidence interval from $20 \%$ to $29 \%)$ and 189 men $(11 \%$, $95 \%$ c.i. from 9 - 12\%) were identified as drug dependent. Table 5.10 shows the main drug on which these inmates were dependent. Opiates predominate and account for the higher prevalence of drug dependence in women.

Table 5.10. Drug dependent prisoners, by gender and main type of drug

\begin{tabular}{||l|c|c|c|c||}
\hline & \multicolumn{2}{|c|}{ women } & \multicolumn{2}{c|}{ men } \\
& $\mathrm{N}=258$ & $\mathrm{~N}=1751$ \\
\hline opiates & $\mathrm{n}$ & 8 & $\mathrm{n}$ & 8 \\
\hline amphetamines & 48 & 18 & 117 & 7 \\
\hline cocaine & 7 & 3 & 37 & 2 \\
\hline others & 5 & 2 & 16 & 1 \\
\hline total & 3 & 1 & 19 & 1 \\
\hline
\end{tabular}

Injecting during the six months prior to the index offence was reported by 127 men (67\% of drug dependent men) and 42 women (67\%). Treatment contact was reported by 41 drug dependent women $(65 \%)$ and 85 men $(45 \%$, O.R. $=2.3,95 \%$ c.i. from 1.3 to 4.1$)$.

There was marked regional variation in the prevalence of dependence, found in 17 (27\%) of the 63 women resident in London and in $19(53 \%)$ of the 36 from the Mersey health region (O.R. $=3.0,95 \%$ c.i. from 1.3 to 7$)$. 
The mean age of the drug dependent women was 26.4 years (s.d. $=6.0 \mathrm{y}$ ), the mean age for the remainder of the sample being 29.1 years (s.d. $=9.3 y: t=2.20, p<.05$ ).

Only three of the drug dependent women reported that prostitution was a important in funding their habit. Of the 58 drug dependent women on whom full CRO information was obtainable, only $7(12 \%)$ had any record of past convictions for offences related to prostitution. CRO information was available on 177 women who were not drug dependent and $12(7 \%)$ had convictions for offences related to prostitution.

Table 5.11. Female sentenced prisoners: index offence by drug dependence

\begin{tabular}{||l|c|c|c|c|c|c||}
\hline index offence & \multicolumn{2}{|c|}{$\begin{array}{c}\text { non- } \\
\text { dependent }\end{array}$} & \multicolumn{2}{c|}{$\begin{array}{c}\text { drug } \\
\text { dependent }\end{array}$} & \multicolumn{2}{c||}{ total } \\
\hline & $\mathrm{n}$ & 8 & $\mathrm{n}$ & 8 & $\mathrm{n}$ & 8 \\
\hline theft & 68 & 35 & 23 & 37 & 91 & 35 \\
\hline drugs & 28 & 14 & 23 & 37 & 51 & 20 \\
\hline burglary/robbery & 30 & 15 & 11 & 18 & 41 & 16 \\
\hline violence & 48 & 25 & 5 & 8 & 53 & 21 \\
\hline arson & 11 & 6 & - & - & 11 & 4 \\
\hline other & 10 & 5 & 1 & 2 & 11 & 4 \\
\hline total & 195 & 76 & 63 & 24 & 258 & 100 \\
\hline
\end{tabular}

Table 5.11 shows the index offences for drug dependent women compared to the remainder of the sample. The drug dependent women are mostly serving sentences for acquisitive offending. Although 23 drug dependent women were serving a sentence for drugs offences, this is a minority of the total of 51 women sentenced for drugs offences i.e. most drug offenders were not dependent on drugs at the time of their arrest. This remains true despite the exclusion of foreign drug couriers, who would further increase the proportion of non-dependent drug offenders. 
Table 5.12. Female sentenced prisoners: relationship between social and criminal history and drug dependence.

\begin{tabular}{|c|c|c|c|c|}
\hline & & \multicolumn{2}{|c|}{ drug dependence } & \multirow{2}{*}{$\begin{array}{c}\text { odds } \\
\text { ratio } \\
(95 \% \\
\text { C.I.) }\end{array}$} \\
\hline & & no & yes & \\
\hline \multirow{2}{*}{$\begin{array}{l}\text { history of } \\
\text { being in } \\
\text { care }\end{array}$} & no & 147 & 51 & \multirow{2}{*}{$\begin{array}{l}0.6 \\
(0.3 \\
1.3)\end{array}-$} \\
\hline & yes & 44 & 9 & \\
\hline \multirow{2}{*}{$\begin{array}{l}\text { conviction } \\
\text { before age } \\
17 y\end{array}$} & no & 131 & 37 & \multirow{2}{*}{$\begin{array}{c}1.5 \\
(0.8 \\
2.8)\end{array}$} \\
\hline & yes & 52 & 22 & \\
\hline \multirow{2}{*}{$\begin{array}{l}\text { past } \\
\text { deliberate } \\
\text { self-harm }\end{array}$} & no & 135 & 41 & \multirow{2}{*}{$\begin{array}{c}1.2 \\
(0.7- \\
2.2)\end{array}$} \\
\hline & yes & 60 & 22 & \\
\hline \multirow{2}{*}{$\begin{array}{l}\text { alcohol } \\
\text { abuse }\end{array}$} & no & 165 & 57 & \multirow{2}{*}{$\begin{array}{l}0.6 \\
(0.2 \\
1.5)\end{array}$} \\
\hline & yes & 30 & 6 & \\
\hline \multirow{2}{*}{$\begin{array}{l}\text { two or more } \\
\text { previous } \\
\text { sentences }\end{array}$} & no & 166 & 45 & \multirow{2}{*}{$\begin{array}{l}2.5 \\
\left(1.3^{-}-\right. \\
4.9)\end{array}$} \\
\hline & yes & 27 & 18 & \\
\hline
\end{tabular}

Drug dependent women are more likely to have served previous sentences although dependence was not associated with some social characteristics that may have been expected to accompany recidivist offending (Table 5.12). Compared to other inmates, drug dependent women have higher ratings on the criminal profile scales for theft and financial gain, but not on the violence scale (Table 5.13).

Table 5.13. Female sentenced prisoners: criminal profile ratings by drug dependence.

\begin{tabular}{|c|c|c|c|c|c|c|}
\hline \multicolumn{2}{|c|}{ scale and rating } & \multicolumn{2}{|c|}{ non-dependent } & \multicolumn{2}{|c|}{ drug dependent } & \multirow{2}{*}{$\begin{array}{c}\text { odds } \\
\text { ratio } \\
(958 \\
\text { C.I.) }\end{array}$} \\
\hline & & $\mathrm{n}$ & 8 & $\mathrm{n}$ & 8 & \\
\hline \multirow[t]{2}{*}{ theft } & $0-2$ & 111 & 83 & 23 & 17 & \multirow{2}{*}{$\begin{array}{c}2.3 \\
(1.3 \\
4.1)\end{array}$} \\
\hline & $3-4$ & 83 & 68 & 39 & 32 & \\
\hline \multirow[t]{2}{*}{ violence } & $0-2$ & 154 & 72 & 59 & 28 & \multirow{2}{*}{$\begin{array}{c}0.5 \\
(0.1 \\
1.5) \\
\end{array}$} \\
\hline & $3-4$ & 40 & 93 & 3 & 7 & \\
\hline \multirow{2}{*}{$\begin{array}{l}\text { criminal } \\
\text { gains }\end{array}$} & $0-2$ & 158 & 89 & 20 & 11 & \multirow{2}{*}{$\begin{array}{c}9.2 \\
(4,9 \\
18)\end{array}$} \\
\hline & $3-4$ & 36 & 46 & 42 & 54 & \\
\hline
\end{tabular}

In those women on whom CRO data was available, drug dependent women were significantly less likely to have ever been convicted of violence against the person (Table 5.14). 
Table 5.14. Female sentenced prisoners: convictions for violence against the person by drug dependence

\begin{tabular}{||l|c|c|c|c|c|c||}
\hline $\begin{array}{l}\text { number of convictions } \\
\text { for violence }\end{array}$ & \multicolumn{2}{|c|}{$\begin{array}{c}\text { non- } \\
\text { dependent }\end{array}$} & \multicolumn{2}{c||}{$\begin{array}{c}\text { drug } \\
\text { dependent }\end{array}$} & \multicolumn{2}{c||}{ total } \\
\hline & $\mathrm{n}$ & 8 & $\mathrm{n}$ & 8 & $\mathrm{n}$ & 8 \\
\hline none & 100 & 55 & 41 & 71 & 141 & 59 \\
\hline one or more & 83 & 45 & 17 & 29 & 100 & 41 \\
\hline total & 183 & 76 & 58 & 24 & 241 & 100 \\
\hline
\end{tabular}

$\mathrm{chi}^{2}=4.03, \mathrm{p}<.05$

\section{Case histories}

Case no. 419: A 20 year old woman who had served five months of a two year sentence for the possession of heroin with intent to supply. Raised in Liverpool, in a close but poor family, her first conviction at 13 years for shoplifting resulted in a care order. She became dependent on heroin at age 17 years, originally "chasing the dragon" and later injecting. "I used to shoplift at first but I was getting caught and I had two children to look after on my own, so I started dealing from the flat, just to people I knew. It was two years before I was caught".

This was her first prison sentence. "I had a hard time in Risley, cold turkey. I told people about the drugs problem but they just put me in a strip cell when I was coming off. I've heard nothing since. I want to stay off, I've been glad for the break from gear. My two kids are with their aunt and I want them back when I go out. I was a real mess when I came in, I'd been using a gram a day and was really thin. I don't want to go back to that".

Primary diagnosis: drug dependence (304.0).

Comment: After several theft convictions, she had adopted a settled lifestyle revolving around her drug addiction and her children and there was no evidence to justify alternative diagnoses. Most users reported selling drugs to other users and many justified dealing as a less stressful way of supporting their habit than theft, whilst recognising that the law views dealing as a more serious offence. This woman's experience on remand was typical of drug user's accounts.

Case no. 453: An 18 year old woman who had served two months of a 12 month sentence for burglary. Having been brought up on a large and neglected housing estate in Liverpool, she had used heroin since the age of 15 years, never injecting 
but "chasing" a gram a day at the time of her arrest. Her habit was funded by burglaries, which had brought her seven court appearances and three previous custodial sentences. At interview she reported: "All my mates are into heroin, I moved to another town to get away from it". "I don't want any help. I'll stay away and stay off it. People can't help you anyway, it's something you have to do for yourself".

Primary diagnosis: drug dependence (304.0).

Comment: Similar accounts were obtained from many women. The description of young people heavily involved in drugs, dealing and theft resembles that contained in an anthropological account of heroin use on an estate in South London ${ }^{144}$. Her attitude towards treatment was also typical of inmates who did not want treatment i.e. she was not resigned to returning to drug use but saw it as an individual problem to which treatment was not relevant.

Case no. 415: A 35 year old woman who had served 15 months of a 40 month sentence for handling stolen goods and the possession of a small amount of heroin. She had first attended a drug clinic at the age of 15 years, claiming to have been "the youngest registered addict in London". She had now been using heroin for 20 years, injecting throughout this time. Heroin was her main drug but she would also inject cocaine and amphetamine "on most days". A total of 30 court appearances included 21 convictions for prostitution-related offences, six drug offences and five theft. This was her fifth prison sentence (the previous four sentences totalled 16 months of imprisonment). She was heavily involved in a criminal and drug-dealing subculture, financing her habit mostly by dealing.

At interview she stated: "I inject and I never share needles. I've tried every treatment, several times. I need drugs - it would be better to stop but I'll die an addict".

Primary diagnosis: drug dependence (304.7).

Comment: This woman was representative of the older heroin users in the study, resigned to continuing drug use and with extensive, unsuccessful experience of treatment. Seventeen of the 63 drug dependent women were over 30 at the time of their sentence. 
Case no 423: A 43 year old woman who had served two months of a 36 month sentence for conspiracy to supply heroin. She had grown up in a close-knit, criminal family and was married with a 15 year old son. She had seven convictions for theft, beginning at the age of 16 years, but no previous prison sentences. She reported "making a comfortable living from crime" along with her husband. At the age of 37 years, she became addicted to heroin.

At interview she reported: "I tried it at a party and just liked it. My husband thinks I'm mad, he doesn't touch it. I started dealing, mostly for money, there's a lot of money in it. I never injected but I was getting through a few grams a day by the time I was caught. I just couldn't control my own habit".

"They confiscated the house and everything, proceeds of drugs. Doesn't bother me - I can always buy another. I won't go back to drugs. I don't need treatment but I've had enough of them. What I did was wrong but it's water under the bridge. Drugs have wrecked our city though, I'd like to do something to stop kids getting involved."

Primary diagnosis: drug dependence (304.0).

Comment: Another older woman, this case illustrates the complex links between drug use and crime. This woman had grown up outside drug-using circles before her late exposure to heroin. Despite her existing involvement in criminal activity, she described an escalation of offending, the turnover from drugs being "beyond anything I had ever dreamed of".

\section{Discussion.}

Drug dependence or abuse is the commonest diagnosis in both sexes and it is much commoner in women. There are no comparable studies of drug dependence in UK prisons but American studies have found that women in prison have higher rates of drug dependence than men (see chapter 1 ).

Estimated from the figures in table 5.4, the sentenced population contains about 280 women (between 210 and 330) who were dependent on drugs before entering prison, compared to about 4,300 men $(3,700$ to 4,800$)$. Women account for six percent of sentenced inmates who were dependent on drugs at the time of their index offence.

In the United Kingdom as a whole, the proportion of women among new addicts notified to the Home Office was $29 \%$ in 1988 and had been between $26 \%$ and $29 \%$ throughout the preceding ten years ${ }^{145}$. This suggests that women who are dependent on 
drugs are under-represented in the sentenced prison population compared to their male counterparts but the degree of under-representation is less than that of women who are not drug dependent, compared to non-dependent men (women make up less than $3 \%$ of the sentenced prison population as a whole). Drug dependence appears to be an important factor contributing to the imprisonment of women.

Despite being significantly younger than the rest of the women serving a prison sentence, those with a history of drug dependence tend to have a more extensive criminal history but their offending is very specialised, being predominantly acquisitive. They share these characteristics with drug dependent men serving a prison sentence ${ }^{146}$.

Most drug users were from inner-city estates and funded their drug use by theft or by dealing in drugs. They resemble the women in D'Orban's description of heroin users in Holloway in 1970, although the mean age of his (mainly remand) sample was only 20 years. The differences are of interest; none of the drug users in his sample faced a charge of selling drugs and most were using relatively small amounts of prescribed drugs. In the present study, practically all drugs were illicitly obtained and dealing was a common method of financing drug use, albeit one that attracted heavy sentences. Many of the dependent women would fit the description of the "new heroin users ${ }^{147 "}$ ", with offending preceding drug use but escalating rapidly with the onset of dependency ${ }^{148}$.

Prostitution was unusual among the drug dependent women in our sample but this may be a selection effect. Prostitution is not an offence and soliciting is not an imprisonable offence, so a sample of sentenced women may exclude an important group of heroin users who are able to fund their habit without risking prison.

Whilst many women reported that their heroin use started with "chasing the dragon", most had moved on to inject. Detailed information about injecting practices was not collected but other drug users passing through the prison system have been found to engage in high-risk behaviour ${ }^{149}$. Although the number tested is not known, two of the drug dependent women were HIV positive.

A survey of sentenced prisoners is the wrong place to look for information about the relationship between drugs and offending but the case histories described above show a diversity in this respect that warns against any single, simple explanation of these intertwined behaviours.

It is remarkable that drug dependence shows no significant association with deliberate self-harm, a history of being in care, violence or a diagnosis of personality disorder. Burr ${ }^{150}$ describes the impact of heroin on a London council estate, stressing the changes brought about by the arrival of a cheap, exciting and profitable commodity 
into a cohesive, working-class community with existing high levels of criminality. Her account emphasises economic and social influences on the spread of drug use, regarding psychological factors as off less importance. The results of the present study are consistent with such a model. The situation is rather different for alcohol, as will be seen in the following section. 


\section{ii. Alcohol abuse}

As with drug abuse, the following account refers to the ratings of problem drinking on the data sheet, as defined in the coding manual, rather than to the ICD9 categories.

Drinking prior to their index offence was reported by 39 women (15\%). A total of 36 women (14\%) were rated as having a significant drink problem, including ten (4\%) regarded as probably dependent and nine (4\%) definitely dependent on alcohol. A total of 374 men $(21 \%)$ were problem drinkers, including $81(5 \%)$ rated as probably dependent and $34(2 \%)$ definitely dependent. The male: female odds ratio for this definition of problem drinking is 1.7 , with a $95 \%$ confidence interval from 1.2 to 2.4 .

At the time of sentencing, the mean age of the problem drinkers was 28.5 years, compared to 28.4 years for the rest of the sample.

Table 5.15. Female sentenced prisoners: relationship between social and criminal history and problem drinking

\begin{tabular}{|c|c|c|c|c|}
\hline & & \multicolumn{2}{|c|}{$\begin{array}{c}\text { problem } \\
\text { drinking }\end{array}$} & \multirow[t]{2}{*}{$\begin{array}{l}\text { odds ratio } \\
\text { (958 C.I.) }\end{array}$} \\
\hline & & no & yes & \\
\hline \multirow{2}{*}{$\begin{array}{l}\text { history of } \\
\text { being in } \\
\text { care }\end{array}$} & no & 180 & 20 & \multirow{2}{*}{$\left(1.3^{2.9}-6.3\right)$} \\
\hline & yes & 40 & 13 & \\
\hline \multirow{2}{*}{$\begin{array}{l}\text { conviction } \\
\text { before age } \\
17 y\end{array}$} & no & 148 & 20 & \multirow{2}{*}{$\left(0.7^{1.6}-3.4\right)$} \\
\hline & yes & 61 & 13 & \\
\hline \multirow{2}{*}{$\begin{array}{l}\text { past } \\
\text { deliberate } \\
\text { self-harm }\end{array}$} & no & 164 & 12 & \multirow{2}{*}{$\left(2.7^{5.7}-12\right)$} \\
\hline & yes & 58 & 24 & \\
\hline \multirow{2}{*}{$\begin{array}{l}\text { two or more } \\
\text { previous } \\
\text { sentences }\end{array}$} & no & 183 & 28 & \multirow{2}{*}{$\left(0.6^{1.4}-3.3\right)$} \\
\hline & yes & 37 & 8 & \\
\hline
\end{tabular}

Problem drinking shows a significant association with a history of local authority care and deliberate self-harm, but not with conviction before the age of 17 years and previous custodial sentences (Table 5.15). This contrasts with the corresponding table for drug dependent women (table 5.12), where the only significant association is with two or more previous sentences. 
Table 5.16. Female sentenced prisoners: criminal profile ratings by problem drinking.

\begin{tabular}{|c|c|c|c|c|c|c|}
\hline \multicolumn{2}{|c|}{ scale and rating } & \multicolumn{2}{|c|}{$\begin{array}{c}\text { no drink } \\
\text { problem }\end{array}$} & \multicolumn{2}{|c|}{$\begin{array}{c}\text { problem } \\
\text { drinkers }\end{array}$} & \multirow[t]{2}{*}{$\begin{array}{l}\text { odds ratio } \\
\text { (958 C.I.) }\end{array}$} \\
\hline & & $\mathrm{n}$ & 8 & $\mathrm{n}$ & 8 & \\
\hline \multirow[t]{2}{*}{ theft } & $0-2$ & 118 & 54 & 16 & 44 & \multirow{2}{*}{$\left(0.7^{1.5}-2.9\right)$} \\
\hline & $3-4$ & 102 & 46 & 20 & 56 & \\
\hline \multirow[t]{2}{*}{ violence } & $0-2$ & 189 & 86 & 24 & 67 & \multirow{2}{*}{$\begin{array}{c}3.0 \\
(1.4-7)\end{array}$} \\
\hline & $3-4$ & 31 & 14 & 12 & 33 & \\
\hline \multirow{2}{*}{$\begin{array}{l}\text { criminal } \\
\text { gains }\end{array}$} & $0-2$ & 155 & 70 & 23 & 64 & \multirow{2}{*}{$\left(0.6^{1.4}-2.8\right)$} \\
\hline & $3-4$ & 65 & 30 & 13 & 36 & \\
\hline
\end{tabular}

Problem drinkers are significantly more likely than other women to score highly on the violence scale of the Criminal Profile but not on the theft and criminal gain scales (Table 5.16). Again, this result contrasts with the findings for drug dependence, which is associated with acquisitive offending (table 5.12) and has a negative association with one measure of violence (table 5.13). Of the 43 women scoring three or four on the violence scale of the criminal profile, $26(61 \%)$ were serving a sentence for murder or attempted murder, including eight with a drink problem.

Table 5.17. Female sentenced prisoners: problem drinking by convictions for violence against the person, arson and drunkenness

\begin{tabular}{|c|c|c|c|c|c|c|}
\hline \multicolumn{2}{|c|}{$\begin{array}{l}\text { offence and number of } \\
\text { convictions }\end{array}$} & \multicolumn{2}{|c|}{$\begin{array}{l}\text { no drink } \\
\text { problem }\end{array}$} & \multicolumn{2}{|c|}{$\begin{array}{l}\text { problem } \\
\text { drinkers }\end{array}$} & \multirow[t]{2}{*}{$\begin{array}{l}\text { odds ratio } \\
\text { (958 C.I.) }\end{array}$} \\
\hline & & $\mathrm{n}$ & 8 & $\mathrm{n}$ & 8 & \\
\hline \multirow[t]{2}{*}{ violence } & 0 & 129 & 62 & 12 & 35 & \multirow{2}{*}{$(1.4-6)$} \\
\hline & 1 or more & 78 & 38 & 22 & 65 & \\
\hline \multirow[t]{2}{*}{ arson } & 0 & 199 & 97 & 25 & 81 & \multirow{2}{*}{$\begin{array}{c}8.0 \\
(2.4-27)\end{array}$} \\
\hline & 1 or more & 6 & 3 & 6 & 19 & \\
\hline \multirow[t]{2}{*}{ drunkenness } & 0 & 203 & 99 & 26 & 87 & \multirow{2}{*}{$\left(2.6^{16}-89\right)$} \\
\hline & 1 or more & 2 & 1 & 4 & 13 & \\
\hline
\end{tabular}

In those women on whom CRO data was available, problem drinkers were significantly more likely to have convictions for violence against the person, arson and, predictably, drunkenness (Table 5.17). 


\section{Case Histories.}

Case no. 409: A 27 year old woman who had served 23 months of a 48 month sentence for robbery: whilst engaged in prostitution and together with male accomplices, she had beaten up and robbed a client. She had been born into a family of 12 children, her father drank heavily and she was also a heavy drinker by the age of 16 years. Her first conviction at 18 years was followed by 26 court appearances, including 22 prostitution-related convictions, numerous disorderly conduct offences and one previous conviction for robbery, in similar circumstances, for which she had served her only previous custodial sentence.

Dependent on alcohol for many years, she had received treatment only in prison. Outside, she worked as a prostitute and lived with her husband (also a heavy drinker) and their ten year old son.

At interview, she described herself as feeling depressed, bored and empty without drink. She had taken several overdoses in the past and used drink "to relieve tension, to relax". Excessive irritability caused her to get involved in many rows and fights, usually with her co-habitee; she felt they were equally responsible for these incidents. She was seeing a psychiatrist, receiving treatment with a tricyclic antidepressant and counselling about her drinking and temper. She valued this treatment but was resigned to a return to drink when she left prison.

Primary diagnosis - alcohol dependence (303).

Secondary diagnosis - personality disorder (301.9).

(DSM-III-R diagnosis of borderline personality disorder).

Comment: The additional diagnosis was justified by her other long-standing symptoms; an alternative formulation would have been a chronic neurotic disorder, or simply the consequeces of chronic alcoholism. An additional diagnosis was favoured as the neurotic symptoms remained prominent after almost two years without alcohol.

Case no 447: A 31 year old woman who had served five months of a 15 month sentence for assault. She had attended normal schools but was in care from 11 to 16 years following family breakup, when she also received child guidance. She had been drinking heavily, mainly in bouts at weekends, since the age of 14 years. Her first conviction, at 14 years, began a total of seven court appearances for petty 
theft and assault, all drink-related. Index offence was the most serious, when she stabbed a woman drinking companion during the course of an argument.

At interview, she reported a drink problem but no symptoms of alcohol dependence. She would often drink until unconscious, waking with no recollection of activities of the previous night; she had no memory of the index offence but accepted she was guilty. She reported minor neurotic symptoms with a CIS score of eight. She was not interested in treatment for her drink problem, stating that she could deal with it alone.

Primary diagnosis - non-dependent abuse of alcohol (305.0).

Case no 889: A 21 year old woman who had served two months of a five month sentence for driving with excess alcohol and driving whilst disqualified. Her childhood was reported to be uneventful, she started drinking at the age of 14 years, by 16 was drunk every day and begun to receive outpatient treatment for depression and alcoholism. She was first convicted at 17 years and had a total of five court appearances, for petty theft and drink-driving. At the time of her index offence, she was drinking every morning as soon as she woke and had the "shakes" on entering prison, treated with benzodiazepines.

At interview, she described herself as an alcoholic and reported that alcohol had led to the breakup of several relationships. She showed some neurotic symptoms, scoring ten on the CIS.

Primary diagnosis - alcohol dependence (303).

\section{Discussion.}

The ECA study found rates of alcohol dependence or abuse of $0.9 \%$ in women and $5.0 \%$ in men. Prison studies which compare women and men find less marked differences in rates of alcohol abuse e.g. $47 \%$ for women and $53 \%$ for men (Guze), four percent of women and seven percent for men in the study by Novick et al. The present study is in line with these findings; the rate for men is higher but not dramatically so.

The prevalence figures for problem drinking suggest absolute numbers for the sentenced prison population of 144 women and 7,480 men, a ratio of 1:52. The situation appears similar to that for drug dependence.

There are noticeable differences between women with a drink problem and those dependent on drugs. The drug dependent women have a very high level of acquisitive 
offending compared to other inmates but a lower level of violent offending. The problem drinkers have a higher level of violent offending and arson. They are also more likely to show other features of psychological disturbance, including a history of care and past deliberate self-harm.

The association of alcohol with violent offending is consistent with the findings of a number of other studies, although it is recognised that the association is complex ${ }^{151}$. In the present study, eight of the 12 problem drinkers with a high score for violence on the criminal profile scale were serving a sentence for murder or attempted murder; the nature of the study population means that the association is with serious violence. In his survey of 59 men and seven women charged with murder, Gillies ${ }^{152}$ found that 36 (55\%) were affected by alcohol at the time of the offence and he described five of the 30 murderers with no other psychiatric diagnosis as "heavy drinkers". He noted that 17 of the victims were also under the influence of alcohol at the time of the assault. Virkkunen ${ }^{153}$ found alcohol use by the perpetrator and/or the victim to be a precipitating factor in 92 of the 116 homicides recorded by police in Helsinki between 1963 and 1968.

The present findings, which refer to problem drinking in the offender rather than alcohol as a precipitating factor, suggest that the association between alcohol and violence persists in the sentenced prison population. The association of problem drinking with many other indicators of psychological disturbance is also consistent with accounts which emphasise the complexity of the links between alcohol and offending ${ }^{154}$. Sentenced prisoners are not representative of all offenders. However, in the case of serious violence, the presence of a drink problem is not likely to result in diversion from the penal system, a point which will be taken up in the final chapter. 


\section{Ethnic Origin and Psychiatric Diagnosis}

When overseas residents are excluded, the sample includes 33 black women. Diagnoses such as psychosis and mental handicap are relatively uncommon, so any relationship between diagnosis and ethnic origin would have to be fairly gross in order to achieve statistical significance.

A psychiatric diagnosis was given to $42 \%$ of black women and $59 \%$ of white women in our sample. Table 5.18 shows the breakdown of diagnosis by ethnic origin. The number of women in the "other" group is too small for valid comparison and the odds ratios relate to the comparison of white and black women.

Table 5.18. UK resident women serving a prison sentence: diagnosis by ethnic origin.

\begin{tabular}{|c|c|c|c|c|c|c|c|c|}
\hline & \multicolumn{2}{|c|}{$\begin{array}{l}\text { white } \\
\mathrm{N}=216\end{array}$} & \multicolumn{2}{|c|}{$\begin{array}{r}\text { black } \\
\mathbf{N}=33\end{array}$} & \multicolumn{2}{|c|}{$\begin{array}{l}\text { other } \\
\mathrm{N}=9\end{array}$} & total & $\begin{array}{c}\text { odds ratio } \\
\text { white:black } \\
\text { (958 c.i.) }\end{array}$ \\
\hline psychosis & 2 & 1 & 2 & 6 & 0 & - & 4 & $\begin{array}{c}0.15 \\
(.02-1.1)\end{array}$ \\
\hline ment. ret. & 5 & 2 & 1 & 3 & 0 & - & 6 & $(0.1-6.8)$ \\
\hline neurosis & 34 & 16 & 4 & 12 & 2 & 22 & 40 & $\left(0.5^{1.4}-4.1\right)$ \\
\hline $\begin{array}{l}\text { personality } \\
\text { disorder }\end{array}$ & 40 & 18 & 6 & 18 & 0 & - & 46 & 1.0 \\
\hline $\begin{array}{l}\text { subst. abuse/ } \\
\text { dependence }\end{array}$ & 84 & 39 & 5 & 15 & 2 & 22 & 91 & $(1.3 .6-10)$ \\
\hline any diagnosis & 128 & 59 & 14 & 42 & - & - & 15 & $\left(0.9^{2.0}-4.1\right)$ \\
\hline
\end{tabular}

Although white women are more likely to receive a diagnosis of neurotic disorder, substance abuse/dependence is the only category in which the confidence interval for the odds ratio suggests that the finding reflects a true difference within the population. Black women in the sample have higher rates of psychosis and mental handicap but the confidence interval for the population odds ratio is too wide to allow the conclusion that this represents a true difference in the population. Nevertheless, the difference in sample rates for psychosis deserves comment, being six percent in black women compared to one percent in white women.

Reference has already been made to the limitations of a small sample. If the larger sample of men is analysed in the same way, a similar trend emerges (table 5.19). 
Table 5.19. UK resident men serving a prison sentence: diagnosis by ethnic origin.

\begin{tabular}{|c|c|c|c|c|c|c|c|c|}
\hline & \multicolumn{2}{|c|}{$\begin{array}{c}\text { white } \\
\mathrm{N}=1472\end{array}$} & \multicolumn{2}{|c|}{$\begin{array}{c}\text { black } \\
\mathrm{N}=182\end{array}$} & \multicolumn{2}{|c|}{$\begin{array}{r}\text { other } \\
\mathrm{N}=78\end{array}$} & total & $\begin{array}{c}\text { odds ratio } \\
\text { white:black } \\
\text { (95\% c.i.) }\end{array}$ \\
\hline psychosis & 26 & 2 & 7 & 4 & 1 & 6 & 34 & $\begin{array}{c}0.45 \\
(0.2-1.0)\end{array}$ \\
\hline neurosis & 92 & 6 & 9 & 5 & 3 & 5 & 104 & $\left(0 . \dot{6}^{3}-2.5\right)$ \\
\hline pers dis & 167 & 11 & 9 & 5 & 1 & 6 & 177 & $(1.5-5.0)$ \\
\hline sex dev & 35 & 2 & 1 & 0.6 & 2 & 3 & 38 & $\begin{array}{c}4.4 \\
(0.6-33)\end{array}$ \\
\hline sub abuse & 385 & 26 & 17 & 9 & 4 & 5 & 406 & $(2.5$ \\
\hline any diag. & 580 & 39 & 40 & 22 & 10 & - & 15 & $\left.(1)^{2.3}-3.3\right)$ \\
\hline
\end{tabular}

Again, black prisoners in the sample have a lower rate of most disorders but a higher rate of psychosis, four percent compared to two percent. As with the women, the 95\% confidence interval for the population odds ratio includes 1.0 at its extreme.

If male and female prisoners are combined for a comparison of the prevalence of psychosis in white and black inmates, the rates are $1.7 \%$ in white and $4.2 \%$ in black inmates. The black:white odds ratio is 2.6 , the $95 \%$ confidence interval being 1.2 to 5.6 . For the same comparison, $\mathrm{Chi}^{2}=5.15$ (using Yate's correction) and $\mathrm{p}<.04$.

\section{Discussion}

These findings may be due to nothing more than chance. However, the figures are consistent with the possibility that black inmates, both female and male combined, have a lower prevalence of most psychiatric disorders but a higher prevalence of psychosis.

In addition to the possibility that this is a chance finding, three possible explanations suggest themselves:

i. Misidentification of psychosis in black inmates. It has been suggested that psychiatrists may label the normal behaviour of some black people as psychosis. There is little evidence to support this explanation in relation to most studies of psychosis and ethnic origin, which have used standardised assessments of mental state. In the present study, diagnosis was heavily dependent on the psychiatrist's clinical interpretation, so this 
explanation cannot be discounted. The case histories above do not suggest that any of the women given a diagnosis of psychosis had a very short-lived or atypical disorder.

\section{ii. A higher rate of psychosis in the black population of England and Wales. Although} controversial, there is an accumulating body of evidence to support this proposition in respect of UK residents of Afro-Caribbean descent ${ }^{155}$ and some studies ${ }^{156}$ suggest rates of schizophrenia may differ by a factor of fourteen. This is not the place to document such evidence in detail. Psychosis in sentenced prisoners represents such a small proportion of psychosis in the community (see above) that, even if the population finding is valid, it is difficult to see it as a full explanation of the present results without reference to the filtering process interposed between the general population and the sentenced prison population.

iii. Differential access to psychiatric services. Informal and formal methods of diversion from the criminal justice system operate at various levels in the path from offence to prison sentence. The attitudes of both user and provider of services could operate at any of these levels to result in black mentally ill people being less likely to reach hospital than their white counterparts. Similarly, it has been suggested that the high number of black mentally ill people among those referred by the police under Section 136 of the Mental Health Act 1983 reflects a failure of other routes of access to mental health care ${ }^{157}$. Apart from possible racism, contributory factors include variation in the presentation of mental illness ${ }^{158}$, cultural attitudes to mental illness ${ }^{159}$, misdiagnosis by doctors in primary care $^{160}$ or an overdiagnosis by psychiatrists of cannabis psychosis in black patients ${ }^{161}$.

These three explanations are not mutually exclusive and elements of each may be important. The present study provides no estimate of their relative importance, if any, and indicates only that there is a need for more information about the ethnic origin of sentenced female and male prisoners suffering from psychosis. Most psychotic inmates had been identified by prison doctors and it would be a relatively straightforward task to monitor the ethnic origin of this small group.

\section{Summary}

The prevalence of psychiatric disorder in women serving a prison sentence has been shown to be broadly in accord with previous surveys of sentenced prisoners, with 
relatively low levels of psychosis and high rates of neurosis, personality disorder and substance abuse. Women from overseas have a different pattern of disorder, confined to a high rate of neurotic disorders. The pattern of psychiatric disorder in sentenced women resembles that in sentenced men but the findings suggest that population rates of mental handicap, neurotic disorder, personality disorder and substance abuse are higher in women serving a prison sentence. In all these categories, the absolute number of women serving a prison sentence is far lower than the corresponding number of men. Women in particular diagnostic categories have been described in more detail and possible explanations of the differences between the male and female populations have been suggested.

The relationship between ethnic origin and psychiatric diagnosis has been described. Most of the results did not reach statistical signficance but trends in the data emphasise the need for more information about the ethnic origin of mentally disordered prisoners.

The following chapter describes the factors which determine the prevalence of mental disorder in sentenced prisoners and reviews previous work on gender differences in the processing of mentally disordered offenders by the criminal justice system. The findings of the present study are placed in the context of this work and the implications for prison health services are discussed. 


\section{CHAPTER 6: CONCLUSIONS}

\section{Introduction}

The chapter begins with an account of the factors which determine the prevalence of mental disorder in offenders and sentenced prisoners, moving from a discussion of "normal" and "abnormal" offending to consider the processes designed to divert the mentally ill offender away from custody. This leads into a review of work on gender differences in the treatment of mentally disordered offenders. The findings of the present study are discussed in relation to this work and the chapter ends with an account of the implications of the findings for prison health services.

\section{Normal and Abnormal Offenders}

\section{Is offending by women abnormal?}

In a purely statistical sense, the answer to this question is "yes", as rates of offending and imprisonment are so much lower in women. It does not follow logically that female offenders are abnormal in the sense of showing disordered psychological functioning. However, it can be argued that the proportion of offenders who are mentally disordered will be higher in women by virtue of the rarity of "normal" offending.

The assumption is that a certain amount of offending is closely related to mental disorder and is determined partly by the prevalence of the disorder. A similar point is made by Coid in his account of variations in the rate of "normal" and "abnormal" homicide between countries ${ }^{162}$. The rate of homicide by mentally abnormal offenders is found to be relatively constant, despite considerable variation in the overall homicide rate. One consequence of this effect is that abnormal homicides account for a greater proportion of the total in populations with an overall low rate of homicide. A Danish study ${ }^{163}$ of a wider range of offences also found that the proportion of offenders who were mentally abnormal was inversely related to the prevalence of the offence in question.

These principles can be applied to offending by women. As overall rates of offending are so much lower than in men, then mentally abnormal offenders may be expected to account for a greater proportion of the total. The necessary assumption, of course, is that the mental disorder in question is related to offending.

One of the advantages of this model is that it depends only on women having a lower rate of offending; it does not make assumptions about the nature of women or female offending in general. Whilst relative proportions differ, "normal" female and male offenders may have much in common, as may "abnormal" female and male offenders. 
There is no suggestion that all female offenders are more psychologically disturbed than their male counterparts.

Some of the results of the present study fit very well into such a framework. It is reasonable to assume that drug dependence is related to offending and this diagnosis was found in a much higher proportion of women. Despite the difference in prevalence, female and male drug dependent prisoners had many characteristics in common. Finally, it was found that the actual number of women prisoners with a drug problem is less than the number of men; the male drug user in the community is more likely to find himself serving a prison sentence than is a similar woman. The best explanation is that drug dependence affects the size of the gender difference in the probability of imprisonment but it does not abolish it.

The same argument can be applied to personality disorder, where rates in prison also vary by gender in the opposite direction to that found outside prison. Again, it seems reasonable to assume that this diagnosis is related to offending.

In contrast, neurotic disorder appeared to have little relationship to offending and gender differences in prison were in line with rates in the community.

The case of psychosis and mental handicap is less straightforward. These diagnoses are likely to be related to "abnormal" offending and the case histories confirm this. Why are both diagnoses not much more prevalent in women in prison? It may well be that these disorders are more prevalent among female offenders but their prevalence in prison can only be understood by reference to the processes of medical surveillance and psychiatric "filtering" of offenders.

\section{The efficacy of medical surveillance and diversion.}

In Chapter 5 it was demonstrated that most of the women suffering from psychosis and mental handicap were mentally disordered offenders before they became mentally disordered prisoners. Only a minority of offenders ever become sentenced prisoners and an attempt was made to determine the reasons for an apparent failure of the system to shift these severely disordered offenders out of the penal system. It is now appropriate to consider the processes of psychiatric surveillance and diversion in more general terms.

Screening, filtering and monitoring processes exist to regulate the progress of some mentally disordered offenders through the criminal justice system ${ }^{164}$. These processes are formalised in the case of the Mental Health Act but they may also operate informally. For example, the police may decide not to arrest an offender who is obviously mentally disordered. 
The number of severely mentally disordered women in the sentenced prison population can be seen as a partial measure of the efficacy of the processes which are meant to divert them into hospital care. In the case of disorders for which diversion is less likely, then their prevalence in prisoners is more likely to reflect their prevalence in offenders, as seems to be the case for drug dependence and personality disorder in the present study.

The failure to find an increased rate of psychosis in women suggests that psychiatric surveillance and diversion may be operating more effectively in the case of female offenders. An increased rate of mental handicap was found and it was suggested in Chapter 5 that one of the factors contributing to this was, in fact, a local failure in procedures for transferring severely disordered prisoners to hospital. It is appropriate at this point to review evidence, from other sources, of gender differences in the processing of mentally abnormal offenders.

\section{Gender differences in the Treatment of the Mentally Disordered Offender.}

A detailed review of the rapidly expanding literature on female offending is beyond the scope of this thesis. D'Orban ${ }^{165}$ provides a useful review of the characteristics of female offenders and some theories which attempt to account for the differences from male offending; Morris ${ }^{166}$ includes more recent evidence and an overview of feminist critiques of traditional criminology.

The feminist perspective has encouraged an examination of the influence of gender within the criminal justice system. In part, this was a response to traditional notions of chivalry. Pollak, ${ }^{167}$ writing in 1950, argued that the apparent differences in the male and female crime rates resulted from a combination of female crime being more difficult to detect and a chivalrous legal system which was reluctant to prosecute and convict those female offenders who were detected. D'Orban ${ }^{168}$ found little evidence to support this view. Gender has an influence on the treatment of offenders at all stages of the criminal justice system but the effects are neither simple nor predictable and cannot be explained in terms of unitary concepts such as chivalry ${ }^{169,170}$.

The following review is restricted to work concerned with gender differences in the processing of the mentally disordered offender. The topic attracts considerable attention but there is a shortage of data.

Women appearing before the courts are roughly twice as likely as men to be dealt with by psychiatric means ${ }^{171}$. This is a stable finding; in 1961, psychiatric disposals accounted for $0.8 \%$ of all women convicted, compared to $0.5 \%$ of $\operatorname{men}^{172}$. Note that, 
despite the gender difference, a psychiatric disposal accounts for a tiny proportion of all cases appearing before the courts.

Edwards, ${ }^{173}$ in a book based on interviews with female defendants and criminal justice professionals, describes the way in which gender influences the operation of the criminal justice system at all stages. It is suggested that one aspect of this is that the criminality of women is more likely to be seen as an indicator of mental disorder deserving of treatment, although comparative information on male offenders is not provided.

A study of magistrates courts ${ }^{174}$ found that $9.3 \%$ of men and $7.1 \%$ of women were remanded for medical reports in Inner London, whilst the figures in Wessex were $4.3 \%$ of men and $5.5 \%$ of women. The similarity in overall rates masks other differences. For the Inner London courts, $6 \%$ of all male medical remands were for a sexual offence, compared to none of the female medical remands. Conversely, medical remands were imposed on $31 \%$ of all women charged with violent offences against property, compared to $15 \%$ of men facing a similar charge ${ }^{175}$. For indictable offences, hospital orders accounted for a greater proportion of male disposals and psychiatric probation orders a greater proportion of female disposals, although there was great variation with type of offence. The figures indicate complex qualitative and numerical differences between the treatment of men and women.

In order to elucidate these complex gender differences in the treatment of offenders by the courts, Allen ${ }^{176}$ examined the decision-making processes surrounding the trials of female and male defendants, selecting cases where psychiatric evidence was likely to be important. Her qualitative study was based on a sample of 24 female and 25 male homicides (selected at random), 11 male "domestic" homicides and 36 female and 33 male cases referred for psychiatric reports. The diversity of psychiatric disposals available to the court, and the flexibility of the rationales for their use, was found to allow ample scope for discretion and the operation of bias, including a sexual bias ${ }^{177}$. Most psychiatric disposals are made at the point of sentencing and this is where gender bias is most apparent, favouring a psychiatric disposal for the female offender.

Allen warns against any simple explanation in terms of a systematic tendency "...to psychiatrise female offenders per $\mathrm{se}{ }^{178}$. Instead, there is an interaction between "...a structure of medico-legal provisions and a structure of gendered understandings about the nature of human beings"179. She makes the point that existing medico-legal structures are "a hotch-potch of provisions", so it is hardly surprising that they produce anomalous and contradictory outcomes. For example, she found that sentencers tended to regard 
disorderly female offenders as less deranged than many disorderly males, which should mitigate against their psychiatric disposal, but the actual outcome was the opposite. Existing provision allows a psychiatric probation order irrespective of whether a diagnosis is made whilst "the fashionable preference for consensual and community based treatment actually makes it easier to offer medical treatment to those offenders who seem least disturbed"180. Conversely, the disordered male offender who is regarded as more disturbed faces two barriers to a psychiatric disposal. Greater weight is attached to moral and retributive factors in male cases, favouring punishment rather than treatment, and there is a grave shortage of facilities for the chronically and dangerously disordered offender.

Allen's work is based on a selected and non-representative sample but is quoted at some length because it is one of the few studies to look at how decisions on psychiatric disposal are reached. It stresses the complexity of the forces which impinge on these decisions and provides an alternative to simplistic accounts of the "psychiatrisation" of female offenders. Finally, Allen makes the point that the discrepancy between the treatment of female and male offenders can be seen in large part as a reluctance to recognise and treat equivalent mental disorder in male offenders.

Most of the other information about gender differences in the treatment of mentally disordered offenders is factual reporting, rather than an attempt to explain the processes involved.

From 1961 to 1985 , women were found to account for $16.4 \%$ of unrestricted and $11.5 \%$ of restricted hospital orders made by the courts, whilst the average proportion of women among those found guilty of an indictable offence during this period was $14 \%{ }^{181}$. Walker and $\mathrm{McCabe}^{182}$ point out that this ratio is "quite different from the sex-ratio for other compulsory admissions to mental hospitals, in which women slightly outnumber men". Women may be over-represented in unrestricted hospital orders made by the courts but women who receive compulsory psychiatric treatment are most likely to do so under "civil" Sections of the Mental Health Act.

Similar results emerge from a comparison of admissions to a London hospital under Section 136 and Section 4 of the Mental Health Act 1983, which found that women comprised $73(30 \%)$ of the 240 Section 136 admissions and $50(55 \%)$ of the 91 Section 4 admissions $^{183}$. Women were significantly less likely to be admitted under Section 136 , compared to Section 4 , the odds ratio being 0.4 , with a $95 \%$ confidence interval of 0.2 to 0.6 . 
Of the 286 individuals found unfit to plead in the period 1976 to $1988,12 \%$ were female, a figure which corresponds quite closely to the proportion of women (14\%) appearing before the crown courts in this period ${ }^{184}$. There is no evidence that women are more likely to be subject to this rare form of psychiatric disposal.

In a survey of transfers of sentenced prisoners to a special hospital between 1960 and 1983 , Grounds ${ }^{185}$ found that the ratio of men to women was $14: 1$, whereas the corresponding ratio in the adult sentenced prison population was 31:1. Even at this late stage of the criminal justice system, women remain more likely to be diverted into psychiatric facilities. This finding, together with the statistical over-representation of women in special hospitals compared to prison, has given rise to concern that female offenders are being labelled unfairly as psychiatrically disturbed ${ }^{186}$.

Quite apart from specific factors that may lead to women being more likely to receive a psychiatric disposal, the relative size of the task of psychiatric surveillance in female and male prisoners may influence the outcome of the process.

The Prison Medical Service in 1988 dealt with over 78,000 receptions of sentenced men, compared to 3,700 receptions of sentenced women ${ }^{187}$. The men were distributed to over one hundred prisons whereas the women were confined to eight. The psychiatric surveillance of the female prison population is a less daunting proposition. Given the tendency of medicine to locate women "at the centre of the professional gaze ${ }^{188 "}$ and to look more closely for psychiatric disorder, it is not surprising that this task is, in fact, accomplished more efficiently. The absolute number of mentally disordered men is higher but their immersion in a mass of "normal" offenders makes surveillance more difficult.

The greater number of disordered men also has implications for any attempt to achieve transfer to hospital. The figures given in Chapter Five suggest that, if all sentenced women suffering from psychosis were to be transferred to the health service, they could be comfortably accommodated in a single hospital ward. A similar process in the male sentenced population would require around 700 beds, a different order of magnitude.

Prisoners with a severe mental disorder are inappropriately placed in the nonmedical setting of prison. They represent a failure of existing systems. Fewer women than men appear to be victims of this failure. Does a similar picture emerge of gender differences in the prevalence of severe mental disorder in other non-medical settings? 


\section{Mental disorder outside medical settings.}

A area of current interest in the epidemiology of schizophrenia is the problem of case-finding ${ }^{189}$. The WHO Collaborative Study on Determinants and Outcome looked for cases in religious agencies, social welfare offices and jails, in addition to medical treatment settings ${ }^{190}$. It has been suggested that this may result in a net increment of $10 \%$ to $20 \%$ of cases ${ }^{191}$, implying a recognition that some cases of schizophrenia will remain outside mental health treatment systems.

Apart from theoretical problems in estimating the incidence of schizophrenia, there are implications for medical audit and the monitoring of community care. A full account of the effectiveness of care depends on knowing how many potential psychiatric patients are living in unsatisfactory settings where they do not receive adequate treatment. The proposition that some of these cases will be found in the criminal justice system and jail populations has received limited support ${ }^{192}$. As noted in the previous chapter, the results of the present study suggest that only a tiny proportion of women suffering from psychosis are to be found within the sentenced prison population. Prison makes a very minor contribution to the accommodation of women suffering from schizophrenia and similar disorders.

This observation must be qualified by the fact that there is no adequate study of the prevalence of psychiatric disorder in the female remand population. Gibbens' work $^{193}$ was never completed and is now out of date, yet no similar study has been carried out in the 24 years that have elapsed since his data were collected. A survey of men in a remand prison found psychosis in $9 \%{ }^{194}$ and the female remand population may represent a reservoir of psychiatric illness of unknown size.

There are some studies of mental illness in other non-treatment settings and they reveal women to be in a minority. Two hostels for the homeless in Oxford were found to contain 48 seriously mentally disordered residents (out of a total of 146) but only four were women ${ }^{195}$. The total proportion of female residents is not reported.

An American study ${ }^{196}$ of seventy-eight residents of an emergency shelter found that only $13(17 \%)$ were female, although 11 of these women had a major mental illness.

It may be that women with serious mental disorder are less likely than men to be excluded from existing treatment provision - perhaps because they are less likely to offend, or to offend violently. Carlen ${ }^{197}$ has made the opposite point, suggesting that homelessness is likely to be a particular problem for the female mentally disordered offender, although she presents no data to demonstrate this. In fact, some of the figures in her book appear to contradict this assertion; NACRO, the major providers of 
accommodation for ex-offenders, reported that $38 \%$ of their residents in 1987-8 were female, a far higher proportion than in offender populations as a whole ${ }^{198}$.

\section{The implications for prison health services}

The implications of the study will be considered in more detail below, according to the type of medical disorder. The theme which runs through these specific recommendations is that the health care of prisoners would benefit from closer links between prison medical services and the National Health Service.

The House of Commons Social Services Committee ${ }^{199}$ argued for a merger of the two services but this was opposed by the then Director of the Prison Medical Service. More recently, an efficiency scrutiny ${ }^{200}$ recommended that the Prison Medical Service become a "Prison Health Service", whose role would be as a purchaser of services for prisoners, the main providers being NHS doctors contracted-in from outside hospitals.

The principle, that the same doctors who provide care outside prison should also treat prisoners, is to be welcomed but many important practical questions remain unanswered. For present purposes, the most important of these questions concerns funding arrangements for mentally disordered prisoners who may require transfer to outside hospitals. The findings above suggest that most severely disordered, sentenced prisoners have been identified but rejected by the NHS. Under present arrangements, a mentally disordered prisoner costs her district or region nothing until transferred from prison to hospital. The system contains a disincentive to transfer patients and, as the internal market within the health service develops, doctors and managers will be forced to become more aware of the financial implications of transferring a prisoner. These pressures encourage those concerned to delay rather than expedite the transfer. It remains to be seen whether the principle of "money following the patient" can be applied to create financial incentives for an efficient system of transferring those mentally disordered prisoners who are too ill to be looked after in prison.

Whilst mentally disordered people remain in prison, either awaiting transfer or because their disorder is not severe enough to warrant transfer, closer links with the NHS should help to improve the quality of their care. In one important respect, the use of trained nurses, prisons for women are closer to the standards of the NHS and provide a model which male prisons should follow.

Specific implications of the findings will now be considered, according to the type of disorder involved. 


\section{i. Severe mental disorder.}

This heading may encompass several diagnostic categories, including psychosis, mental handicap, severe personality disorder and neurotic disorder. The common factor is that adequate treatment may require transfer out of prison to hospital. The findings of the present study and the arguments presented above suggest that this type of problem will be encountered in a greater proportion of female offenders and prisoners than in men. To this extent, the prevalence of severe mental disorder is seen to justify the closer psychiatric surveillance of the female prison population described ny Sim. There is evidence of the effects of this process in, for example, the relative over-representation of women in prison transfers, as described by Grounds.

Despite closer scrutiny, the present study found that some forms of severe mental disorder remained significantly more common in female prisoners and a small number of women were being held in unsuitable conditions, with psychiatric needs that could only be met by transfer to hospital.

It has been argued that this finding reflected the peculiarities of one institution but it emphasises the fragility of those mechanisms which limit the number of mentally ill women in prison. Given the reluctance of many parts of the health service to accept difficult patients, irrespective of gender ${ }^{201}$, it becomes doubly important that doctors working in prison explore all possibilities for transfer. The problem is exacerbated by the nature of the Prison Medical Service, the professional isolation of its doctors and the lack of integration of with the National Health Service ${ }^{202}$.

Of course, these problems are shared by male prisons and planned reforms of prison health services ${ }^{203}$ may offer a partial solution. Over and above these organisational issues, there remain questions which the psychiatric profession must address. One concerns the quality of reports and the maintenance of adequate professional standards. A doctor's actions in preparing a report may have dramatic and long-lasting consequences for the offender-patient yet the process of obtaining reports seems haphazard. A first step in establishing standards would be to insist that psychiatric reports are prepared by a doctor with a psychiatric qualification, which is not always the case under existing arrangements.

If this measure were adopted, there would still be a responsibility on the profession to ensure adequate training in the preparation of reports and to ensure continuing audit of their quality. During the course of the study, I saw many reports that contained strong elements of censure and calls for punishment, including active opposition to programs of treatment offered by other doctors. Legislation giving patients access to their health 
records came into force in November 1991 and applies equally to medical records within prisons. This may moderate some of the worst excesses and will presumably open the way for offender-patients to sue doctors whose reports fail to meet reasonable standards. The Royal College of Psychiatrists must also address the training and ethical issues involved in this area, where an individual doctor can exercise enormous power with very limited accountability. Psychiatric reports provide ideal material for medical audit, as they summarise an assessment within a short document.

One of the messages of the present study is that severely mentally disordered prisoners, whether male or female, share many characteristics that make them difficult to place in the health service. The smaller number of women involved, little more than a handful, means that it should be possible to achieve their transfer from prison to hospital within the existing framework of services and without any increase in health service provision. The question is one of efficiency, rather than a requirement for structural change. As with reports, this provides ideal material for medical audit, especially as outcome measures (e.g. delay in assessment, delay in transfer) are easy to derive.

Finally, the possibility that black people are over-represented among prisoners suffering from psychosis is a cause for concern and requires further investigation. It would be a relatively simple matter for prison doctors to monitor the ethnic origin of those inmates who are known to suffer from psychosis.

\section{ii. Personality disorder.}

The problem of diagnosis has already been discussed. Studies of prison populations find consistently high levels of personality disorder, precise rates being determined by the criteria used.

The female and male prison systems differ in their provision for the treatment of personality disordered inmates. Psychiatric surveillance of the female population may be more intensive but treatment provision for personality disordered inmates is better developed for men. HMP Grendon and the Wormwood Scrubs annexe provide treatment in a therapeutic community setting and Glen Parva has a similar facility for male young offenders. The first two facilities are described by Gunn et $\mathrm{al}^{204}$ and Genders and Player $^{205}$ provide a more recent account of Grendon. The number of places available does not meet the needs of the sentenced male population but the situation is worse for female prisoners, who have no access to this form of treatment.

Many women with a personality disorder receive adequate treatment within prison, including counselling, psychotherapy or other psychological interventions. If this is 
insufficient, the only alternative is hospital transfer. As treatment for personality disorder is poorly developed in the health service, this will often mean transfer to a special hospital. This situation has a number of disadvantages. Many women who could benefit from this type of treatment, whether for problems of self-mutilation or substance abuse, are unable to receive it. The minority who are transferred become liable to detention under the Mental Health Act which may extend beyond their date of release, giving rise to concern about unnecessary restrictions on their liberty ${ }^{206}$. Both these problems would be reduced by the provision of a therapeutic community within the female prison system. The small size of the female prison population means that this could probably be accomplished in a small, specialised unit within an existing prison. The failure of an experiment with a "psychiatric prison" (see Chapter One) does not mean that there is no demand for this type of treatment facility among a selected minority of women.

The mistake in the past has been to infer from high prevalence rates of personality disorder that all female prisoners are more disordered than their male counterparts. There has also been a tendency to dismiss personality disorder as a homogeneous entity, failing to recognise the range of problems subsumed under this unsatisfactory label. The findings reported above emphasise this diversity, showing personality disorder to be associated with psychosis, learning difficulties, serious violence, chronic neurotic symptoms and selfharm. No single treatment or service can be an adequate response and the challenge now is to provide a range of services for selected offender-patients with personality disorder, both in and out of prison.

\section{iii. Neurotic disorder.}

The main implication of the high level of neurotic disorder is the need for medical services in prison to provide easy access to assessment and treatment, including psychotherapy and counselling, for women suffering from minor affective disorders who are deprived of many of their usual social supports. The findings suggest a pro rata level of demand roughly twice that in the male prison population.

To some extent, womens' prisons have addressed this problem by using trained nurses as hospital officers. There was great praise for the supportive function of nursing staff at some of the prisons visited and this is a practice that could usefully be extended to male prisons.

Foreign drug couriers have a particular treatment need in this area which may require the services of voluntary agencies who can provide support and overcome cultural and language barriers. 


\section{iv. Substance abuse.}

In qualitative terms, the relationship between offending and substance abuse appears to be similar in the male and female prison populations. Drug dependence, predominantly on heroin, is associated with recidivist, acquisitive offending but not with some measures of social and psychological problems. By contrast, problem drinking shows an association with measures of psychological disturbance and social disadvantage and with violent rather than acquisitive offending.

Both forms of substance abuse represent a challenge to treatment services. Drug dependence is the commonest diagnosis given to women in prison. It was felt that many of these women would benefit from treatment in a therapeutic community and many of the comments made under personality disorder would apply here also.

Recent initiatives have stressed the importance of liaison with services outside prison and HMP Holloway has now introduced a pilot treatment project which involves prison officers and outside agencies in group meetings with a self-help orientation. It is recognised that the amount of treatment which can be provided in prison is limited and the most useful function of intervention may be to raise awareness of the problem and put women into contact with treatment agencies which can support them after release.

\section{Summary}

As women offend at a much lower rate than men, women whose offending is associated with psychiatric disorder appear more prominent as they are not lost among a large number of "normal" offenders. In gender comparisons of prisoners, percentages may be misleading; invariably, the number of male prisoners with a particular psychiatric diagnosis far exceeds the number of female prisoners with the same diagnosis, partly because it is easier to operate a system of psychiatric surveillance and hospital transfer when the population is small. The evidence of the present study suggests that the system for detecting and treating mental disorder works more effectively in the case of female prisoners and leaves large numbers of men in prison when they should be transferred to hospital. The female system is not perfect and changes are suggested to reduce further the number of mentally disordered women in prison. These include closer links between prison health services and the National Health Service, audit of psychiatric reports and transfer procedures and changes in the funding of care for offender-patients. Services within prisons should be developed to cater for those women whose problems do not warrant hospital transfer. 


\section{APPENDIX A: CODING MANUAL}

In these notes $\mathbf{S}=$ subject and page numbers refer to those used in Appendix $\mathrm{C}$.

\section{PAGE 1}

\section{Research Number}

Assigned before interview; arbitrary.

\section{Prison}

As per list of codes (not included).

\section{Interview Date}

For refusers, code date of attempt.

\section{PAGE 2}

\section{Birth Date}

As recorded in prison file; check later with interviewee.

\section{Address (Region)}

Code from table of health regions and additional list of other countries. Use address given in prison file. Unknown $=99$ but this should be avoided where possible; those of no fixed abode remain the responsibility of a health region and will be coded elsewhere as No Fixed Abode.

\section{Occupation}

Use occupation as stated in prison file to derive rough measure of social class. Registrar General's categories are combined as follows: Unemployed $=0,1 \& 2=1,3,4 \& 5=2$.

\section{Sex}

Coding specified on questionnaire

\section{Offence}

\section{a. Home Office \\ b. Special Hospital}

To be coded according to both systems; see separate tables (not included). Use offence recorded in prison file, supplemented by any written account in the file in doubtful cases. If multiple offences, code that which seems most representative eg. a minor assault on police during arrest for burglary should be coded as burglary. If in doubt, code the more serious offence. Additional offences not coded should be recorded in writing. Offences not coded here will appear on the Criminal Profile.

Additional code: if drugs offence (Home Office code 52) use Special Hospital code is 21 if cannabis offence only, 20 for other drugs. 


\section{Sentence Date}

As recorded in prison file

\section{Type of Sentence}

Life \& determinate are the alternatives. If life, then length of sentence, LDR and EDR are coded as 9's.

\section{Length of Sentence(mths)}

As recorded in file. Note total length of time to be served, ignoring concurrent sentences.

Suspended parts of sentences are not recorded

\section{Earliest Date of Release (EDR)}

\section{Latest Date of Release (LDR)}

As recorded in file.

\section{Lost Remission}

Record total number of days of remission lost during this sentence, as recorded in file. Take a note of reasons for loss of remission.

No. of Prisons since sentence.

Record total number of prisons in which subject has been held since date of sentence, as specified in the file. Note reasons for frequent transfers.

\section{PAGE 3}

\section{1st Conviction Age}

Record age at first conviction as in CRO sheet when available. If not available, use other information in prison file eg. Social Enquiry Reports or a clear statement that this is the subject's first conviction. Unknown is coded 99 but ask at interview when appropriate and code the answer if no more reliable source of information is available.

\section{In Care \& Children's Homes}

Code 1 on each of these items only if significant periods of time have been involved i.e. greater than three months. Code initially from social enquiry or other reports when available then check information at interview.

\section{Disciplinary Offences in past 3 months}

Code number of offences as recorded in prison file. Note details if relevant.

\section{Control Problem}

Code 1 if identified by Governor or other prison staff and recorded in the file under "warnings and precautions". High escape potential alone is often recorded but would not warrant coding here. 


\section{Disciplinary Transfer}

Code 1 if inmate has ever been transferred for disciplinary reasons, as recorded in file (includes transfer after absconding from prison).

\section{Offence details}

\section{Personal History}

\section{Behaviour in Prison}

Use this section of the questionnaire to record any useful information contained in the prison file or other records. Not coded here, this is an aide memoire for the later interview and may assist in making a diagnosis after interview.

\section{PAGE 4}

\section{Date of birth}

Check with date from file.

\section{Location}

Codes specified on questionnaire. Location of the prisoner will usually be obvious from place of interview. Establish and note reasons for special location. Code 5 (Rule 43/own protection) when subject is being segregated from prisoners on normal location for his own protection even when the particular prison is carrying this out without using the provisions of Rule $43 \mathrm{eg}$. in "vulnerable prisoner units". Additional code for women: Mother and Baby Unit $=7$.

\section{People in cell}

Record number, including subject. $9=$ unknown (usually only used when interview has been refused) and $8=$ eight or more people when location is a large dormitory.

\section{Place of birth}

Codes specified on questionnaire

\section{Ethnic Origin}

Code from prison file if information is available and confirm with interviewee.

\section{Schooling Age}

Record age at which full-time education ended.

\section{School Type}

If in doubt, code one school only, choosing the most significant in terms of likely mental disorder ie any type of special school, even if most of time was spent in a normal school 


\section{Qualifications}

Include any gained as adult or in prison

\section{PAGE 5}

\section{Marital Status}

Codes specified on questionnaire

\section{Housing}

Codes specified on questionnaire

\section{Employment}

This rating is based on the subject's account (in contrast to that from the prison file on Page 2). Unemployed $=0$ and should indicate $S$ regards self as unemployed and is signing-on. Crime does not count as employment.

\section{Social Class}

Use condensed form of Reg. Gen's categories: $1 \& 2=1,34 \& 5=2$. As for employment, rating here is based on subject's own account.

\section{Contact with relatives and friends}

Ask if in contact with anyone outside prison, whether anyone visits or writes regularly. "Professional" visitors, eg. Probation officer, do not count.

\section{PAGE 6}

\section{Medical screening questions}

Code answers after establishing that question has been satisfactorily understood. Use space at foot of page to record dates of illness, place and nature of treatment and any current difficulties.

Most of coding is straightforward but following should be noted:

\section{Hepatitis}

Ask about type and for type B ask about how acquired, particularly whether there is a history of injecting illicit drugs.

\section{Diabetes}

Code positive only when it requires treatment (insulin or tablets) other than diet alone.

\section{Hearing Problem}

To be coded, problem must be sufficient to cause significant handicap in everyday life or require a hearing aid. 
STD

Record any history of treatment for sexually transmitted diseases. No questions are asked about HIV but if it emerges in the course of the interview or from the prison file that subject is HIV+, code as 2 under "other medical or surgical problems".

Psychiatric Code 1 if subject reports any problem for which medical help has been sought or given. Details to be included in later section, which could be completed at this point if it seems appropriate to ask further questions now.

\section{PAGE 7}

\section{Drink Problem}

Disregard flippant answers; otherwise, code all self-reports of drink problems, at any time.

Elicit details (see below)

\section{Offence Drinking}

Code if $S$ had been drinking in few hours before offence, unless amount is felt to be trivial (this will partly depend on S's view and usual level of consumption). Elicit and record further details of likely role of alcohol in the offence

If answer to either question is positive, go on to take an alcohol history and code the following items. With the exception of "Seen doctor about drinking", all are coded with reference to reported drinking in the six months preceding the index offence

\section{Seen Doctor}

Code 1 if inmate has consulted a doctor at any time about his drinking

\section{Daily Drinking}

Coded according to response to questions "did you ever go a day without drinking?" or "did you drink every day?", if necessary adding the proviso "when you had the money to do so".

\section{Morning Shakes}

\section{Relief Drinking}

\section{Blackouts}

For a coding of 1 , these symptoms must be reported on more than one occasion in the six months preceding the offence.

\section{Drunken Violence}

"Do you get into fights when you have been drinking?" Code 1 if this is reported on more than one occasion. 


\section{Stolen for Drink}

Coded according to response to question "did you ever steal specifically in order to get drink" i.e. if inmate sees drink as a specific motivating factor. Do not code if subject reports financing all spending by theft but drink is only incidental. Again, coding refers to six month period before offence only.

\section{Overall Drink Rating}

"Problem drinking" denotes consumption clearly in excess of Royal College guidelines which is felt by subject to have caused significant physical, psychological or social problems; this would include subject's view that alcohol had contributed to offending behaviour. Excess consumption alone would not be coded if subject felt it caused no problems; however, it should be noted elsewhere if felt by interviewer to be highly excessive.

\section{"Probable alcohol dependency" and "Definite Dependency":}

Based on Edwards ${ }^{207}$ criteria for the alcohol dependence syndrome i.e. salience of drink-seeking behaviour; increased tolerance; repeated withdrawal symptoms; subjective awareness of the compulsion to drink; reinstatement after abstinence; narrowing of drinking repertoire; stereotyped drinking style.

"Probable dependency" should be used when in doubt about a firm diagnosis. All drinking histories will be retrospective, sometimes by months or years so a degree of uncertainty in diagnosis is to be expected. Reported daily drinking is essential and symptoms must be present on a number of occasions. If in doubt about presence of symptoms of dependency, code as "Problem drinking".

"Definite Dependency" requires a high degree of certainty about the presence of symptoms; on withdrawal when entering custody, inmate should report severe shakes, DT's or preventative treatment with medication.

Note that this rating refers to the six months prior to index offence; past experience of dependency should not be coded here but would feature under past psychiatric history.

\section{PAGE 8}

\section{Gambling}

\section{Video Games}

Coding here indicates that interviewee reports gambling on average at least once a week when last at liberty to do so.

\section{Gambling Problem}


Simply a screening question, a lead in to a fuller history of gambling behaviour; code response unless flippant. Question may be clarified to ask about financial problems, crime or family difficulties which subject sees as being caused by gambling. Elicit further details to allow a more accurate rating to be made.

\section{Compulsive Gambling}

Subject must feel that his gambling has got out of control, that he has been unable to stop even though he wanted to.

\section{Wants Help}

Would accept help if offered now

\section{Sought Help}

Code if subject reports he has tried to get help specifically in order to reduce gambling via Probation service, doctor, social worker or Gamblers Anonymous. Receiving such help within prison would also count. Elicit and record as many details as possible.

\section{Overall Gambling Rating}

A rating of 1 ("heavy gambling") indicates that subject gambles "every day or on most days, finances permitting". Interviewer may suspect that it causes problems for $\mathbf{S}$ but $\mathbf{S}$ denies this.

A rating of 2 ("Heavy gambling causing significant financial, family or personal problems") requires that subject and interviewer agree that heavy gambling has caused significant problems. Interviewer should use DSM-III-R criteria for Pathological Gambling" to decide this i.e.

"Maladaptive gambling behaviour, as indicated by at least four of the following:

(1) frequent preoccupation with gambling or with obtaining money to gamble

(2) frequent gambling of larger amounts of money or over a longer period of time than intended

(3) a need to increase the size or frequency of bets to achieve the desired excitement

(4) restlessness or irritability if unable to gamble

(5) repeated loss of money by gambling and returning another day to win back losses

(6) repeated efforts to reduce or stop gambling

(7) frequent gambling when expected to meet social or occupational obligations

(8) sacrifice of some important social, occupational or recreational activity in order to gamble

(9) continuation of gambling despite inability to pay mounting debts, or despite other significant social, occupational or legal problems that the person knows to be exacerbated by gambling ${ }^{208}$. 


\section{PAGE 9}

\section{Illegal Drugs}

Screening question; if response is no, ask about cannabis if appropriate (i.e. in younger subjects) as some may not regard this as a drug. If response is yes, ask about specific drugs and pattern of use. Mention names of all drugs on list, using alternative and street names if their is any question of a problem in comprehension. Rating of 1 or 2 should be used to distinguish frequency of use (criteria on questionnaire). Drug use less frequent than once a month on average would not be coded. Elicit fuller history if any drug is used regularly; note length of abuse, how funded and relationship to offending.

\section{Injected Drugs}

Code 1 if subject has injected self in six months prior to offence. Elicit and record further details; code "addiction" below.

\section{Drugs in Prison}

False negatives are to be expected; do not jeopardise relationship with inmate by pursuing this topic.

\section{Addiction}

Cannabis is excluded when considering this code. Otherwise, the all three of the following criteria must be fulfilled before coding 1: daily use of drug concerned throughout the sixmonths prior to the index offence, symptoms of withdrawal on entering custody and the inmate regards him/herself as having been drug-dependent at the time of the offence.

When inmate is coded positive for "Addiction", record full details of past attempts at treatment (code under psychiatric history, Page 12) and ask about how drug use was financed, if inmate is willing to discuss this. Also ask about current attitude towards treatment and past experience of treatment, if any. When asking about attitude to treatment, stress that this is not prescribing i.e. it is treatment aimed at remaining abstinent, rather than substituting one drug for another.

\section{PAGE 11}

\section{Self-harm}

Coding on the questionnaire is mostly self-explanatory. Assessment of suicidal intent should be by as in a normal clinical interview i.e. to determine the extent to which the inmate believed his behaviour would lead to his life being ended. It is accepted that such judgements may be difficult, especially when the attempt was in the distant past. Many subjects will be coded "possible". However, it should be possible to identify habitual cutters (code 0 ) and a minority who have made very serious attempts (2). In doubt, code 
down. Record details. Also, note institutional response to self-harm. Code the most serious attempt i.e. single serious attempt in habitual cutter is coded 2 and notes made.

\section{PAGE 12}

\section{Seen psychiatrist before coming in to prison?}

If reports only, code as 1 and make appropriate notes. Child Guidance alone would be coded 3. Treatment or assessment by a psychologist should be coded as if it were by a psychiatrist; the distinction is not likely to be reliable. Treatment for drug and alcohol problems should be coded here also, even if not provided in a medical setting e.g. residence in a therapeutic community such as Phoenix House would be coded as inpatient treatment. Length of treatment should be noted but is not coded i.e. a single outpatient appointment for assessment is coded 1, a single night's stay is coded 2. Record as many details as possible, particularly for in-patients (date of discharge is very important)

\section{Discharge within 6 months}

To be used flexibly to indicate recent discharge and possibly help to define a group of chronic patients who cannot cope outside institutions. Note details.

\section{PAGE 13}

\section{Seen psychiatrist during this sentence}

"At own request" is to be used fairly loosely but should indicate that $\mathrm{S}$ or someone within the prison felt there was a current psychiatric problem i.e. not just for routine reports or because of the nature of the offence (both coded as 1). Self-harm leading to psychiatric assessment would be coded 2 .

\section{Outcome}

3 would include referral for transfer to prison hospital or psychiatric facility e.g. Grendon, C wing

\section{Treatment by others}

Includes attendance at drug and alcohol groups run by non-medical staff. AA would be coded 3.

\section{Do you feel you need any help?}

Use in the widest sense; S may not regard his problem as appropriate for prison medicine. Refer to "ideal world" i.e. if good quality, confidential and non-stigmatizing help were available from someone independent of the institution. Many people will say they do not want help because they do not believe it to be available or assume it would have negative consequences e.g. for parole. A subsidiary question should be whether there is any service 
subject feels the Prison Medical Service should be providing for him and is failing to do so.

Have you had any medical treatments in prison or been given drugs or medicines by a doctor?

Intended to describe past treatment in prison, during current sentence or on remand prior to this sentence. Record subject's answers but check as much as possible in prison medical record before coding. Code even very brief treatments e.g. single dose of neuroleptic medication would be coded as 1 .

Individual and group psychotherapy refers to treatment which involves a psychotherapist.

Psychological treatments refer to individual counselling, anger management etc.

Non-professional support includes attendance at drug and alcohol groups run by nonmedical staff or AA. Are you currently having any medical treatments?

\section{PAGE 14}

\section{Are you currently having any medical treatments?}

Current treatments would be coded here only i.e. not also under past treatments, even if they have been continuing for many years. Similar definitions apply.

\section{How long were you in prison before being seen by a psychiatrist?}

Self-explanatory. Note details, especially reasons for any long delay reported by the inmate. Check with prison medical record.

Were you satisfied with the treatment you received?

The coded answer is less important than recording the details of reasons for dissatisfaction and any complaints about treatment. Try to establish what the inmate would have liked rather than simply a negative account of what was wrong with what he actually got. Complaints may concern the setting as much as the actual treatment. Also note comments on any treatment received on remand e.g. for drug withdrawal.

\section{PAGE 16 - 20}

Clinical Interview Schedule (CIS) - complete according to instruction manual and training. 


\section{PAGE 21}

\section{Reading age}

Use Schonnell reading test if there is any suspicion that subject has learning difficulties. Aim of test is to exclude learning difficulties; instructions are provided with the test.

PAGE 22 -23

\section{Criminal Profile.}

Definitions for most ratings are contained on the Questionnaire. Complete from CRO data only for most subjects. In addition, use can routinely be made of written reports (e.g. SER) in prison file. Only ask subject about his criminality when it seems necessary to clear up some ambiguity and when it seems possible to do so without causing offence. The survey is not primarily concerned with criminality and this type of question should not be allowed to jeopardise the interviewer's relationship with the subject.

Whilst most ratings can be made from criteria on questionnaire, the following guidelines were also used:

Theft

"Substantial gains by stealing" implies a likely profit of more than $£ 10,000$

\section{Violence}

Use of firearms will normally lead to a rating of 4 whether or not they are fired. Rape should be regarded as a violent offence as well as a sexual one and will usually be rated under both sections.

\section{Number of previous sentences}

Record number of previous custodial sentences. $8=8$ or more sentences, $9=$ information not available. Remands, suspended sentences and fine defaults do not count but all other custodial sentences do (inc. borstal, D.C.).

Information normally available from CRO or elsewhere in prison file. Ask subject only if information is missing and of particular interest.

\section{PAGE 24}

To be completed for probable or possible "cases" only (criteria at top of page).

The emphasis here is on determining current requirements for treatment i.e. what treatment does $\mathrm{S}$ believe he needs and what would he be willing to accept? 
Do you want any form of psychiatric help at the moment?

Expand upon this for each subject by describing the likely form of treatment. Stress "ideal world" rather than what is available at present. If help not wanted, elicit and record reasons.

Do you think you'll try and get psychiatric help once you leave prison?

Again, record reasons for answer, particularly if help is not wanted in prison but will be sought outside.

\section{PAGE 26}

\section{Diagnosis and management}

Up to three diagnoses may be given, using ICD9 four-digit codes. In cases given more than one diagnosis, the first should be the most significant in terms of immediate treatment or management requirements. Psychotic illness should always be placed first. Add secondary and tertiary diagnoses when necessary i.e. when a description of the case would be incomplete without them.

The following ICD9 codes may be used frequently:

295.0 - 295.9 Schizophrenia.

296.0 - 296.9 Affective psychoses

300.0 - 300.9 Neurotic disorders

301.0 - 301.9 Personality disorders

303.0 Alcohol dependence syndrome

304.0 - 304.9 Drug dependence

305.0 - 305.9 Non-dependent abuse of drugs or alcohol

309.0 - 309.9 Adjustment reaction

The following four-digit codes, not contained in ICD9, are also to be used:

000.0 No diagnosis. To be used in place of diagnoses 1,2 or 3 as appropriate.

444.4 Significant psychiatric disorder at time of offence but no longer present. Appropriate ICD9 code to identify the past disorder should follow on next line as diagnosis 2 . (NB This does not apply to cases of alcohol and drug dependence; in 
the absence of the substances concerned these must always be "past" diagnoses but they are to be coded as present diagnoses in the normal way.)

666.6 Indicates that possible of significant psychiatric disorder. It is anticipated that this will mainly apply to people who have committed bizarre or unusual crimes but lack clear symptoms of mental disorder or are believed to be concealing evidence of disorder. This category should be used only when there is good circumstantial evidence to suspect disorder and all methods of obtaining the information necessary to make a decision have been explored without success. Implies need for further assessment by prison doctor.

888.8 Indicates good evidence of some form of psychiatric disorder but specific diagnosis is in doubt. "Best guess" diagnosis should then be coded as diagnosis 2 and reasons for uncertainty recorded.

999.9 Used in place of diagnosis 1, this indicates that data collection was not completed, usually because the inmate refused to be interviewed or terminated the interview before the end. In this case complete as much of the data sheet as possible from available information. In exceptional circumstances, available information may indicate that a psychiatric diagnosis is highly probable. If this is thought to be significant, record the information and code the likely diagnosis under diagnosis 2 . Otherwise, code all diagnoses as 9999.

\section{For diagnosis of personality disorder:}

Use all available information to attempt to make a classification under the scheme detailed in DSM-III-R. This scheme allows a case to fall into more than one category; choose the single category that best fits the particular case. 


\section{Any role for prison psychiatric services?}

Judgement should be based on:

1. diagnosis

2. severity of symptoms and impairment of social function

3. attitude to treatment

4. previous treatment and response to treatment

These factors should be evaluated as if patient was being seen for assessment in a clinic. This should allow a judgement as to whether or not treatment is required and the likely nature of the treatment. Compare this assessment with treatment currently being given; are needs being fully met? At all stages, the reference standard must be the standard of care the patient could expect to receive were he being looked after by the health service.

\section{Nature of treatment?}

All available information is now used to decide ideal recommended future management for every inmate given a diagnosis. In the first instance, each case is to be considered by the authors. If the decision is difficult and in all cases where a recommendation for hospital transfer is likely, the case is to be referred to a formal meeting of the interdisciplinary research group.

Decisions about management should be based on current standards of optimal treatment, unconstrained by present availability of resources.

The six possible treatment recommendations are:

i. None. Automatically applied to subjects with no diagnosis, also given to those with a diagnosis but felt to be untreatable because of lack of motivation, unless the nature and degree of mental disorder was such as to require involuntary treatment under the Mental Health Act 1983.

ii. Treatment within prison. Treatment which an average General Practitioner or psychiatrist could provide on a mainly outpatient basis e.g. supportive psychotherapy and/or medication. A brief period of special supervision or admission to a prison "hospital" may be required but with the expectation that most of the sentence could be completed under the normal prison regime without undue risk to the health of the inmate or staff.

iii. Therapeutic Community. The type of contract-based regime found within the prison system at HMP Grendon and outside prison at the Henderson hospital and drug or alcohol rehabilitation centres. Allocation to this category does not require a judgement as to where 
the treatment is provided but does imply that the inmate is capable of entering into a therapeutic contract.

iv. Further Assessment. Where there is uncertainty over diagnosis, treatment or motivation, it is assumed that at least the initial stages of assessment would take place in prison, some cases requiring no more than a further interview. Outcome of assessment may range from no treatment to hospital transfer. This category was used only when there was a high degree of suspicion that mental disorder was present.

v. Hospital. Inpatient treatment outside the prison system, either within the NHS or a Special Hospital. Includes all cases needing involuntary treatment under MHA 1983 and inmates willing to accept treatment voluntarily but suffering from psychiatric disorder which cannot be managed adequately and safely in a prison setting.

\section{Need for liaison at end of sentence?}

Rate 1 when it is desirable that contact be made with the appropriate psychiatric service outside prison when the inmate is due for discharge. Again, use clinical criteria: if the inmate was discharging himself from hospital after a single night's stay and assessment, would you contact his local services? Patient's attitude to treatment must be taken into account.

\section{Severity of personality disorder}

Make a rating for all subjects given the diagnosis of personality disorder, according to the following criteria:

1. Mild.

Symptoms apparent but able to be contained on normal prison regime (possibly with psychiatric input). No evidence of major difficulties outside prison.

2. Moderate.

Evidence of difficulties within prison, requiring some form of special management or significant problems outside prison - personality difficulty appears to be a factor in offending less serious than 3 (below) or requires a degree of psychiatric care whilst continuing to function independently in the community.

\section{Severe.}

Severe behavioural problems in prison requiring containment within a special regime or evidence from outside prison that his personality disorder gives rise to life-threatening violence or impairs social functioning to such a degree that in-patient or residential care 
is frequently necessary. The type of patient who would be found in the special hospitals. 


\section{APPENDIX B: LIST OF PRISONS}

\section{Holloway Prison}

A closed remand and allocation centre, Holloway has an average daily sentenced population of around 120 women. Some are in transit, awaiting allocation to another prison, whilst others will serve most or all of their sentence here for various reasons:

a. Sentenced women provide the inmate work force of the prison.

b. The prison has good "hospital" facilities and holds sentenced women who need a high level of psychiatric care, particularly if efforts are being made to arrange transfer to an outside hospital.

c. It has a mother and baby unit

The original sample included 64 women in Holloway.

\section{Styal Prison}

A closed training prison which holds a general cross-section of women serving their sentences. It has full-time medical cover and regular visiting psychiatrists. Specialist units include a mother and baby unit, a "hospital" and a vulnerable prisoner unit unit.

The original sample included 120 women in Styal.

\section{Drake Hall}

An open training prison, representing the lowest level of security within the prison system. The "hospital" does not have a full-time medical officer but is staffed by nurses who provide a ready source of help and advice. Inmates would not be allocated to open conditions if known to be mentally disordered or to represent an escape risk. It is relatively common for inmates to abscond from open prisons, resulting in their return to a closed institution.

The original sample included 96 women in Drake Hall.

\section{Durham Prison H Wing}

A closed, high security wing for long-sentenced prisoners, situated within the perimeter of a male prison. It holds approximately 40 women and all female life prisoners spend the first part of their sentence here, usually around three years. Women who require a high level of security remain in Durham for longer periods as it is the only high security facility for women. At the time of my visit, the longest serving woman had been there for fifteen years. 
The small size and stable population present a number of problems. All work is provided on the wing and is limited in scope. Both staff and inmates commented on the claustrophobic atmosphere.

The "hospital" consisted of the top landing of the wing. There is a full time medical officer and regular sessions by a visiting psychiatrist. The nurses who are alway present in the "hospital" were seen by the inmates as helpful and sympathetic and, to some extent, independent of the disciplinary structure of the prison.

The original sample included 21 women in $\mathrm{H}$ Wing. 
DATA SHEET PAGE ONE

\section{APPENDIX C: DATA SHEET}

PRISON HEALTH SURVEY

Research No.

Name of Prison

Interview Date___

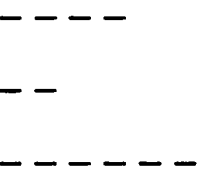

Name

Research No. 


\section{Information from Prison File}

Prison number

CRO Number

Date of Birth___

Last known address

Occupation

$\operatorname{Sex} M=1 \quad F=2$

Offence (Home Office Coding) (Special Hospitals Coding)

Date of sentence ___

Type of sentence Life $=0$ Det $=1$

Length of sentence (mths)

Earliest date of release

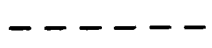

Latest date of release

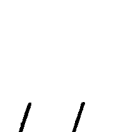

Lost remission (in days)

Number of prisons since sentence 
1st Conviction age

In Care

Childrens Homes

Disciplinary offences in past 3 months

Control Problem

Disciplinary Transfer

$\underline{\text { Record information from notes where relevant }}$

Offence details:

Personal History:

Behaviour in Prison: 


\section{Information from Interview}

Explain the purpose of visit, stressing the medical nature of the enquiry.

What is your date of birth? _ _ I

Which part of the prison are you in now? (If special location - note reasons for this)

$$
\begin{aligned}
& 1 \text { - Ordinary - cell } 2 \text { - Ordinary - dorm } \\
& 3 \text { - Hospital } 4 \text { - Segregation (GOAD) } \\
& 5 \text { - R } 43 \text { (own protection) } \\
& 6 \text { - Other (specify) }
\end{aligned}
$$

How many people are there in your cell or dormitory?

Before asking about medical problems, I would like to get some information about your past.

Where were you born?

$$
\begin{aligned}
& 1 \text { - UK } 2 \text { - Eire } \\
& 3 \text { - W.Africa 4-Caribbean } \\
& 5 \text { - Indian Subcontinent } \\
& 6 \text { - Other (Specify) }
\end{aligned}
$$

To which ethnic group do you see yourself as belonging?

1 - Caucasian 2 - Afro-Caribbean

$$
\text { 3-Asian } 4 \text { - Other (Specify) }
$$

How old were you when you stopped going to school regularly?

What type of school did you attend?

1 - Comprehensive/Sec modern 2 - Grammar or Public

3 - Learning difficulties/esn 4 - Approved or CHE

5 - Residential/Malad

Did you get qualifications or certificates? (Before or after leaving school)

$$
0 \text { - None } 1 \text { - CSE or RSA only }
$$

2 - 0 Level or City \& Guilds

3 - A Level and above 
Have you ever been married?

If yes, Were you living with your wife before coming into prison?

$1=$ Single (Never married)

2 = Married (Includes common law)

$3=$ Separated/Divorced

$4=$ Widowed (Other than 5 below)

$5=$ Killed Spouse

Where were you living (what type of accommodation were you in) at the time of the offence

$1=$ Own home or with own family

$2=$ Unsettled lodgings

(eg. squat, bed \& breakfast or hostel)

3 = NFA (Sleeping rough)

4 = Hospital

Do you have anywhere to stay when you get out of prison?

(Note answer and code as above)

$5=$ Nowhere to go/don't know

Were you working at the time of the offence or in regular employment during the previous 6 months?

Yes $=1 \quad$ No $=0$

If 'yes' type of work

Assessment of Social Class

$1=\mathrm{I} \&$ II $\quad 2=$ III IV \& V

Assessment of contact with relatives or friends outside prison: (Lead questions: anyone visits or writes and how often)

0 - No real contact with anyone on the outside

1 - A visit or letter about once every 6 months

2 - A visit or letter more frequently than (1) 
Have you ever had: $\quad$ Yes $=1 \quad$ No $=0$

TB?

Hepatitis?

Epilepsy?

Diabetes?

Other medical or surgical problems?

Problems with hearing?

Treatment for S.T.D.?

Any psychiatric or nervous problems?

Record medical diagnosis and treatment: 


\section{Alcohol \& Drugs}

Have you ever had a drink problem?

How much do you drink?

Had you been drinking before the present offence?

Then, if appropriate, ask about:-

Seen doctor about drinking

Daily drinking

Stolen for drink

Morning shakes

Morning relief drinking

Violence when drunk

Blackouts

$0=$ absent $\quad 1=$ present

(in six months prior to offence)

Interviewer's rating of drink problem (within 6 months of offence)

$0=$ No evidence of drink problem

1 = Evidence of problem drinking - not dependent

2 = Probable alcohol dependency

3 = Definite dependency 


\section{Gambling}

Do you gamble?

OR play video games regularly?

How much did you spend on it? (£/day)

Has it caused you any problems?

If there is evidence of problems related to gambling obtain details (type of gambling, how financed, frequency etc.)

Compulsive in nature?

Would like help?

Has sought help in past?

\section{Overall Rating}

$0=$ No gambling problem

$1=$ Heavy gambling, but not seen as problem

2 = Heavy gambling causing significant financial, family or personal problems 
Illicit Drug Use

Have you ever taken illegal drugs? (before or in prison)

$$
\begin{aligned}
& \text { Yes }=1 \quad \text { No }=0 \\
& \text { If 'yes' }
\end{aligned}
$$

Which of the following drugs did you use in the 6 months before you were arrested?

Code answers

$0=$ No

1 = Occasional (Less than 4 times per week)

$2=$ Frequent (Four or more times per week)

Cannabis

Heroin/Morphine or Methadone

Amphetamines

Barbiturates

Solvents

Cocaine

Have you ever injected drugs?

$0=$ Never $1=$ Yes

Have you ever used drugs since coming into prison?

Yes $=1 \quad$ No $=0$

Cannabis

Heroin/Morphine or Methadone

Amphetamines

Barbiturates

Solvents

Cocaine

Evidence of addiction?

$$
0=\text { No } 1=\text { Yes }
$$


DATA SHEET PAGE TEN

For drug abusers record information on: length of addiction, nature of this offence and previous offences and how they fund their habit, any attempts at treatment: 


\section{Deliberate Self-Harm}

Have you ever tried to kill yourself or done any deliberate harm to yourself, either in or out of prison?

$$
\begin{aligned}
& 0=\text { Never } \\
& 1=\text { Once } \\
& 2=\text { More than once }
\end{aligned}
$$

If 'yes' above, determine whether D.S.H. was:

Place

This remand

This sentence (other prison)

This sentence (this prison)

During other sentence

Outside prison

Method Overdose

Fire

Hanging/Strangulation

Cutting

Other

(Interviewer to rate for evidence of serious suicidal intent, using supplementary questions as appropriate)

$$
\begin{aligned}
& 0=\text { No evidence of suicidal intent } \\
& 1 \text { = Possible suicidal intent } \\
& 2 \text { - Probable suicidal intent }
\end{aligned}
$$

Note details of interest here (eg. whether ever cut her/himself or swallowed dangerous objects) 
Previous Psychiatric Treatment

Have you ever seen a psychiatrist before coming to prison this time? (Note details of reply especially age at time, whether CGC, reason for referral etc.)

$$
\begin{aligned}
& 0=\text { Never } \\
& 1=\text { Op only } \\
& 2=\text { Has been in-patient }
\end{aligned}
$$

If 'yes' note details
$\underline{\text { Year }}$
Problem
Management
Hospital

If in-patient, was discharge within 6 months of present offence? 
Have you seen a psychiatrist during this sentence or seen a doctor for psychiatric or nervous problems? (Including anxiety or depression)

$$
\begin{aligned}
& 0=\text { Never } \\
& 1=\text { Reports only } \\
& 2=\text { At own request } \\
& 3=\text { Own request }- \text { on remand only }
\end{aligned}
$$

\section{$\underline{\text { Outcome }}$}

$0=$ Assessment - no further action

$1=$ Treatment by prison doctor

$2=$ Referral to visiting psychiatrist

$3=$ Referral for ?Transfer to psychiatric hospital

Have you seen anyone else for treatment for psychiatric problems - such as a Psychologist or Probation Officer? (Explain this includes nervous troubles such as anxiety etc.)

$$
\begin{array}{ll}
0=\text { No } & 2=\text { Probation Officer } \\
1=\text { Psychologist } & 3=\text { Other }
\end{array}
$$

If not:

Do you feel you need any help with such problems?

$$
1=\text { Yes } \quad 0=\text { No }
$$

Have you had any medical treatments in prison or been given drugs or medicines by a doctor?

(During sentence) $\quad 1=$ Yes $\quad 0=$ No

Neuroleptics

Antidepressants

Anxiolytics

Night sedation

Psychological $t / m e n t s$

Group psychotherapy

Individual psychotherapy

Non-Professional support in prison 


\section{Current Treatment}

Are you currently having any medical treatment?

$$
1=\text { Yes } \quad 0=\text { No }
$$

Neuroleptics

Antidepressants

Anxiolytics

Night sedation

Psychological $\mathrm{t} /$ ments

Group psychotherapy

Individual psychotherapy

Non-Professional support in prison

$\underline{\text { Record other medical treatment if relevant: }}$ 
How long were you in prison before being seen by a psychiatrist (months including time on remand)

Were you satisfied with the treatment you were given?

$$
\text { Yes }=1 \quad \text { No }=0
$$

Note details of treatment in prison:- 
Have you noticed anything else wrong with your health apart from the things you have already told me?

In the past week, have you been troubled with headache or indigestion?

If the rater suspects that psychological mechanisms may be implicated in any of the somatic symptoms described, elicit more details as follows:

How long have you had this trouble?

Does it seem to get worse when your nerves are bad?

How much does it upset you?

How often have you had it in this past week?

SOMATIC SYMPTOMS $4 \begin{array}{lllll}3 & 2 & 1 & 0\end{array}$

\section{All Patients:}

Are you at all worried about your health at the moment?

Do you find yourself thinking a lot about your health, or about the working of any part of your body?

Do you ever worry about having Cancer or Heart Disease?

The following Part 2 rating may be made at this point if the rater wishes

\section{EXCESSIVE CONCERN WITH BODILY FUNCTIONS 43210}

Have you noticed that you get tired easily or seem to be lacking in energy?

If the patient's replies indicate excessive fatigue or lethargy, go on as follows:

How long have you noticed this?

Do you feel tired the whole time, or just now and then?

What sort of things do you find most tiring?

Do you feel completely tired out in the evening?

How has it been this past week? - Has it stopped you from doing anything you've wanted to do?

FATIGUE 43210 
What about your sleep?

If reply indicates difficulties, ask for details:

Do you have difficulty dropping off?

Are you restless at night?

Do you wake early?

Have you lost any sleep in the past week?

If the patient's replies indicate loss of sleep in the past week, go on as follows:

How long have you had this trouble?

Have you any idea why you can't sleep?

How many nights in the past week have you lost sleep?

How many hours sleep do you think that you miss on a bad night?

\section{SLEEP DISTURBANCE 43210}

Do you find that you are easily upset or irritable with those around you?

\section{If the patients reply indicates irritability, go on as follows:}

How long have you been like this?

Are you like it all the time, or just occasionally?

What sort of things upset you?

How has it been in the past week?

Have you had any rows with anyone in the past week?

Are there still any hard feelings?

\section{IRRITABILITY 43210}


Do you find it difficult to concentrate?

Do you get muddled or forgetful?

If replies indicate impairment, go on as follows:

How long have you noticed this trouble?

Do you notice it all the time, or just now and then?

Has it caused any difficulty at home or at work?

Can you concentrate on a newspaper or on a play on TV?

How bad has it been in this past week?

- has it stopped you from doing anything?

- how many of your activities are affected?

LACK OF CONCENTRATION 43210

How have you been feeling in your spirits in the past week?

Have you had spells of feeling sad or miserable?

If the patient's replies indicate despondency or sadness, go on as follows:

Have you felt low the whole time, or just occasionally?

Does it seem connected with anything that happens?

How bad does it get?

Do you ever get weepy?

Can you snap out of it?

Do you sometimes feel hopeless?

Have you felt like making an end to it all?

DEPRESSION 43210

If indicated, ask the following questions for the Part 2 rating of depressive thoughts:-

Do you ever blame yourself for being like this?

Do you ever find yourself feeling guilty?

Do you sometimes feel inferior to other people?

How do you feel about the future?

DEPRESSIVE THOUGHTS (Part 2 rating) 43210 
Q. Would you say that you are a highly strung or nervous person?

Do you ever find that you get anxious or frightened for no good reason?

Do you worry a lot about things?

If the patient's replies indicate anxiety and worrying, go on to ask more:

What sort of things do you chiefly worry about?

Have you always been like this, or is it something that has only started recently?

Do you worry all the time, or only now and then?

Do you find yourself worrying more than you need about little things?

Have you been very upset by worries in the past week?

\section{ANXIETY 43210}

Are there any special things or situations that you find frightening or upsetting?

- What about being alone in the house?

- Travelling on buses or trains

- Animals? Insects? Heights? The dark?

If patient's replies indicate any phobias, go on to elicit details, viz:

How severe is this?

Do you get it all the time, or just now and again?

How bad has it been in this past week?

Do you have to go out your way to avoid or alter your usual activities in any way?

PHOBIAS 43210 
Do you ever find that you have to do things over and over to make sure that you've done them right?

- $\underline{\text { OR }}$ that you keep having unwelcome thoughts that you can't get rid of?

\section{If patient asks what is meant:}

- Well, any sort of unpleasant thought that come into your mind against your will?

Do you find it hard to make decisions?

If the patient's replies indicate possible obsessions or compulsions, ask appropriate questions from the following:

\section{(Checking)}

How many times do you find yourself checking work?

Do you check it even though you know that it's right really?

Are there any other things you find yourself having to do a number of times?

(Unwelcome thoughts)

Can you describe them to me?

\section{(Difficulty with decisions)}

Is this something that you've always had, or is it something new?

Is it just over important issues, or does it affect trivialities as well?

\section{(All Phenomena)}

Do you try and struggle against it?

Is it very distressing?

Does it take up much of your time?

How bad has it been in this past week? 
Is there anything else to do with your health that you think might be important?

- $\underline{\text { OR }}$ anything I haven't asked you about?

READING AGE

$0=$ Not tested - probably normal

$1=$ Not tested

$2=$ Tested

Result months 
Using CRO and information from prisoner complete criminal profile:

Theft

0 No convictions or reported behaviour.

1 No convictions but self-confessed occasional theft or one or two juvenile convictions for petty theft.

2 One theft conviction or self-confessed frequent stealing

3 Several theft convictions but only small amounts involved.

4 Substantial gains by stealing.

Sex

0 No convictions for illegal sexual behaviour

1 One conviction for indecent exposure.

2 Several exhibitionism convictions or one indictable (other than in 4)

3 Several indictable convictions (other than in 4)

4 Rape/SI with children.

\section{Violence}

0 Never been convicted of violence. Never gets into fights.

1 Some evidence of violence, but only to a minimal degree, i.e. occasional fights or damage to property. No convictions for violence.

2 One or two convictions for violence, or repeated acts of violence to a person or property without convictions being brought, neither the conviction offences nor the repeated acts to have cased serious personal damage to health.

3 Three or more convictions for violence, none of which amounts to severe violence.

4 One or more severely violent episodes in which someones life or health has been seriously endangered.

\section{Prostitution}

0 No evidence of involvement in prostitution.

1 Occasional episodes reported; no related convictions.

2 Convictions for related offences but not main source of income.

3 Prostitution has been major source of income

4 Involvement in organised prostitution eg. living off earnings. 


\section{Drugs}

0 No drug-related convictions; may be user but denies dealing

1 Convictions for possession or small-scale dealing/importing

2 Dealing has been a major source of income

3 Conviction for importing drugs obviously not for personal use.

4 Involvement in planning of large-scale drug offences.

\section{Drink}

0 No convictions or self-confessed drunkenness.

1 No convictions but occasional drunkenness.

2 One drinking offence or self-confessed frequent drunkenness

3 Two or three drinking offences.

4 Four plus drinking offences.

\section{Assessment of Financial Gain Involved in Criminal Behaviour}

0 His criminal behaviour has never involved financial gain.

1 Has made some financial gains from criminal activities but these have been very small and has not been dependent on these gains.

2 Has at times made money from crime but for the most part financial gain has come from legitimate activities.

3 Has largely been financially dependent upon crime. Activities have been regular and may have been planned but they are not "large scale" in the sense of "4".

4 Is a professional criminal who has been involved in large scale, well-planned crime (usually with evidence of adult gang activity).

Number of previous custodial sentences

$$
\begin{aligned}
& 0=\text { None } \\
& 1=1 \\
& 2=2 \text { or more }
\end{aligned}
$$




\section{TO BE COMPLETED IF INTERVIEWEE:}

(1) has a psychiatric history or

(2) has significant symptomatology

(3) is alcohol dependent or frequent drug user

(4) has said s/he needs help

Do you want any form of psychiatric help at the moment?

$$
\text { Yes }=1 \text { No }=0
$$

Do you think you'll try and get psychiatric help once you leave prison?

$$
\text { Yes }=1 \text { No }=0
$$

If 'yes'

What do you think your main problem is? (record problem as defined by the prisoner)

How do you think psychiatric treatment can help you/what do you think a psychiatrist could do for you?

Then rate:
(a) Motivation for treatment

0 - No desire for treatment

1 - No desire but would accept if offered

2 - Ambivalent about personal suitability

3 - Wants treatment partially for side benefits

4 - Wants treatment

(b) Whether expectations of treatment seem realistic

0 - Expectations and understanding of treatment realistic

1 - Expectations of treatment too high/unrealistic

2 - Expectations too low/pessimistic

(c) Availability of help which s/he rejects

$$
0=\text { No } 1-\text { Yes }
$$




\section{C.I.S. PART TWO RATINGS:}

Evidence for Psychiatric Disturbance Noted at Interview. Circle appropriate rating.

\begin{tabular}{|c|c|c|}
\hline Name of Rating & Reason for Morbid Rating: & $\begin{array}{l}\text { Rating } \\
\text { Assigned }\end{array}$ \\
\hline $\begin{array}{l}\text { SLOW, lacking } \\
\text { Spontaneity }\end{array}$ & & $\begin{array}{lllll}4 & 3 & 2 & 1 & 0\end{array}$ \\
\hline SUSPICIOUS, Defensive & & $\begin{array}{lllll}4 & 3 & 2 & 1 & 0\end{array}$ \\
\hline HISTRIONIC & & $\begin{array}{lllll}4 & 3 & 2 & 1 & 0\end{array}$ \\
\hline DEPRESSED & & $\begin{array}{lllll}4 & 3 & 2 & 1 & 0\end{array}$ \\
\hline $\begin{array}{l}\text { ANXIOUS, tense, } \\
\text { AGITATED }\end{array}$ & & $\begin{array}{lllll}4 & 3 & 2 & 1 & 0\end{array}$ \\
\hline ELATED, euphoric & & $\begin{array}{lllll}4 & 3 & 2 & 1 & 0 \\
\end{array}$ \\
\hline FLATTENED， INCONGRUOUS & & $\begin{array}{lllll}4 & 3 & 2 & 1 & 0 \\
\end{array}$ \\
\hline $\begin{array}{l}\text { DELUSIONS, } \\
\text { Misinterpretations, } \\
\text { THOUGHT DISORDER }\end{array}$ & & $\begin{array}{lllll}4 & 3 & 2 & 1 & 0\end{array}$ \\
\hline HALLUCINATIONS & & $\begin{array}{lllll}4 & 3 & 2 & 1 & 0 \\
\end{array}$ \\
\hline $\begin{array}{l}\text { EXCESSIVE CONCERN with } \\
\text { BODILY FUNCTIONS }\end{array}$ & & $\begin{array}{lllll}4 & 3 & 2 & 1 & 0\end{array}$ \\
\hline DEPRESSIVE THOUGHTS & & $\begin{array}{lllll}4 & 3 & 2 & 1 & 0\end{array}$ \\
\hline
\end{tabular}

Intellectual Impairment

CIS Part I

CIS Part II $x 2$

OVERALL SEVERITY 43210 
Can you give me a brief account of your present offence?

Summary and Formulation:

I.C.D. Diagnosis

(1)

(2)

(3)

For diagnosis of personality disorder, give DSMIII-R category

$$
\begin{array}{ll}
0=\text { Paranoid } & 5=\text { Histrionic } \\
1=\text { Schizoid } & 6=\text { Narcissistic } \\
2=\text { Schizotypal } & 7=\text { Sadistic } \\
3=\text { Antisocial } & 8=\text { Dependent } \\
4=\text { Borderline } &
\end{array}
$$

Any role for prison psychiatric services?

$$
\begin{aligned}
& 0=\text { No } \quad 1=\text { Yes (unmet need) } \\
& 2=\text { Yes/Receiving treatment }
\end{aligned}
$$

Nature of treatment?

$0=$ Monitor; probable treatment in future

$1=$ "OP" in prison: support/medication

$2=$ "OP" in prison: Psychotherapy

$3=$ IP in prison hospital

$4=$ Therapeutic Community (Grendon)

$5=$ Further assessment

Need for liaison at end of sentence?

$$
\text { No }=0 \quad \text { Yes }=1
$$

Severity of personality disorder

$$
\begin{aligned}
& 0=\text { None } \quad 1-\text { Mild } \\
& 2=\text { Moderate } 3=\text { Severe }
\end{aligned}
$$




\section{APPENDIX D: REFERENCES}

1. Gunn J, Maden T \& Swinton M. Mentally Disordered Prisoners. 1991, London: Home Office.

2. Smith R. Prison Health Care, p128, 1984 London: British Medical Association.

3. Dobash RP, Dobash RE and Gutteridge S. The Imprisonment of Women, p127-8. 1986 Oxford: Blackwell.

4. Callaghan J. Hansard, 16.12.68.

5. Moorehead C. The strange events at Holloway. New Society $198511: 40$.

6. Allen C. (Governor of HMP Holloway, 1985-89). "Women in Prison", speech to conference "Perspectives on Female Violence", St. George's Hospital, 8.3.91.

7. Allen, C. 1991 op. cit.

8. Carlen P. Women's Imprisonment. A study in social control. 1983, London: Routledge \& Kegan Paul.

9. Dobash RP, Dobash RE and Gutteridge S. Chapter 6, "Therapy and Discipline", pp124-158 in The Imprisonment of Women. 1986 Oxford: Blackwell.

10. Sim J. Medical power in prisons. The prison medical service in England 1774-1989. 1990, Milton Keynes: Open University Press.

11. Taylor PJ and Gunn J. Violence and Psychosis 1.Risk of violence among psychotic men. BMJ 1984 288: 1945-9.

12. Dooley E. Prison suicide in England \& Wales 1972-87. B J Psych 1990 156:40-45

13. Epps P. A preliminary survey of 300 female delinquents in Borstal institutions. British Journal of Delinquency, 1951, $1: 187-197$.

14. Epps P. A further survey of female delinquents undergoing Borstal training. British Journal of Delinquency, 1954, 4:270271 .

15. Epps P \& Parnell RW. Physique and temperament of women delinquents compared with women undergraduates. British Journal of Medical Psychology, 1952, 25:249-255

16. Woodside M. Instability in women prisoners. Lancet 1962 $2: 928-30$

17. Roper WF A comparative study of the Wakefield Prison population in 1948, parts I \& II. Brit J Delinquency 1950 $1: 15-28$ \& $1: 243-70$

18. Gibbens TCN Female offenders. British Journal of Hospital Medicine, Sept 1971 279-86 
19. Dobash RP, Dobash RE and Gutteridge S. The Imprisonment of Women, p127-9. 1986 Oxford: Blackwell.

Heidensohn F. Women and Crime, p73-5. 1985 London: Macmillan.

20. Gunn J, Robertson G, Dell S \& Way C. Psychiatric aspects of imprisonment, p217 Table 59 "Medical History". 1978

London: Academic Press

21. Gunn et al 1978 op. cit., p218-20.

22. Turner TS \& To fler DS. Indicators of psychiatric disorder among women admitted to prison. BMJ 1986 292:651-653

23. Morris A. Women, Crime and Criminal Justice, p56. 1987 Oxford:Blackwell

24. Gunn et al, 1978 op. cit.

25. Eysenck $S$ \& Eysenck $H$. The personality of female prisoners. British Journal of Psychiatry $1973122: 693$.

26. For method see Altman DG \& Gardner MJ. Calculating confidence intervals for means and their differences, p20-26 in Gardner MU \& Altman DG (eds). Statistics with confidence Confidence intervals and statistical guidelines. 1989, London: British Medical Association.

27. d'Orban PT. Heroin dependence and delinquency in women a study of heroin addicts in Holloway prison. British Journal of Addictions, 1970, 65:67-78.

28. d'Orban PT. Female narcotic addicts: a follow-up study of criminal and addiction careers. BMJ 1973, 4:345-347.

29. d'Orban PT. A follow-up study of female narcotic addicts: variables related to outcome. British Journal of Psychiatry, 1974 , $124: 28-33$.

30. Cookson HM. A survey of self-injury in a closed prison for women. British Journal of Criminology, 1977 17:332-46

31. Wilkins $J$ \& Coid J. Self-Mutilation in Female Remanded Prisoners: I. An Indicator of Severe Psychopathology. Criminal Behaviour and Mental Health. 1991 in press

32. Woodside M. Women Drinkers admitted to Holloway Prison During February 1960. British Journal of Criminology, 1961 $1: 221-35$

33. d'Orban PT. Baby Stealing. BMJ 1972 2:635-9

34. d'Orban PT Women who Kill their Children. British Journal of Psychiatry 1979 134:560-71

35. d'Orban PT Psychiatric aspects of contempt of court among women. Psych Med 1985 15:597-607

36. Guze SB. Criminality and Psychiatric Disorders. 1976 New York: Oxford University Press. 
37. Feighner JP, Robins E, Guze SB et al. Diagnostic criteria for use in psychiatric research. Arch Gen Psychiatry 1972, $26: 57-63$.

38. Regier DA, Boyd JH, Burke JD, Rae DS, Myers JK, Kramer M, Robins LN, George LK, Karno M \& Locke BZ. One-Month Prevalence of Mental Disorders in the United States. Based on Five Epidemiologic Catchment Area Sites. Arch Gen Psychiatry 1988 $45: 977-86$.

39. Novick LF, Penna RD \& Schwarz MS. Health care status of the New York Prison population. Med. Care 1977, 15:205-16.

40. Daniel $A D$, Robins AJ, Reid JC \& Wilfley MA. Lifetime and Six-Month Prevalence of Psychiatric Disorders among Sentenced Female Offenders. Bull Am Acad Psychiatry Law 1988, 16:333-42

41. Robins LN, Helzer JE, Croughan J et al. National Institute of Mental Health Diagnostic Interview Schedule: its history, characteristics and validity. Arch Gen Psychiatry 1981 38:3819 .

42. Robins LN, Helzer JE, Weissman MM et al. Lifetime prevalence of specific psychiatric disorders in three sites. Arch Gen Psychiatry 1984, 41:949-58.

43. Coid $J$ How many psychiatric patients in prison? Brit $J$ Psychiatry 1984, 145:78-86

44. Bluglass $R$ A psychiatric study of Scottish convicted prisoners p69. 1966, University of St Andrews MD thesis

45. Lewis, Aubrey. Psychopathic personality: a most elusive category. Psych Med 1974 4:133 - 140 .

46. Coid $J$ How many psychiatric patients in prison? Brit $J$ Psychiatry 1984, 145:78-86

47. Raven JC. Guide to using the Standard Progressive Matrices. 1958 London:Lewis

48. Wood PHN. International Classification of Impairments, Disabilities and Handicaps. 1980, Geneva:WHO

49. Campbell, L. Impairments, disabilities and handicaps: assessment for court, p419-24 in Bluglass R \& Bowden $P$ (eds) Principles and Practice of Forensic Psychiatry 1990 London:Churchill Livingstone

50. Hunter H. Forensic Psychiatry and Mental Handicap. In James FE \& Snaith RP (eds). Psychiatric Illness and Mental Handicap p131-146. 1979 London:Gaskell

51. Tizard J. Community Services for the Mentally Handicapped, p17. 1964, Oxford University Press.

52. James FE, Introduction to James $F E$ \& Snaith RP (eds). Psychiatric Illness and Mental Handicap. 1979 London:Gaskell 
53. Campbell, L, p422 in Bluglass $R$ \& Bowden $P$ (eds). Principles and Practice of Forensic Psychiatry 1990 London:Churchill Livingstone.

54. Corbett JA. Psychiatric Morbidity and Mental Retardation, p11-25 in James FE \& Snaith RP (eds) 1979 op. cit.

55. Farrington DP. Implications of criminal career research for the prevention of offending. Journal of Adolescence 1990 $13: 113$.

56. Hirschi \& Hindelang. Intelligence and delinquency, a revisionist review. American Sociological Review, 1977, $42: 571-87$.

57. Roper WF A comparative study of the Wakefield Prison population in 1948, parts I \& II. Brit J Delinquency 1950 $1: 15-28 \& 1: 243-70$

58. Epps P. A preliminary survey of 300 female delinquents in Borstal institutions, p192. British Journal of Delinquency, $1951,1: 187-197$.

59. Woodside M. Instability in women prisoners. Lancet 1962 $2: 928-30$

60. Robinson CB, Patten JW \& Kerr WS A psychiatric assessment of criminal offenders Med Sci Law 1965 5:140-146

61. Bluglass $R$ A psychiatric study of Scottish convicted prisoners. 1966 Univ of St Andrews MD thesis

62. Raven JC Guide to using the Mill Hill Vocabulary Scale. 1943 London:Lewis

63. Guze SB. Criminality and Psychiatric Disorders. 1976 New York: Oxford University Press.

64. Home Office. Prison Statistics: England and Wales 1988, p32. London: HMSO

65. Home Office. Prison Statistics: England and Wales 1988, p31. London: HMSO

66. Gunn J, Maden A \& Swinton M. How many prisoners should be in hospital. The prevalence of psychiatric disorders in sentenced prisoners. In press

67. Goldberg DP, Cooper B, Eastwood MR, Kedward HB \& Shepherd M. A standardized psychiatric interview for use in community surveys. British Journal of preventive and social medicine, 1970, 24:18-23

68. Schonell and Goodacre (eds). The Psychology and Teaching of Reading p216-7 1974 London:Oliver and Boyd

69. Gunn J \& Robertson G. Drawing a Criminal Profile. British Journal of Criminology, 1976, 16: 156-160. 
70. Gunn J, Robertson G, Dell S \& Way. Psychiatric Aspects of Imprisonment p280-1 1978 London: Academic Press

71. Gunn et al 1978 op. cit. p 265-267.

72. World Health Organization. Mental Disorders: Glossary and guide to their classification in accordance with the Ninth Revision of the International Classification of Diseases 1978 WHO: Geneva

73. American Psychiatric Association. Diagnostic and statistical manual of mental disorders, 3rd edition, revised. 1987, Washington DC:APA.

74. Wing JK, Cooper JE \& Sartorius B. The measurement and classification of psychiatric symptoms. 1974, London: Cambridge University Press.

75. World Health Organization. Mental Disorders: Glossary and guide to their classification in accordance with the Ninth Revision of the International Classification of Diseases 1978 WHO: Geneva

76. Home Office. Prison Statistics: England and Wales 1988. 1989, London: HMSO

77. Home Office. Table 1.10, p30 in Prison Statistics: England and Wales 1988. 1989, London: HMSO

78. Home office. The ethnic origin of prisoners: the prison population on January 30 th 1985 and persons received, July 1984 - March 1985. Home Office, 1986, Statistical Bulletin $17 / 86$.

79. Walker MA. The ethnic origin of prisoners. British Journal of Criminology, $198727: 202-6$.

80. Home Office. Prison Statistics: England and Wales 1988. 1989, London: HMSO

81. Home Office. Prison Statistics: England and Wales 1988, p14. 1989, London: HMSO

82. Cope R. Psychiatry, ethnicity and crime. In Bluglass R \& Bowden P (eds), p849-61, 1989 op. cit.

83. Green P. Drug Couriers. 1991, London: Howard League for Penal Reform.

84. Walker MA. 1987 op. cit.

85. Gunn J, Maden A \& Swinton M. Treatment needs of prisoners with psychiatric disorders. British Medical Journal, 1991 $303: 338-341$.

86. Population in Prison Service establishments under sentence on 30 June 1988, Table 1.9 p29 \& Table 1.12 p34 in Home Office. Prison Statistics England and Wales 1988. London:HMSO. 
87. Home Office. Prison Statistics England and Wales 1988, Table 1.10, p30. 1989, London:HMSO.

88. Nie NH. SPSS-X: Statistical Package for the Social Sciences. 1983, New York: McGraw Hill.

89. Altman DG \& Gardner MJ. Calculating confidence intervals for regression and correlation. Chapter 5 in Gardner MJ \& Altman DG (eds) Statistics with Confidence, p34-49. 1989 London: BMJ

90. Morris JA \& Gardner MJ. Calculating confidence intervals for relative risks, odds ratios and standardised ratios and rates. Chapter 6 in Gardner MJ \& Altman DG (eds). Statistics with Confidence, p50-63. 1989 London:BMJ

91. Gardner MJ \& Altman DG. Calculating confidence intervals for proportions and their differences. Chapter 4 in Gardner MJ \& Altman DG (eds). Statistics with Confidence, p28-33. 1989 London:BMJ

92. Barnett V. Elements of Sampling Theory, p24-42. London:English Univ Press

93. Home Office. Prison Statistics: England and Wales 1988. 1989, London: HMSO

94. Mayhew $\mathrm{H}$ \& Binny $J$. The Criminal Prisons of London and Scenes of Prison Life p180-82. 1862 London: Griffin, Bihn \& CO.

95. Quinton R. Crime and Criminals. 1910 London: Longmans, Green \& Co.

96. Dobash RP, Dobash RE and Gutteridge S. Chapter 4, "Penal Regimes" in The Imprisonment of Women pp62-88. 1986 Oxford: Blackwell.

97. Larkin E, Murtagh S \& Jones S. A preliminary study of violent incidents in a special hospital. British Journal of Psychiatry 1988, 153:226-231.

98. Offences against discipline in women's prisons. 1986, London: NACRO.

99. Carlen P. (ed) Criminal Women, p134. 1985 Cambridge: Polity Press.

100. Mandaraka-Sheppard A. The Dynamics of Aggression in Women's Prisons in England, p189. 1986, Aldershot: Gower.

101. Kozuba-Kozubska J \& Turrel D. Problems of dealing with girls. Prison Service Journal 1978 29:4.

102. King RD \& McDermott $K$. British Prisons 1970-1987. The Ever-Deepening Crisis. British Journal of Criminology 1989, $2: 107-128$.

103. Mandaraka-Sheppard A. The Dynamics of Aggression in Women's Prisons in England, p52-53. 1986, Aldershot: Gower. 
104. Wilkins $J$ \& Coid J. Self-Mutilation in Female Remanded Prisoners: I. An Indicator of Severe Psychopathology. Criminal Behaviour and Mental Health. 1991 in press.

105. Cookson HM. A survey of self-injury in a closed prison for women. British Journal of Criminology, 1977, 17:332-46

106. Wolff S. Non-delinquent disturbances of conduct. Chapter 24, p400-13 in Rutter M \& Hersov L (eds), Child and Adolescent Psychiatry. Modern Approaches. 2nd ed., 1985, London: Blackwell.

107. Prison Department. Report on the Work of the Prison Department 1985-86, p93. London: HMSO

108. Benn M. Women in prison....breaking the silence. Spare Rib 1983, November p51-55.

109. Glick $R$ \& Neto V. National study of women's correctional programs. Washington: 1977 Government Printing office.

110. Morris A. Women, Crime and Criminal Justice, p124. 1987 Oxford:Blackwell

111. Dept. of Health. On the State of the Public Health for the year 1989 - The Annual Report of the Chief Medical Officer, pp54-61. 1990, London: HMSO.

112. World Health Organization. Mental Disorders: Glossary and guide to their classification in accordance with the Ninth Revision of the International Classification of Diseases 1978 WHO: Geneva

113. Gunn $J$, Maden A \& Swinton M Treatment needs of prisoners with psychiatric disorders. BMJ 1991, 303:338341 .

114. Green P. Drug Couriers, p29. 1991, London: Howard League for Penal Reform.

115. Weller MP. Mental illness - who cares? Nature 1989 $339: 249-252$

116. Penrose LS. Mental Disease and Crime: Outline of a Comparative Study of European Statistics. Brit J of Medical Psychology 1939, 18:39-41.

117. Bebbington $\mathrm{PE}$ \& Hill PD. A Manual of Practical Psychiatry, p38. 1985, London: Blackwell.

118. Cheadle $J$ \& Ditchfield J. Sentenced mentally ill offenders. 1982, London: Home Office Research and Planning Unit.

119. Coid, JW. "Difficult to place" psychiatric patients: The game of pass the parcel must stop. BMJ 1991 302:603-604.

120. Grounds A. The Transfer of Sentenced Prisoners to Hospital 1960 -1983. Brit. J. Criminol. 1991 31:54-71. 
121. Grounds A. The transfer of sentenced prisoners to hospital 1960-1983. A study in one special hospital. British Journal of Criminology, 1991, 31:54-71.

122. Allen H. Justice Unbalanced. Gender, Psychiatry and Judicial Decisions, p55-56. 1987 Milton Keynes: Open University Press.

123. Coid J. Mentally abnormal prisoners on remand BMJ 1988 $296: 1779-84$

124. Robertson G. The 1959 Mental Health Act of England and Wales: Changes in the Use of Its Criminal Provisions. In Gunn $J$ \& Farrington DP (eds) Abnormal Offenders, Delinquency and the Criminal Justice System, p245-68. 1982, London: Wiley.

125. Jones, DA. The health risks of imprisonment. 1976, Lexington Massachusets:Lexington Books, cited in Coid $\mathrm{J}$, How many psychiatric patients in prison? Brit J Psychiatry $1984,145: 78-86$

126. Roper WF A comparative study of the Wakefield Prison population in 1948, parts I \& II. Brit J Delinquency 1950 $1: 15-28$ \& $1: 243-70$.

127. Guze, SB. Criminality and Psychiatric Disorders. 1976, New York: Oxford University Press.

128. Maudsley H. Responsibility in Mental Disease. 1874, London:King, quoted in Lewis, A. Psychopathic personality: a most elusive category. Psych Med 1974 4:133 - 140 .

129. Lewis A. Psychopathic personality: a most elusive category. Psych Med 1974 4:133-140.

130. Dell $S$ and Robertson G. Sentenced to Hospital: Offenders in Broadmoor. Maudsley Monograph No. 32. 1988 Oxford Univ Press.

131. Regier DA, Boyd JH, Burke JD et al. One-Month Prevalence of Mental Disorders in the United States. Based on Five Epidemiologic Catchment Area Sites. Arch Gen Psychiatry 1988 45:977-86.

132. Cloninger $C R$, Christiansen KO, Reich $T$ \& Gottesman IL. Implications of Sex Differences in the Prevalences of Antisocial Personality, Alcoholism, and Criminality for Familial Transmission. Arch Gen Psychiatry, 1978, 35:94151 .

133. Morris A. Women, Crime and Criminal Justice, p53-4. 1987 Oxford:Blackwell

134. Sim J. Medical power in prisons. The prison medical service in England 1774-1989. "Researching women: Psychiatrizing behaviour", p157-164. 1990, Milton Keynes: Open University Press.

135. DSM-III-R, p347 
136. Dobash RP, Dobash $R E$ and Gutteridge $S$. The Imprisonment of Women, p128-9. 1986 Oxford: Blackwell.

137. Dell S \& Gibbens TCN. Remands of Women Offenders for Medical Reports. Medicine, Science and the Law, 1971 $11: 117-127$.

138. Carlen P. Law, Psychiatry and Women's Imprisonment. A sociological view. British Journal of Psychiatry, 1985, 618621 .

139. Carlen, 1985 op. cit. p620.

140. Carlen P. 1985 op. cit. p619.

141. Lewis, Aubrey. Psychopathic personality: a most elusive category. Psych Med 1974 4:133 - 140.

142. Bebbington P, Hurry J, Tennant C, Sturt E \& Wing JK. Epidemiology of mental disorders in Camberwell. Psychological Medicine, 1981, 11:561-79.

143. Goldberg D \& Huxley P. Mental Illness in the Community: the Pathway to Psychiatric Care. 1980, London: Tavistock.

144. Burr A. Chasing the Dragon. British Journal of Criminology, 198727 4:333-357.

145. Home office. Statistics of drug addicts notified to the Home Office, United Kingdom, 1988, Home Office Statistical Bulletin 13/89. 1989, London:Government Statistical Service.

146. Maden A, Swinton M \& Gunn J. A survey of pre-arrest drug use in sentenced prisoners. British Journal of Addictions, in press.

147. Pearson, G. The New Heroin Users. 1987, Oxford: Blackwell.

148. Jarvis, G. and Parker, H. Young Heroin Users and Crime. How do the new users finance their habits? British Journal of Criminology, 1989. 29:2 175-185.

149. Carvell ALM \& Hart GJ. Risk behaviours for HIV infection among drug users in prison. BMJ 1990 300:1383-4

150. Burr A. Chasing the Dragon. Brit J Crim $1987274: 333-357$

151. Coid J. Alcoholism and Violence. Drug and Alcohol Dependence 1982, 9:1 - 13 .

152. Gillies, H. Homicide in the West of Scotland. British Journal of Psychiatry, 1976, 128: 105-127.

153. Virkkunen M. Alcohol as a Factor Precipitating Aggression and Conflict Behaviour Leading to Homicide. British Journal of Addictions, 1974, 69: 149-154. 
154. Alcohol and Violence. Editorial, The Lancet, 1990, $336: 1223-4$.

155. Wessely S, Castle D, Der G \& Murray R. Schizophrenia and Afro-Caribbeans. A Case-Control Study. British Journal of Psychiatry, 1991, 159:795-801.

156. Harrison G, Owens D, Holton A, Neilson D and Boot D. A prospective study of severe mental disorder in Afro-Caribbean patients. Psychological Medicine, 1988, 18:643-657.

157. Fahy TA. The Police as a Referral Agency for Psychiatric Emergencies - a Review. Medicine, Science and the Law, 1989, $29: 315-322$.

158. Littlewood $\mathrm{R}$ \& Lipsedge $M$. Acute psychotic reactions in Caribbean patients. Psychological Medicine, 1981, 11:289-302.

159. Hitch PJ \& Clegg P. Modes of referral of overseas immigrant and native-born first admissions to psychiatric hospitals. Social Sciences and Medicine, 1980, 14A:369-74.

160. Burke AW. Racism and psychological disturbance among West Indians in Britain. Int. J. of Social Psychiatry, 1984, 30:5068 .

161. Thornicroft G. Cannabis and psychosis. Brit J Psychiatry $1990157: 25-33$.

162. Coid $J$. The epidemiology of abnormal homicide and homicide followed by suicide. Psychological Medicine, 1983, $13: 855-860$.

163. Inghe G. Mental abnormality among criminals. Acta Psychiatrica et Neurologica, 1941, 16:421-458.

164. Joseph P. Mentally disordered offenders: diversion from the criminal justice system. Journal of Forensic Psychiatry, $1: 133-137,1991$.

165. d'Orban PT. Social and psychiatric aspects of female crime. Medicine, Science and the Law 1971 11:104-116.

166. Morris A. Women, Crime and Criminal Justice. Ch 1, "Gender differences in crime", p19-40 \& Ch 2, "Theories of Women's Crime", p41-78. 1987, Oxford:Blackwell.

167. Pollak O. The Criminality of Women. 1950 New York: University of Pennsylvania Press.

168. D'Orban PT. 1971 op. cit. p104.

169. Heidensohn F. Women and Crime, Ch. 3 "Women and Justice", p. 31-58. 1985 London: Macmillan.

170. Morris A. 1987 op. cit. Ch 4 "Women in the Criminal Justice System", p79-103. 
171. Allen H. Justice Unbalanced. Gender, Psychiatry and Judicial Decisions."Official Statistics on Psychiatric Disposals" p123-6. 1987 Milton Keynes: Open University Press.

172. Walker N. Crime and Punishment in Britain. 1965, Edinburgh: Edinburgh University Press.

173.Edwards SSM. Women on Trial. 1984, Manchester: Manchester University Press.

174. Gibbens TCN, Soothill KL \& Pope PJ. Medical Remands in the Criminal Court. 1977, Oxford: Oxford University Press.

175. Gibbens TCN, Soothill KL \& Pope PJ. 1977 op. cit., p18.

176. Allen H. Justice Unbalanced. Gender, Psychiatry and Judicial Decisions. 1987 Milton Keynes: Open University Press.

177. Allen $\mathrm{H}, 1987$ op. cit., p66.

178. Allen H. 1987 op. cit., p113.

179. Allen H. 1987 op. cit., p117.

180. Allen H 1987 op. cit. p114.

181. Robertson G. The restricted hospital order. Psychiatric Bulletin, 1989, 13:4-11.

182. Walker $\mathrm{N}$ \& McCabe S. Crime and Insanity in England. Vol. 2: New Solutions and New Problems, p146. 1973, Edinburgh: University Press.

183. Fahy TA, Bermingham D \& Dunn J. Police Admissions to Psychiatric Hospitals: A Challenge to Community Psychiatry? Med. Sci. Law, 1987, 27:263-268.

184. Grubin D. Unfit to Plead in England and Wales 1976-1988. 1991 Brit J Psych. In press.

185. Grounds A. The Transfer of Sentenced Prisoners to Hospital 1960 -1983. British Journal of Criminology, 1991, $31: 54-71$.

186. Stevenson $P .$, address to the conference "Perspectives on Female Violence", St. George's Hospital, 8.3.91.

187. Home Office. Table 1.1, p18 in Prison Statistics: England and Wales 1988. London: HMSO

188. Sim J. At the centre of the professional gaze: women, medicine and confinement. Ch 6 , p129-176 in Medical power in prisons. The prison medical service in England 1774-1989. 1990, Milton Keynes: Open University Press.

189. Beiser M \& Iacono WG. An Update on the Epidemiology of Schizophrenia. Can. J. Psychiatry, 1990, 35:657-68. 
190. Sartorius N, Jablensky A, Korten A et al. Early manifestations and first contact incidence of schizophrenia in different cultures: a preliminary report on the initial evaluation phase of the WHO collaborative study on determinants of outcome of severe mental disorders. Psychological Medicine, 1986, 16:909-28.

191. Cooper JE, Goodhead D, Craig T et al. The incidence of schizophrenia in Nottingham. Brit. J. Psychiatry, 1987, $151: 619-26$.

192. Teplin LA. The Criminalization of the Mentally Ill: Speculation in Search of Data. Psychological Bulletin, 1983, 94:54-67.

193. Gibbens TCN Female offenders. British Journal of Hospital Medicine, Sept 1971 279-86.

194. Taylor PJ and Gunn J. Violence and Psychosis 1.Risk of violence among psychotic men. BMJ 1984 288: 1945-9.

195. Marshall M. Collected and neglected: Are Oxford hostels for the homeless filling up with disabled psychiatric patients? BMJ 1989, 299:706-709.

196. Bassuk EL, Rubin L \& Lauriat A. Is Homelessness a Mental Health Problem? Am J Psychiatry, 1984, 141:1546-50.

197. Carlen P Alternatives to Women's Imprisonment. 1990 Milton Keynes: Open University Press.

198. NACRO Annual Report 1987-8. London: NACRO, cited in Carlen P. 1990 op. cit. p43.

199. Report of the House of Commons Social Services Committee on the Prison Medical Service (Social Services Committee Session 1985 - 86)

200. Home Office. Report on an Efficiency Scrutiny of the Prison Medical Service. Home Office. London: 1990.

201. Coid J. Difficult to place psychiatric patients. BMJ $1991,302: 603-4$.

202. Smith R. Prison Health Care, p94-101, "Ethics, invisibility and quality". 1984 London: British Medical Association.

203. Report on an Efficiency Scrutiny of the Prison Medical Service. July 1990.

204. Gunn J, Robertson G, Dell S \& Way C. Psychiatric aspects of imprisonment. 1978 London: Academic Press.

205. Genders E \& Player E. Grendon: a study of a therapeutic community within the prison system. 1989 University of oxford: Centre for Criminological Research. 
206. Grounds, A. Detention of "Psychopathic Disorder" Patients in Special Hospitals. Critical issues. BY Psych 1987 151:4748 .

207. Edwards G \& Gross M (1976) Alcohol Dependence: Provisional Description of a Clinical Syndrome. British Medical Journal, 1:1058-61

208. American Psychiatric Association. Diagnostic and statistical manual of mental disorders, 3rd edition revised, p324. 1987, Washington DC:APA. 